


$$
-778013 \% \text { in } 2
$$




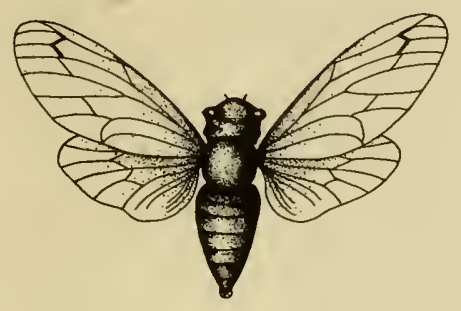

\section{LIBRARY OF}

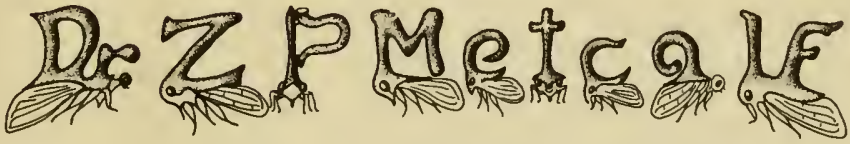
1885_1956 



\section{ENTOMOLOGIA}

PARISIENSIS;

$$
S I V E
$$

Catalogus Infectorum qux in Agro Parifienfi reperiuntur;

SECUNDU.M methodum Geoffranam in fectiones, genera \& Species diftributus:

CUI addita funt nomina trivalia \& fere trecentæ novæ Species.

Edente A.F. DE FOURCROY, Doct. Med. Parifo; è Reg. Scientiar, Academ.; è Reg. Soc. Medic. Ec.

\section{P A R S P R I M A.}

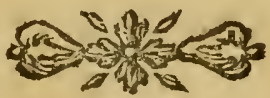

$P$ A R I S I I S,

VIA ET FEDIBUS SERPENTINEIS.

$$
\text { M. D C C. LXXXV. }
$$

Sub Pritifegio $A$ cadehtaro 
i:

$\therefore$

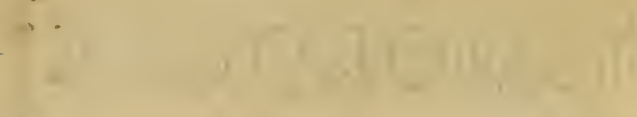

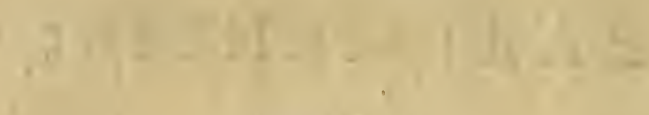
$(1=-11$

: $11=0$

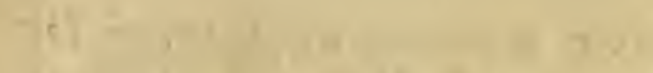

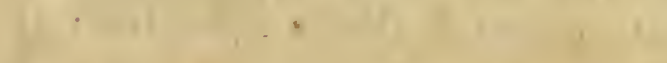

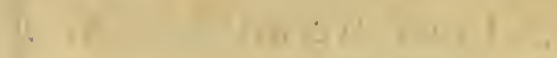

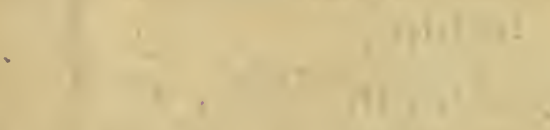

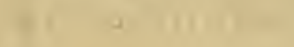

$$
\text { in } 1
$$$$
-
$$

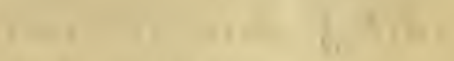

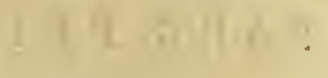




\section{LECTORI ENTOMOPHYLO}

\section{MONITUMF EDITORIS.}

$J$

$A M$ ì viginti annis prodiit celeb. Geoffroy de infectis opus eximium, quod multo favore profecuti funt hifloria naturalis cultores. Dudum à plurimis expectabatur manuale Compendiumi quod nomenclaturam E methodum complectens, omiffâ fcilicet hiftoricâ porte, rus deferri polfet. Non ergo ingralum entomophylis fore arbitratus eft illufir. autor, $f$ catalogus infectorum qua circid Parifios reperiuntur typis parvâ formâ mandaretur, Botanicon Parifienfis ad infar. Felicifjmo apud cives fuos praxeos medica curis diftractus, hoc quod fufceperat opus omnino abfolvere non potuit. Entomologia olim deditus E autoris auxilio fretus, hunc catalogum

a iij 
publici juris facere non timui. Methodum ill. Geoffroy, genera," fpecies, defcriptivas fententias, religio/e Jervavi. Trivialia, foxpius Linneana, ip Je autor addidic., quo in magno opere (1) neglexerat. Hâc fimul datâ occafione quadan in methodo Juâ emendavit, adjecit plirima. Sic genus Eulophi poft Tenthredines omnino omiffum eft, cum Sedulâ attentione factâ, Eulophus nihil aliud fut quàm verus Cynips antentiis ramofis. Hinc infectum illud inter synipes nunc incedit. Procterè̀ mulice à viginui annis nova in agro Parifien/i - deiectur funt infectorum 'species, quo ad Jua quaque genera revocata funt; fed ut novo illo Species qux ducentum $\mathcal{E}$ quinquaginta Juperant à cocteris in hiftoriâ Infectorum in-4 $4^{\circ}$. defcriptis

(I) Hiff abreg. des Infectes, par M. Geoffroy, 2 vol. in $-4^{\circ}$. Paris, 176 ag. 


\section{EDITORIS?}

'diftinguantur, fingulas afterico notandas curavi. Specierum dimenfiones, E habitationum loca adjeci; fic ergo quoad numerum fpecierum $\varepsilon$ nomenclaturam hic catalogus multo auctior E emendatior magno opere in- $4^{\circ}$. prodit, E hanc. illuftrationem celeb. Geoffroy omnino deberifateor. Levia quodam vel addidi, vel mutavi tantum, quce hic commemorare fupervacuum duco; fimplicis igitur editoris munus fufcepi, utilitatis potius quàm glorix $\int p e$ ductus.

Dabam Lutetice, menfe apr. 1785 :

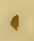

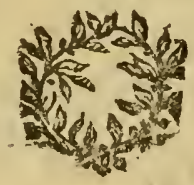


INSECTORUM, DIVISIO GENERALIS.

Infecta dividuntur in fex fectiones.

Secrio I. Coleoptera, quorum alæ coleoptris feu elytris teguntur \& quibus eft os maxillofum.

Secrio II. Hemiptera, querum alx fupe= riores elytris accedunt, \& quorum os fub thorace eft inflexum.

Sectio III. Tetraptera alis farinaceis, quibus funt quatuor alæ fquamulis tectx.

Sectro IV. Tetraptera alis nudis, quibus alx quatuor funt membranacex.

Sectro V. Diptera, quibus funt alæ dux 2 halteres fub alarum origine.

Sectio VI. Aptera, quæ carent alis.

Prima autem fectio, coleopterorum fcilicet, cum maxime numerofa fit, in articulos \& ordines difpertitur.

Articulus primus infecta coleoptera comprehendit qux coleoptra gerunt integra \& dura. 
Articulus fecundus ex iis. componitur quorum coleoptra dura funt, fed dimidiata, feu femifeeta ita ut abdomen non omnino tegant.

Articulus tertius ea exhibet infecta, quorum coleoptra mollia funt $\&$ membranacea.

Ex is articulis quifque in varios ordines dividitur, prout tarfi infectorum varium referunt articulorum numerum, duos nempe, tres, quatuor aut quinque articulos, vel quinque in primo \& fecundo pedum pari, quatuor verò in pofteriore.

\section{$E R R T U M$.}

Pag. 82, lin. 8, tribus lege tibiis. 


\section{EXTRAIT des regiftres de l'Académie des Sciences.}

\section{Du 13 Juillet $1785^{\circ}$}

L

ES Commiffaires nommés par l'Académie, lui ayant rendu compte d'un Ouvrage de M. DE FOURCroy, intitulé : Entomologia Parifienfis, elle a jugé cet Ouvrage digne de fon approbation, \& de paroître fous fon Privilège.

Je certifie le préfent extrait conforme à l'original \& aux regiltres de l'Académie. Le I J Juillet 1785. Signé, le Marquis DE CONDORCET.

EXTRAIT des regifires de la Société

$I$ Royale de Médecine. Aans la reance Royale de Médecine ayant entendu, dans la féance tenue au Louvre le 23 Juin préfent mois, la lecture d'un rapport très-avantageux fait par MM. Geofrroy \& MaUdUYt, fur un Ouvrage de M. DE FOURCROY, intitulé : Entomologia Parifienfis, five Catalogus Infectorum qua circa Lutetiam reperiuntur, Ec. a penfé que cet Ouvrage étoit trèsdigne de fon approbation. En foi de quoi j'ai figné le préent. A Paris, ce 28 Juin 1785.

Signé; VICQ D'AZIR, Secrétaire perpétuel.

ENTOMOLOGIA 




\section{ENTOMOLOGIA \\ I. P LATYCERUS. $L_{E} C_{E R F-}$ VOLANT.}

Antennx in extremo uno verfu pectinatx. Familia I. Antennis fractis.

I. P. Cervus.

Le grand Cerf-volant.

Longueur 2 I lignes. Largeur 7 lignes.

P. furcus, cornubus duobus mobilibus, afpice bifurco, intus ramo denticulifque inftructis.

Locus. Habitat flivas \& præcipue ilices.

2. P. fomina cervi.

La grande Biche.

Long. I 6 lig. Larg. 6 lig.

P. fufcus, elytris lrvibus, capite lxvi.

Loc. Latya carie exclos fraxinorum truncos habitat.

3. P. parailelipipedus.

La petite Biche.

Long. 9 lig. Iarg. 4 lig.

P. niger, elytris lævibus, capitis puncto duplici prominente.

Loc. Habitat arbores catiofas, 

e 


\section{P A R I SIE NSIS。}

4. P. caraboides.

La Chevrette blene.

Long. 5 lig. Larg. 2 lig.

P. violaceo-coruleus, elytris lævibus.

$V$ arietas A. Platycerus caraboideslatior, fuperne viridis, inferne fufcus. $L a$ Chevrette verte.

Loc. Habitat eafdem a rbores.

FAMIL. II. Antennis integris.

5. P. Ariatus.

La Chevrette brune.

Long. $3 \frac{x}{2}$ lig. Larg. $1 \frac{1}{3}$ lig.

P. furcus, capite \& thorace punqatis; elytris punctato-ftriatis.

Loc. Hahitat vetuftas arbores.

* 6. P. pygmxus.

Le Cerf-volant mignonette.

Long. I lig. Larg: $\frac{\pi}{3}$ lig.

P. nigro fufcus, elytris ftriatis, pedibus fufcis, capite brevi, antennis vis apparentibus.

Lre.

A if 
4 ENTOMOLOGIA

II. PTILINUS. LA PANACHE.

Antennæ fecundùm totam longitudinem uno verfu pectinatie.

s. P. fufcus.

La Panache brune.

Long. 2 lig. Larg. I lig.,

P. atro-fulcus, thorace convexo, pedibus antennifque pallidis.

Loc. Habitar vetuftas falices quas rotundis fora: minibus larva terebrat.

2. P. flavefcens.

Ia Panache jaune.

Long. $2 \frac{x}{2}$ lig. Larg. I lig.

P. niger, fubvillofus, thorace plano marginato, elytris davis mollioribus.

Loc. Habitat flores apertos.

III. SCARABAUS. LE SCARABÉ.

Antennx clavatæ, clavâ lamellatâ; Ćcụ: tellum inter elytrorum origines. 




\section{PARISIENSIS.}

Famil. I. Antennarum lamellis

\section{Septem:}

I. S. naficornis.

Le Mioine.

Long. Is lig. Larg. , lig.

S. capite unicorni recurvo, thorace gibbo, abdomine hirfuto.

Loc. Habitat hunum recertem (les couøhes)

s. arborum catiem.

2. S. fullo.

Le Foulori.

Long. 7 lig. Larg. 7 lig.

S. antennarum lamellis maximis, cort pore nigro, fquammis albis, varie maculato.

Loc, Habitat metidionales Galliax provincias; in mufxis frequens.

3. S. melolontha.

Le Hanneton.

Long. I pouce. Larg. 6 lig.

S. teftaceus, thorace villoro, abdominis incifuris lateralibus albis, caudâ inflexâ.

Loc. Habisar arbores.

A iij 
FAMIL. II. Antennarum lamellis iribus.

4. S. typhxus.

Le Phalanoifte. Long. 8. lig. Larg. $4 \frac{x}{2}$ lig.

S. niger, elytris frriatis, thorace antror: fum tricorni.

Loc. Habit. bovinas fæces, gallicè Bouzes de vaches,

s: S. auratus.

L'Eniéraudine.

Long. 9 lig. Larg. 5 lig.

S. viridi-ænæus, thoracis parte pronă, antice prominente.

Zoc. Habitar flores pracipue rofx \&: pxonix.

6. S. nobilis.

Le Verdet.

Long. 7 lig. Larg. 4 lig.

S. - viridis nitens, thorace infra axquali, non prominente.

Zoc. Habitat flotes umbellatos.

7. S. autumnalis.

Le petit Hanneton d'automne:

Long. 7 lig. Larg. $3 \frac{\mathrm{T}}{2}$ lig.

S. teftaceus, thorace villoro, elytris luteo: 




\section{PA R I S I ENSIS.}

pallidis, lineis tribus elevatis pallidioribus.

$V$ arietas A.Scarabrus autumnalis omnino viridis.

Loc. Habitat circa arbores.

8. S. horticola.

Le petit Hanneton à corcelet vert:

Long. 4 lig. Larg. $2 \frac{2}{3}$ lig.

S. capite thoraceque coeruleo piloro; elytris rufis.

Loc. Habitat bovinas feces,

9. S. ftercorarius.

Le grand Pilulaire, le fouille-merde:

Long, so lig. Larg. s lig.

S. ater, dorfo glabro, elytris fulcatis; capitis clypeo rhomboide, centro prominulo.

Loc. Habitat bovinas faces.

I0. S. vernalis.

Le petit Piluluire.

Long. 7 lig. Larg. 5 lig.

S. cœrulcfcens, dorio elytrifque glabris ixvifimifque, capitis clypeo rhomboide, centro prominulo.

Loc. Habitas bovinas faces.

$A$ iv 
II. S. fubterraneus.

\section{Le Scarabé perlé. \\ Long. $3 \frac{r}{2}$ lig. Larg. 2 lig.}

S. ater, punctis elevatis, per ftrias digeftis.

Loc. Habitat arenam ferilem; in urbe Fontainebleall frequeris.

I2. S. hamipterus.

Le Scarabé à tarrière.

$$
\text { Long. } 4 \text { lig. Larg. } 2 \text { lig. }
$$

S. ater depreffus \& fquamofus, maculis albis variegatus, elytris abdomine bre. vioribus, frmina aculeo ani. Icc. Habitat arbores exefas \& cortices.

I3. S. argenteus.

L'Ecailleux violet:

Long. 4 lig. Larg. I lig. $\frac{3}{4}$.

S. violaceus \& fquamolus, fquamis fubtus argenteis.

Loc. Habitat exefos arborum truncos.

14. S. funerarius.

Le Drap mortuaire. Iong. 5 lig. Larg. 3 lig. 



\section{PARISIENSIS.}

S. nigro-cœrulefcens, maculis albis [parfis, ordine nacularum abdominalium longitudinali.

Loc. Habitat umbelliferarum flores.

Is. S. marginatus.

Le Scarabé à bordure.

Long. 3 lig. Larg. I $\frac{\pi}{2}$ lig.

S. niger, elytris croceis margine nigro.

Loc.

I 6: S. fafciatus.

\section{La Livrée d'ancre.}

Long. $4 \frac{\mathrm{x}}{2}$ lig. Larg: 3 lig.

S. niger hirfutie-flavus, elytris luteis, falciis tribus nigris interruptis.

Loc. Habitat flores umbellatos.

17. S. villofus.

\section{L'Arquelin velu.}

Long. 4 lig. Larg. 2 lig.

S. villofus albo, nigro flayoque irregulariter variegatus.

Loc.

I8. S. bicolor.

Le Scarabé bedeau.

Iong. 3 lig. Larg. I $\frac{2}{3}$ lig. 
10

\section{ENTOMOLOGIA}

$S$. capite thoraceque nigro, antennis elytrifque rubris.

Loc. Larva \& Scarabxus fxces bovinas habitat,

19. S. fimetarius.

Le Scarabé gris des bouzes.

Long. I, 2,3 lig. Larg. $\frac{x}{2}$ I, I $\frac{x}{2}$ lig.

S. capite thoraceque nigro glabro, elytris grifeis, pedibus pallidis.

Loc. Abundat in bovinis facibus.

20. S. forfor.

\section{La Tête armée.}

Iong. $2,3,4,5$ lig. Larg. $1,2,2 \frac{x}{2}$ lig.

$S$. totus niger, [pinulis tribus capitis tranfverfim pofitis.

Loc. Abundat in bovinis fxeibus.

21. S. gagatinus.

Le Scarabé jayet. Long. 4 lig. Larg. 2 lig. .

S. totus niger, capite inermi.

Loc. Halitat bovinas faces.

22. S. fulvefcens.

Le Scarabé fauve aux yeux noirs: Long. $3 \frac{x}{2}$ lig, Larg. I $\frac{x}{2}$ lig. 



\section{PARISIENSIS.}

S. fulvus, oculis nigris, thorace glabro. Loc. Habitat arbufta fepium.

23. S. atratus.

Le Velours noir.

Long. 2 lig. Larg. I $\frac{1}{3}$ lig,

S. niger hirfutus.

Loc. In hotto regio Parifienfi frequens.

24. S. fumofus.

Le Scarabé couleur de fuie. Long. 4 lig. Larg. $1 \frac{3}{4}$ lig.

S. ater, thorace fubvillofo, elytris fufcis friatis.

Loc.

25. S. lamellatus.

Le Scarabé brun chagriné.

Long. 4 lig. Larg. 2 lig.

S. atro-fufcus, fupra veluti cinerafcens, antennis pedibufque fufcis, lamellis antennarum longis, elytris friatis.

Loc.

26. S. aquaticus.

Le Scarabé noir des marais.

Long. 2 lig. Larg. I lig.

A vi 


\section{I2 ENTOMOLOGIA}

S. piceus.

Ioc. Habitat putridas paludum aquas.

27. S. natator.

Le Scarabé nageur.

Iong. 2 lig. Larg. I $\frac{T}{4}$ lig.

S. totus rufo-niger, maculis nigrioribus. $\boldsymbol{L}_{\text {oc. Habitat rivulos \& aquas. }}$

28 . S. perla.

La Perle aquatique.

Long. I lig. Larg. $\frac{3}{4}$ lig.

S. fubrotundus lucidus, capite thorace: que nigro, elytris pallidis pellucidis.

Ioc. Habitat rivulos.

2.9. S. putridus.

Le petit Scarabé noir frié.

Long. $\frac{3}{4}$ lig. Latg, $\frac{1}{3}$ lig.

S. niger, pedibus rufis, elytris profunde Ariatis.

Zoc. Habitat putridas plantas.

$4-3$ 30. S. florilegus.

Le petit Scarabé des fleurs. Long. $\frac{x}{2}$ lig.

S. nigro-cœrulefcens.

Loc, Habitą flores. 



\section{PARISIENSIS.}

* 3 r. S. fulcatus.

Le Scarabé à côtes.

Long. $2 \frac{x}{2}$ lig. Larg, $1 \frac{2}{3}$ lig.

S. ater, fupra coftis elevatis friatisa

Loc.

IV. COPRIS. LE BOUSIER:

Antennæ clavatæ , clavâ lamellatâ. Scutellum inter elytrorum origines nullum.

I. C. lunaris.

Le Boufier capucin.

Long. 8 lig. Larg. $4 \frac{2}{3}$ lig.

C. capitis clypeo lunulato, margine ele vato, corniculo denticulato.

Loc. Habitat fimetaria \& bovinas faces rato

2. C. ferratus.

Le Hottentot.

Long. 7 lig. Larg. $s$ lig.

C. niger ; capite clypeato, margine ferrato, thorace lato lævi; elytris ftriatis.

Loc. Habitat bovinas faces; rat, in agris luretianis. 


\section{ENTOMOLOG IA}

3. C. nuchicornis.

Le petit Boufier noir cornu.

Long. $3 \frac{x}{2}, 2 \frac{x}{2}$ lig. Larg. $2, I \frac{1}{3}$ lig.

C. fufco-niger, capite clypeato angulato, pone cornuto, elytris ferrugineonebulofis, brevibus, ftriatis.

Loc. Habitat bovinas faces.

4. C. acornis.

Le petit Boufier noir fans cornes. Long. 2 , I $\frac{x}{2}$ lig. Larg. I, I $\frac{x}{3}$ lig.

C. fufco-niger, capite clypeato augulato, non cornuto, elytris brevibus, friatis.

Loc. Habitat bovinas fæces.

5. C. confpurcatus.

Le Boufier à deux cornes. Long. 4 lig. Larg. $2 \frac{x}{2}$ lig.

C. obfcure ænæus, capite pone bicor$\mathrm{ni}$, thorace antice prominente, ely, tris rufis nigro maculatis.

Ioc. Habitat hovinas fxces.

6. C. fulvus.

Le Boufier fauve.

Long. $2,2 \frac{x}{2}$ lig. Larg. $I \frac{\pi}{2}, 2$ lig. 


C. fulvus, capite $x$ næo , thoracis utrinque cavitate laterali furcâ.

Loc. Habitat bovinas fæces.

7. C. hxmorrhoidalis.

Le Boufier à points rouges. Long. 3 lig. Larg. I $\frac{3}{4}$ lig.

C. niger nitidus, thorace antice gibbo duplici, elytro fingulo maculâ duplici rubrâ.

Loc. Habitat bovinas fxces.

s. C. finuatus.

Le Boufier à couture.

Long. 5 lig. Larg. 4 lig.

C. niger, capite clypeato, elytris mart gine exteriore finuatis.

Loc. Habitat bovinas faces.

9. C. arachnoides.

Le Boufier araignée. Long. 4 lig. Larg. $2 \frac{\pi}{2}$ lig.

C. niger, pedibus longis, femorum polteriorum bafi denticulatâ, elytris portice gibbis.

Loc. Idem. 


\section{I6 ENTOMOLOGIA}

10. C. corniger.

Le Boufier à cornes retrouffées: Long. $4 \frac{x}{2}$ lig. Larg. $2 \frac{x}{2}$ lig.

C. niger, capite pone bicorni, corniculis tenuibus arcuatis, longitudine thoracis, thorace utrinque finuato.

Loc. Habitat bovinas fæces.

V. ATTELABUS. L'ESCARBOT. Antennz clavatx, clavâ integrâ, in medio fractx.

Caput intra thoracem.

I. A. unicolor.

L'E carbot noir:

Long. I, 3,4 lig. Larg. I, 2, 3 lig.

A. totus niger, elytris lxvibus nonnihil ftriatis.

Ioc. Habitat identidem fæces bovinas, fxpius glaream fterilem.

2. A. bimaculatus.

L'Efcarbot à taches rouges. Long. I, I $\frac{I}{2}$ lig. Larg. I, I $\frac{1}{4}$ lig. A. niger, elytro fingulo macula rubra. Loc. Cum pracedent. 




\section{PARISIENSIS.}

3. A. cupretis.

L'Efcarbot bronzé.

Long. 2 lig. Larg. I lig.

A. nigro-cupreus, capite nonnihil prominulo.

I.oc. Cum pracedent.

VI. DERMESTES. LE DERMESTE.

Antennx clavatx perfoliatx, ultimo. articulo folido gibboro.

Elytra non marginata.

I. D. vefpillo.

Le Dermefte à point d'Hongrie.

Long. 9 lig. Larg. 4 lig.

D. thorace marginato, elytris abfcifis, nigris, fafciis duabus tranfverfis undulatis luieis.

Ioc. Habicat cadavera putrida.

2. D. Lifterianus.

Le grand Dermefte noir.

Long. 14 lig. Larg. 6 lig.

D. thorace marginato, elytris abfciflis; totus niger.

Loc. Cum pracedente, ratior: 


\section{ENTOMOIOGIA}

3. D. bipunctatus.

Le Dermefte à 2 points rouges.

Long. 2 lig. Larg. I lig.

D. niger, coleoptris punctis rubris binis. Loc. Futrida cadavera habitat.

4. D. pellio.

Le Dermefle à 2 points blancs.

Long. 2 , I $\frac{x}{2}$ lig. Larg. I $\frac{2}{3}$ lig.

D. niger, coleoptris punftis albis binis. Loc. Habitat hortos \& domos.

s. D. lardarius.

Le Dermejte du lard.

$$
\text { Iong. } 3 \text { lig. }
$$

D. niger, elytris antice cinereis.

Ioc. Habitat partes animalium putridas, mus fais ubi pelles confervantur infertus.

6. D. pallidus.

Le Dermefte effacé.

Long. I $\frac{x}{2}$ lig. Larg. $\frac{2}{3}$ lig.

D. nigro-fufcus, elytris antice pallidio: ribus nebulofis.

Zos. Habitat partes animalium putridas, mufxis ubi pelles confervantur infeftus. 


7. D. murinus.

Le Dermefie à écuffon jaune.

Long. 2 , 3 lig. Larg. I lig.

D. lævis niger, cinereo-nebulofus, $\mathrm{Ccu}-$ tello luteo.

Loc. Cadavera \& exefas arbores habitat.

8. D. Alavefcens.

Le Velours jaune.

Long. 2 lig.

D. Aavefcers pilofus, oculis nigris.

Loc. Habitat lignum exefum.

9. D. oblongus.

Le Dermefte levrier à fries. Long. I lig. Latg. $\frac{x}{4}$ lig.

D. oblongus fufcus, elytris ftriatis:

Loc. Habitat ligneas fupellectiles in domis.

IO. D. contractus.

Le Dermefle levrier ponatué E frié.

D. oblongus ferrugineus; elytris puncta:o-ftriatis.

Loc. Habitatio pracedentis, 


\section{ENTOMOLOGIA}

II. D. auriculatus.

Le Derinefte à oreilles.

Long. 2 lig. Larg. $\frac{3}{4}$ lig.

D. tentaculis ante oculos antenniform. bus mobilibus.

Loc. Vere novo in aquas natat.

12. D. Atercoreus.

Le Dermefte du funier.

Iong. $\frac{r}{2}$ lig.

D. oblongus, glaber, teftaceus, oculis nigris.

Ioc. Fimetaria habitat, identidem in domis reperitur.

3. D. variegatus:

Le Dermefle panaché.

Long. 2 lig. Larg. I lig.

D. nigro fufcoque nebulofus, elytris vis friatis.

Loc. Habitat corrices cariofos.

2.4. D. Itriatus.

Le Dermefte à côtes. Long. I $\frac{x}{2}$ lig. Larg. $\frac{2}{3}$ lig.

D. nigro fufcoque nebulofus, thorace 


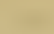

(n)

and

$=$ 


\section{PARISIENSIS.}

elytrifque profundè friatis \& punctatis,

Loc. Habitar vetuftas arbores.

I5. D. aquaticus.

Le Dermefte bronzé.

Long. I $\frac{\pi}{2}, 3 \frac{x}{2}$ lig. Larg. $\frac{2}{3}$, I $\frac{3}{4}$ lig.

D. viridi-ænæus, thorace facciis quatuor elevatis, elytris punctato-ftriatis.

Loc. Confervas rivorum habitat.

16. D. 4-punctata.

Le Dermefte à 4 points rouges, frié. Long. $2 \frac{x}{2}$ lig. Larg. I lig.

D. niger, coleoptris punctis rubris qua ternis, elytris ftriatis oblongus.

Loc. Habitat arbores; rarus.

17. D. hortenfis.

Le Dermefte à 4 points rougès, fans fries.

Long. 3 lig. Larg. I $\frac{3}{4}$ lig.

D. niger, coleoptris punctis rubris quaja ternis, elytris lævibus fubrotundus.

Loc. Habitat arbores in fylvis \& hortis:

38. D. gagatinus.

Le Dermefte jayet.

Long. I $\frac{x}{2}$ lig. Ḷarg. $\frac{3}{4}$ lig 
22 ENTOMOLOGIA

D. niger fubrotundus elytris lævibus.

Loc. Habitat flores.

x. D. lugubris.

Le Dermefte en deuil.

Long. I $\frac{1}{4}$ lig. Larg. $\frac{2}{3}$ lig.

D. niger fubrotundus, elytris friatis.

Loo. Habitat plantas aquaticas. .

20. D. longicornis.

Le Dermefte noir à longues antennes:

Long. I lig. Larg. $\frac{T}{2}$ lig.

D. niger fubrotundus, elytris lævibus, antennis thorace longioribus.

Ioc. Habitat flores.

2 I. D. fulvipes.

Le Dermefte noir à pattes fauves. Long. I lig. Larg. $\frac{x}{2}$ lig.

D. niger oblongus, elytris punctatis, pedibus fulvis.

Loc. Habitac flores.

22. D. pellucidus.

Le Dermefte à étuis tranjparens. Long. I lig. Larg. $\frac{2}{3}$ lig.

D. elytris corneis pellucidis, thorace obrcuriore: 




\section{PAR I S IENSIS.}

Loc. Habitat umbelliferarum flores.

\section{D. futuratus.}

Le Dermefte à couture.

Long. I lig. Larg. $\frac{3}{4}$ lig.

D. totus niger, fubrotundus, thorace elytrifque profunde friatis \& punctatis. Ioc.

24. D. trifulcus.

Le Dermefte à tête noire. Long. $2 \frac{x}{2}$ lig. Larg. $\frac{3}{4}$ lig.

D. oblongus, fufcus capite nigro, tho race coftis tribus elevatis, elytris ftriatis. Loc.

25. D. fafciatus.

Le Dermefte à bande noire.

Long. I $\frac{1}{3}$ lig. Larg. $\frac{1}{3}$ lig.

D. oblongus, niger, pedibus coleoptrifque fulvis, elytrorum fafciâ tranf. versâ nigra.

Loc.

* 26. D. fcapularis.

Le Dermefte à épaulettes.

Long. I lig. Larg. $\frac{x}{2}$ lig. 


\section{ENTOMOLOG A}

D. capite thoraceque rubro, elytris niLoc. gris, maculis antice extufque rubris.

* 27. D. pygmxus.

Le Dermefte puce.

$$
\text { Long. } \frac{2}{3} \text { lig. Larg. } \frac{\mathrm{r}}{2} \text { lig. }
$$

D. ovatus teftaceus, fubpilofus oculis nigris.

Loc.

* 28. D. thoracicus.

Le Dermefte puce à corcelet rouge. Long. $\frac{2}{3}$ lig. Larg. $\frac{1}{3}$ lig.

D. ovatus, capite, thorace pedibufque rubicundis, elytris nigris.

Ioc.

29. D. tefudinarius.

Le Dermefie-tortue noire. Long. $2 \frac{x}{2}$ lig. Larg. 2 lig.

D. niger nitens ovatus, elytris poftice lividis.

Los.

* 30. D. tricolor.

Le Dermefte-tortue ì tache rouge. Long. $2 \frac{r}{2}$ lig. Larg. 2 lig.

D. 




\section{PARISIENSIS.}

D. niger nitens ovatus, elytris poftice, antice maculâ rubrâ.

Loc.

3. D. teffelatus.

Le Dermefte à l'échiquier.

Lon. I $\frac{1}{3}$ lig. Larg. $\frac{2}{3}$ lig.

D. niger; maculis fufcis, plurimis con nexis, elytris punctatis.

Loc.

32. D. femi-coleopterus.

Le Dermefte noir à étuis courts.

Long. I $\frac{x}{2}$ lig. Iarg. $\frac{3}{3}$ lig.

D. ater, elytris marginatis brevibus, pedibus fufcis.

Ioc.

33. D. dimidiatus.

Le Dermefte à demi-étuis.

Long. I $\frac{2}{3}$ lig. Larg. $\frac{2}{3}$ lig.

1). niger, elytris dimidiatis pene flavis. Ioc.

VII. BIRRHUS, LA VRILLETTE.

Antennx articulis tribus ultimis longifimis femi-clavatx. 


\section{ENTOMOLOGIA}

I. B. domefticus.

La V riliette des tables.

Long. I $\frac{x}{2}, 2$ lig. Larg. $\frac{1}{2} \frac{3}{4}$ lig.

B. teftaceo-niger, thorace fubhirfuto.

Loc. Ligneas fuppelectiles foraminibus rotundis terebrat.

2. B. paniceus.

La Vrillette de la farine.

Long. I lig. Larg. $\frac{1}{3}$ lig.

B. teftaceus glaber oculis nigris.

Loc. Habitat cerealia.

3. B. mollis.

La Vrillette fauve.

Long. $2 \frac{\mathrm{T}}{2}$ lig. Larg. I lig.

B. fulvus obfcurus, oculis nigris.

Loc. Habitat pinum.

4. B. pertinax.

La Vrillette favoyarde.

Long. = $\frac{\mathrm{r}}{2}$ lig. Larg. I lig.

B. totus nigrc-fufcus.

Loc. Habitat ligna tabulata domorum.

s. B. fafciatus.

La V rillette brune à bandes grifes.

Llong. I $\frac{x}{2}$ lig. Larg. $\frac{\pi}{2}$ lig. 




\section{PARISIENSIS.}

B. furcus, fafciis elytrorum tranfverfis cinereis.

Loc.

6. B. corulefcens.

La Villette bleuâtre. iong. 2 lig. Larg. I lig.

B. totus nigro-cœruleus fubvillofus. Loc.

\section{VIII.ANTHRENUS. L'AN THR $\hat{E} N E$.}

Antennæx clavatæ integrax, clavâ folidà compreffâ.

I. A. fcrophularix.

L'Anthrêne à broderie.

Long. I lig. Larg. $\frac{3}{4}$ lig.

A. fquamo (us niger, fafciâ punctifque coż leoptrorum albis, futuris fufcis,

Loc. Habitat Hores, multiplex.

2. A. florilegus.

L'Amourette.

Long. $\frac{T}{3}$ lig. Larg. $\frac{x}{2}$ lig.

A. fquamolus niger, elytris fufcis, faC. ciâ triplici undulatâ albâ.

Loc, Larva cadavera habitat, alatus-fore

$B$ ij 
2 ENTOMOLOGIA

IX. Cistela. La Cistele.

Anternx extrorfum craffiores nonnihil perfoliatx.

Thorax conicus non marginatus.

7. C. viridefcens.

Ia Ciftele fatinée.

Long. 4 lig. Larg. $2 \frac{2}{3}$ lig.

C. fubvillofa viridefcens, fafciis longitu* dinalibus furcis interruptis.

Loc. Habitat arenam \& gramina.

2. C. atra.

La Ciftele à bande.

Long. $2 \frac{7}{2}$ lig. Larg. $1 \frac{3}{4}$ lig.

C. Cubvillora atra, fafciâ elytrorum tranfverโâ aurato.fulcâ.

Loc.

3. C. nitens.

La Ciftele noire lifje.

Long. I $\frac{1}{3}$ lig. Larg. $\frac{2}{3}$ lig.

C. nigra nitens glabra. Lyc. 


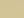




\section{PELTIS. LE BOUCIIER.}

Antenne extrorfun craffiores nonnihil perfoliatx.

Thorax \& elytra marginata.

1. P. atrata.

Le Bouclier noir à trois raies $\&$ corcelet liffe.

Long. 4, 5, 6 lig. Larg. 2, 3, 4 lig.

P. nigra, elytris lineis tribus elevatis, fpatio interjecto punctato, thorace lxvi.

Variet. A. ead. Patio interjecto punctato, thoracelævi, utrin. que fulco armato.

B. ead. Spatio interjecto punctato, thorace lrvi, ubique æquali.

C. ead. Cpatio interjęto punctato, thorace lxvi, punc" tis duobus imprefis.

D. ead. Fpatio interjecto punctis latis inxqualibus, thorace lavi.

Loc. Habitat putrefacta animalium cadavera.

$B$ iij 


\section{0 'ENTOMOLOGIA}

2. P. fcabra.

Le Bouclier noir à corcelet raboteux. Long. 5, 6 lig. Larg. 2, 5 lig.

P. nigra, elytris lineis tribus elevatis, tio interjecto minutifime punctato, thorace fcabro.

Icc. Habitat cadavera, rarior.

3. P. gibbora.

Le Bouclier à bolfes.

Long. 9 lig. Larg. 4 lig.

P. nigra, elytris lineis tribus elevatis, primâ \& fecundâ gibbofitate conne= xis, thorace lrvi. .

Loc. Habitat cadavera.

4. P. complicata.

Le Bouclier noir chiffoné à corcelet raboteux.

Long. $5 \frac{x}{2}$ lig. Larg. 2 lig.

P. nigra, elytris lineis tribus elevatis acutis, Ppatio interjecto veluti complicato, thorace fcabro.

Loc. Habitat cadavera. 




\section{PARISIENSIS.}

\section{s. P. inæqualis.}

Le Bouclier noir chiffonné à corcelet lif]e.

Long. I lig. Larg. 2 lig.

P. nigra, elytris lineis tribus elevatis acutis, fpatio interjecto veluti complicato, thorace lavi.

Loc. Habitat cadaveta.

6. P. thoracica.

Le Bouclier à corcelet jaune.

Long. 6 lig. Larg. $2 \frac{x}{2}$ lig.

P. nigra, lineis tribus elevatis acutis, thorace ferrugineo.

Ioc. Habitar cadavera.

7. P. maculata.

Le Bouclier jaune à taches noires. Long. 6 lig. Larg. 3 lig.

P. nigra, thorace elytrifque teftaceis, thoracis maculâ coleoptrorumque punc= tis quinque nigris.

"Zoc. Habitat cadavera, ratior.

8. P. excavata.

La Goutiere.

Long. 6 lig. Larg. 3 lig.

$B$ iv. 
32 ENTOMOLOGIA

P. nigra tota, elytris levibus, punatis minimis excavatis.

Loc. Habitat ligna humida.

9. P. teftacea.

Le Bouclier fauve.

Long. $2 \frac{x}{2}$ lig. Larg. I $\frac{3}{4}$ lig.

P. tota teftacea.

Ioc.

10. P. villofa.

Le Bouclier brun velouté.

Long. I $\frac{T}{2}$ lig. Larg. $\frac{x}{2}$ lig.

P. nigro-fufca fubvillofa.

Loc. Habitat arenam.

XI. CUCUJUS. LE RICHARD.

Antennæ ferratæ breves.

Thorax fubtus nudus.

Caput dimidium intra thoracem craftun.

I. C. chryfoitygma.

Le Richard à folfettes.

Long. 5 lig. Larg. 2 lig.

C. aureus, elytrorum foffulis quatuor impreffis nitentibus. 




\section{PARISIENSIS.}

Loc. Habitat excelfas arbores; frequenter in infula luteciana Louvier dicta reperitur. ad quam cum ligno advehitur, ex fylvis.

2. C. 8-guttatus.

Le Richard à points blancs. Long. 5 lig. Larg. I $\frac{1}{3}$ lig.

C. viridi-xnæus, punctis quatuor impreffis albis.

Loc. Idem.

3. C. rufticus.

Le Richard doré à fries. Lorg. 7 lig. Larg. I lig.

C. viridi-auratus, oblongus, thorace punctato, elytris ftriatis.

Loc. Habitat arbufta fepium.

4. C. rubinus.

Le Richard rubis.

Long. 4 lig. Larg. I $\frac{x}{2}$ lig.

C. æneus, elytris fufcis, thorace rubro fafciis fufcis.

Loc, Habitat rofas.

S. C. viridis.

Le Richard vert allonget.

Long. $2 \frac{x}{2}$ lig. Larg. $\frac{x}{2}$ lig.

B y 


\section{ENTOMOLOGIA}

C. viridi-cupreus, lævi oblongus.

Ioc. Habitat arbores fepium.

6. C. minutus.

Le Richard triangulaire ondé.

Long. I $\frac{x}{2}$ lig. Larg. I lig.

C. fufco-cupreus, triangularis, fafciis undulatis villoro albidis.

Loc. Idem.

* 7. C. ater.

Le Richard noir allonge.

Iong. 4 lig. Larg. I lig.

C. niger oblongus, punctatus, elytris Ariatis.

Ioc.

* 8. C. dentatus.

Le Richard noir chagriné. Long. 4 lig. Larg. I lig.

C. niger thorace punctato, portice dentato, elytris fulcatis.

Ioc. Habitat infulas Sequanx propè locum dictum le Gros Caillou. 




\section{PARISIENSIS.}

\section{ELATER. LE TAUPIN.}

Antennx ferratx vel filiformes intra capitis cavitatem fubtus receptr.

Thorax fubtus aculeo intra cavitatem abdominis recepto.

I. E. ruber.

Le Taupin rouge.

Long. $8 \mathrm{lig}$, Larg. 3 lig.

E. thorace elytrifque rubris.

Ioc. Habitar cariofas falices.

2. E. fanguineus.

Le Taupin à étuis rouges.

Long. 5 lig. Larg. I $\frac{x}{2}$ lig,

E. niger, elytris rubris.

Loc. Habitat cortices arborum.

3. E. Alavefcens.

Le Taupin à étuis jaunes E corcelet lifje.

Long. 5 lig. Larg. $\frac{x}{2}$ lig.

E. niger, elytris flavis.

Varietas A. niger, elytris omnino flavis.

B. niger, elytris Alavis apice nigris。

$$
B \text { vi }
$$


C. niger, elytris tefta = ceo-furcis.

Loc. Habitat vetuftas arbores.

4. E. caftaneus.

Le Taupin à corcelet velouté.

Long. 5 lig. Larg. I $\frac{x}{2}$ lig.

E. thorace villoro, elytris teftaceis apice nigris.

Varietas A. thorace villoro, elytris flavefcentibus apiv ce nigris.

B. thorace villoro, elytris rubefcentibus api-

Ioc. Idem. ce nigris.

5. E. ruficollis:

Le Taupin noir à corcelet rouge. Long. 3 lig. Larg. I lig.

E. niger, thorace rubro.

Loc.

6. E. cruciatus.

Le Taupin porte-creix. Larg. s lig. Larg. I $\frac{x}{2}$ lig. 




\section{PARISIENSIS.}

E. thorace nigro, circulo rubro, ely. tris fulvis, cruce-nigra.

Loc.

7. E. pectinicornis.

Le Taupin brus cuivreux.

Long. 6 lig. Larg. 2 lig.

E. fufco-viridi-æneus.

Loc. Habitat gramina.

8. E. niger.

Le Taupin brun nébuleux. Long. 5 lig. Larg. 2 lig.

E. nigro-fufcus, cinereo-nebulofus.

Loc. Habitat mefles.

9. E. teffellatus.

Le Taupin à plaques velues. Long. 5 lig. Larg. I $\frac{2}{3}$ lig.

E. niger, villofo undulatus.

Loc. Habitat agtos.

I0. E. murinus.

Le Taupin gris de fouris. Long. 4, $5 \frac{8}{2}$ lig. Larg. I $\frac{T}{2}$ lig.

E. niger, elytris villoro $=$ murinis

Loc. 


\section{ENTOMOLOQI}

i. E. balteatus.

Le Taupin bedeau.

Long. 4 lig. Larg. I lig.

E. niger; elytris furcis, fingulo fafcia longitudinali fulvâ.

Loc. Habitat arva.

I2. E. obfcurus.

Le Taupin noir à étuis bruns.

Long. 4 lig. Larg. I lig.

E. niger, elytris fufcis.

Ioc, Idem.

I3. E. ater.

Le Taupin en deuil.

Long. 5 lig. Larg. I $\frac{x}{2}$ lig.

E. totus niger nitidus.

Eoc. Idem.

14. E. rufipes.

Le Taupin noir à pattes fauves.

Long. 3 lig. Larg. $\frac{2}{3}$ lig.

E. niger pedibus rufis.

Loc. Habitat cortices.

Is. E. bimaculatus.

Le Taupin noir à taches rouges. Long. 3. lig, Latg. I lig. 




\section{PARISIENSIS.}

E. niger elytrorum bafi maculis rubris. Loc. Habitat cortices.

16. E. clavicornis.

Le Taupin à antennes en mafles. Long. I lig. Larg. $\frac{x}{2}$ lig.

E. fufcus, antennis ferrato-clayatis:

Loc. Habitat fylvas.

* 17. E. rachifer.

Le Taupin à bandes.

Long. I $\frac{x}{2}$ lig. Larg. $\frac{x}{2}$ lig.

E. niger, elytris fulvis, rachi nigra.

Loc.

* 18. E. melanophtalmos.

Le Taupin fauve aux yeux noirs. Long. $3 \frac{x}{2}$ lig. Larg. I lig.

E. fufcus, oculis nigris.

Loc.

* 19. E. fufcus.

Le Taupin brunet.

Long. 4 lig. Larg. I $\frac{T}{\Sigma}$ lig.

E. totus fufcus, thorace punctato, elytris friatis.

Los. 


\section{ENTOMOIOGIA}

20. E. villofus.

Le Taupin brun velouté.

Long. 9 lig. Larg. 2 lig.

E. fulvus vellere levi fafciatim confperfus.

Loc.

XIII. BUPRESTIS. LE BUPRESTE.

Antennæ filiformes.

Trochanter magnus feu appendix ad bafim femorum pofteriorum.

FAMIL. I. thorace cordato capite latiore elytris angufiore.

I. B. coriaceus.

Le Buprefte noir chagriné.

Long. I 4 lig. Larg. 6 lig.

B. ater, elytris rugofis.

Loc. Habitat humida hortorum loca.

2. B. nitens.

Le Buprefte doré Es filloné à larges bandes.

Long. II lig. Larg. 4 lig.

B. viridis, elytris obtufe fulcatis, non 




\section{PARISIE IN I S.}

punctatis, pedibus antennifque ferru: gineis.

Loc. Halitat frequentifinc hortos \& agros.

3. B. granulatus.

Le Buprefe galonné.

Long is lig. Larg. s lig.

B. niger, elytris xneis convexe punc: tatis friatifque.

$V$ arietas A. totus violaceus, elytris convexe punctatis friatifque.

Loc. Idem. rarior.

4. B. purpurafcens.

Le Buprefe azuré.

Long. lig. Larg. lig.

B. totus nigro-violaceus, elytris denfe Atriatis.

$V$ arietas A. Elytro fingulo Ariis $\mathrm{xvr}$, oris aureo-cupreis.

B. Elytro fingulo friis $x \mathrm{~V}$, tribus interruptis.

C. Ely tro fingulo Atriis xxII, tribus interruptis.

Loe, Habitat hortos humidos. 


\section{ENTOMOLOGIA}

5. B. fycophanta.

Le Buprefte quarré couleur d'or. Long. 7 lig. Larg. 3 lig.

B. nigro-violefcens, elytris latis æxeis è viridi purpureis, fingulo friis fexdecim.

Loc. Habisar ilicem, ubi papilionum larvas devorat.

6. B. antiquus.

Le Buprefte quarré couleur debronze antique.

$$
\text { Long. } 6 \text { lig. Iarg. } 3 \text { lig. }
$$

B. totus è fulco-viridi cupreus, elytris latis, fingulo ftriis rexdecim.

Loc. Idem.

7. B. leucophtalmos.

Le Buprefte tout noir.

Long. 8 lig. Larg. $3 \frac{3}{4}$ lig.

$B$, ater, elytro fingulo ftriis octo lrvibus, pedibus nigris.

Loc. Idem.

* 8. B. longicornis.

Le Buprefte Luifant.

Long. Io lig. Larg, $3 \frac{x}{2}$ lig.

B. ater, elytro fingulo friis octo lavi- 




\section{PARISIENSIS.}

bus vix impreflis pedibus nigris, antennis fufcis, thorace duplo longioribus.

Loc. Idem.

9. B. rufipes.

Ie Buprefte noir à pattes rougeâtres. Long. 4 , 5 lig. Larg. 2 lig.

B. niger, elytro fingulo ftriis octo punctatis, pedibus ferrugineis.

Loc. Idem.

10. B. Alavipes.

Le Buprefte noir à pattes jaunes.

Long. 3 lig. Larg. I lig.

B. niger, elytro fingulo ftriis octo lxvi: bus, pedibus lividis.

Loc. Idem.

II. B. vinearum.

Le Buprefte à $f i x$ points enfoncés.

- Long. 3 lig. Larg. $x \frac{x}{4}$ lig.

B. nigro-viridis, ely tro fingulo ftriis octo punctis tribus impreffis.

Loc. Habitat vite:. 


\section{ENTOMOLOGIA}

I2. B. agrorum.

Le Buprefte vert pointillé à huit fries $\varepsilon$ pattes fuuves.

Long. 4 lig. Larg. I $\frac{x}{2}$ lig.

B. viridis punctatus, elytro fingulo firiis octo, pedibus pallidis.

Loc. Habitat agros.

I3. B. lucorum.

Le Buprefte vert liffe, à huit ftries $\mathcal{E}$ pattes fauves.

B. viridis nitens; elytro fingulo ftriis octo, pedibus pallidis, puntis tribus impreflis.

Loc. Habitat fylvas atidas.

I4. B. bicolor.

Le Buprefte à étuis verts E bruns: Long. 3 lig. Larg. I $\frac{x}{2}$ lig.

B. viridis, elytro fingulo ftriis otto, pedibus elytrorumque anticâ parte \& margine fulvis.

Ioc. Habitat arenam. 
$+$

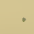

.

$-$ 


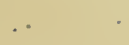




\section{PARISIENSIS.}

Is. B. 6-punctatus.

Le Buprefte à étuis cuivreux.

Long. 4 lig. Larg. I $\frac{x}{2}$ lig.

B. nitens, capite thoraceque viridi, elytris cupreis punctulis duodecim.

Loc. Habitat arenam, propè rivulos.

16. B. thoracicus.

Le Buprefle à corceles cuivreux.

$$
\text { Long. }
$$

B. nitens, capite elytrifque viridibus, thorace cupreo, puntis duodecin.

Loc. Iden.

17. B. cyano-céphalus.

Le Buprefte bleu à corcelet rouge: Long. 3 lig. Larg. $\frac{x}{2}$ lig.

B. capite elytriqque cxruleis, thorace rubro.

Loc. Idem.

18. B. equeftris.

Le Chevalier noir.

Long. 3 lig. Larg. I $\frac{x}{4}$ lig.

B. niger, thorace atro, elytris rubris cruce nigrâ.

Loc. In loco dido Fontainebleait frequens. 


\section{ENTOMOLOGIA}

19. B. crux major.

Le Chevalier rouge.

Long. 3 lig. Larg. I $\frac{x}{2}$ lig.

B. niger, thorace pedibufque rubris elytris rubris, cruce nigra.

Loc.

20. B. crepitans.

Le Buprefte à tête, corcelet Es pat- tes rouges E étuis bleus. Long.

B. capite, thorace, pedibufque rubris, elytris cæruleo-nigris.

Loc. Habitat humum umbrofum, fub lapidibus:

2I. B. uftulatus.

Le Buprefte quadrille à corcelet rond $\mathcal{E}$ étuis friés.

Long. I $\frac{T}{2}, 2 \frac{x}{2}$, 3 lig. Larg. $\frac{r}{2}$, I lig.

B. niger, thorace ovato, nigro, elytris friatis maculis quatuor lividis.

Loc. Habicat rivorum ripas.

22. B. 4-maculatus.

Le Buprefte quadrille à corcelet plat E étuis liffes.

Long. idem. Larg. idem. 



$$
-
$$




\section{PA R I S I E N S I S.}

B. niger, thorace plano ferrugineo, elytris lxvibus, maculis quatuor lividis.

Luc. Idem. .

23. B. crucifer.

Le Buprefte quadrille à corcelet plat, brun $\mathcal{E}$ étuis friés.

Long. idem. Larg. idem.

B. niger, thorace plano ferrugineo, ely: tris friatis, maculis quatuor lividis.

Loc. Idem.

24. B. quadrifer.

Le Buprefte quadrille à corcelec plat $\mathcal{E}$ noir E étuis friés.

B. niger, thorace plano nigro, elytris friatis, maculis quatlior lividis.

Loc. Idem.

25. B. octo-maculatus.

Le Buprefte noir à huit taches

fauves.

Long. I lig. Larg. $\frac{x}{2}$ lig.

B. niger, elytris friatis, maculis octo. lividis.

Loc. Habitat arenam. 


\section{ENTOMOLOGIA}

26. B. fulvus.

\section{Le Buprefte fauve à tête noire.} Long. 2 lig. Larg. $\frac{3}{3}$ lig.

B. teftaceus, capite nigro. Loc. Idem.

27. B. minutus.

Le Buprefte noir fans ftries.

$$
\text { Long. I lig. Larg. } \frac{\pi}{3} \text { lig. }
$$

B. totus niger, lavis.

Loc. Habitat arenam.

Famil. II. Thorace capite elytrifque anguftiore.

28. B. campeftris.

Le Velours vert à I 2 points blancs.

Long. 6 lig. Larg. $2 \frac{\mathrm{x}}{2}$ lig.

B. inauratus, fupra viridis, coleoptris punctis duodecim albis.

Loc. Habitat loca ficca, arenam.

* 29. B. epifcopalis.

Le Buprefte épifcopal.

Long. 4 lig. Larg. I $\frac{x}{2}$ lig. 


\section{.}





\section{PARISIENSIS.}

B. totus violaceus, pedibus antennifque fufcis.

Loc. Idem.

30. B. fafciatus.

Le Buprefte à broderie blanche:

Long. 6 lig. Larg. $2 \frac{x}{2}$ lig.

B. inauratus, fupra fufco-viridis, coleop. tris fafciis fex undulatis albis.

Loc. Idem.

* 3 I. B. futuratus.

Le Buprefte à bandes. Long. I $\frac{x}{2}$ lig. Larg. $\frac{2}{3}$ lig.

B. niger; elytris Ariatis, coleoptrorum anticâ parte futurâque lividis.

. Loc,

32. B. germanicus.

Le Buprefte vert à 6 points blancs. Long. 4 lig. Larg. I lig.

$B$. inauratus, fupra fufco-viridis, coleopj tris punctis fex albis.

Loc. Habitat atenam, prope tivulos,

33. B. marginatus.

Le Buprefte bordé.

Long. 2 lig. Larg. I lig. 
so

\section{ENT OMOLOGIA}

B. fulvus, oculis nigris; elytris nigris, poftice fulvis.

Loc.

34. B. riparius.

Le Buprefte à mamelons.

Long. $2 \frac{x}{2}$, 3 lig. Larg. I lig.

B. viridi-2neus, elytris punctis latis excavatis mammillofis.

Loc. Habitat arenam humidam.

*

35. B. fcapularis.

Le Buprefte taché à corcele rouge. Long. 2 lig. Larg. I lig.

B. teftaceus, capite nigro : elytris ftrintis nigris utrinque maculâ antice fulvâ.

Loc.

36. B. aquaticus.

Le Buprefte à tête cannelée. Long. 3 lig. Larg. $\frac{4}{5}$ lig.

B. fulco-æneus, capite profunde ftriato, elỷtrorum frriâ primâ remotiflimâ.

Loc. Habitat atenam humidam.

37. B. contractus.

Le Buprefte levrier.

$$
\text { Iong. } 2 \frac{x}{2} \text { lig. Larg. } \frac{2}{3} \text { lig. }
$$






\section{PARISIENSIS. SI}

B. niger, elytris fulvis ftriatis, femoribus latis, pedibus valde fpinofis.

Loc.

38. B. impreffus.

Le Buprefte à 4 points enfoncés.

Long. I $\frac{x}{2}, 3$ lig. Larg. $\frac{x}{2}$; I lig.

$B$. cupreo viridique variegatus, punctis quatuor impreflis, pedibulque pallidis.

Loc. Habirat arenam prope rivulos.

* 39. B. lunulatus,

Le Buprefte à lunules.

Long. I $\frac{2}{3}$ lig. Larg.

B. niger, elytris friato puntatis; poltice maculis duabus, \& apice flavis.

Loe.

40. B. Atagnorum.

Le Buprefte bronzé à 2 points enfoncés.

Long. 2 lig. Larg. $\frac{4}{5}$ lig.

B. fufco-æneus elytris ftriatis, punctis duobus impreffis.

Loc, Habitat arenam humidam, rarior.

$\mathrm{C}$ ij 


\section{ENTOMOLOGIA}

* 4.I. B. foveatus.

Le Buprefte Irié à 4 points enfoncés.

Long. I $\frac{\mathrm{r}}{3}$ lig. Larg. $\frac{x}{2}$ lig.

B. totus niger, elytris ftriatis, punctis quatuor impreflis.

Loc.

FaM. III. Thorace capite latiore, elytrorum lacitudine.

42. B. piger.

Le Buprefte pareffeux.

Long. 6 lig. Larg. 3 lig.

B. ater, thorace lato, elytrorum frriis punetatis.

Loc. Habitat ficcam arenam,

* 43. B. capitatus.

Le Buprefte brun à tête noire. Long. I $\frac{x}{2}$ lig. Larg. $\frac{x}{2}$ lig.

B. totus fuicus, capite nigro.

Loc.

44. B. viridulus.

Le Buprefte verdet.

Long. 4 lig. Larg. 3 lig. 




\section{PARISIENSIS.}

B. totus viridis, thorace lato.

Los.

* 45. B. maxillofus.

Le Quadrille is machoires brunes.

- Long. $2 \frac{1}{3}$ lig. Latg. $t$ lig.

B. niger maxillis thoraceque ferrugineis: elytris Ariatis, maculis quatuor luteis.

Loc.

46. B: vulgaris.

Le Buprefe rofette.

Long. 3 lig. Larg. I $\frac{x}{2}$ lig.

$B$. infra niger, fupra nigro ænets, thorace lato.

Loc. Habitat arenam.

* 47. B. plateofus. $\cdots$

Le Buprefte is plaģues.

Long. 3 lig. Larg, 1 lig.

B. capite cœruleo-nitido, thorace fulvo; elytris luteis frriatis maculis fex atris.

Loc.

48. B. Juctuofus.

Le Buprefte en deuil.

Long. 5 lig. Larg. I $\frac{3}{4}$ lig.

$\mathrm{C}$ iij 


\section{ENTOMOIOGIA}

B. totus niger, thorace lato lævi, elytrorum ftriis lævibus.

Loc, Habitat humum fub lapidibus.

\section{*}

49. B. fumolus.

Le Buprefle noir à pattes brunes. Long. I $\frac{x}{2}$ lig. Larg. $\frac{2}{3}$ lig.

B. totus niger, elytris Atriatis, pedibus furcis.

Ioc.

so. B. fericeus.

Ie Buprefie noir velouté.

Long. 6 lig. Larg. 2 lig.

B. ater fubvillofus, antennis peditufque ferrugineis.

Ioc, Habitat agros.

5 5. B. zruginofus.

Le Buprefte cuivreux à pattes brunes.

Iong. I $\frac{x}{2}$ lig. Larg. $\frac{3}{4}$ lig.

B. totus nigro-auratus, elytris ftriatis, pedibus furcis.

Ioc. 

.

$-$ 


\section{PARISIENSIS.}

S2. B. leporinus.

Le Buprefte noir à pattes brumes.

B. ater, livis, pedibus antennarumque bafi ferrugineis.

Loc.

* 53. B. connexus.

Le Buprefte ì future.

Long. 4 lig. Larg. I lig.

-B. niger, pedibus fulvis : elytris fulvis futurâ margineque poftico nigriss.

Ioc.

54. B. pfittaceus.

Le Buprefie perroquet.

Long. S, 3 lig. Larg. 2 , I lig.

B. totus viridi cupreus, antennis nigris.

Loc. Habitat agros \& hortos, frequentiffimus.

SS. B. variegatus.

Le Buprefte vert à bordure. Iong. $4 \frac{\mathrm{r}}{2}$ lig. Larg. 2 lig.

B. viridis, pedibus elytrorumque margine exteriore pallide tefaceis.

Loc. Hebitat agros. 


\section{ENTOMOLOGIA}

s6. B. melanocephalus.

Le Buprefte noir à corcelet rouge.

Long. 3 lig. Larg. I $\frac{x}{4}$ lig.

B. riger, thorace, antennis pedibufque ferrugineis.

Loc. Habitat agros.

* 57. B. rubefcens.

Le Buprefte fauve.

Long. 2 lig. Larg. $\frac{3}{4}$ lig.

B. ferrugineo-lividus, elytris punetato Ariatis.

Loc.

* s8. B. rofaceus.

Le Buprefte rouget.

Long. 3 lig. Latg. I lig.

B. niger lwvis, thorace antennis pedi= bufque rubris.

Loc.

* 59. B. ruficus.

Le Buprefte brunet.

Long. 3 lig. Larg. I lig،

B. riger punctatus, thorace capite antẹnnis pedibufque furcis.

Ioc. 


$$
\begin{aligned}
& \text { (n) } \\
& \sqrt{2}+x^{2} \\
& 4 \\
& \text { - } \\
& \text { car }
\end{aligned}
$$


- 


\section{PARISIENSIS.}

* 60. B. humeralis.

\section{Le Buprefte à noud d'épaule.}

Long. 3 lig. Larg. I lig.

B. niger Atriatus; pedibus pallidis, ely. trorum bafi maculâ flavâ.

Ioc.

\section{BRUCHUS, LA BRUCHE.}

Antennæ filiformes.

- Thorax fuibrotundus gibbus.

Corpus Sphæroidxum, dorfo convexo.

s. B. fur.

La Bruche à baindes.

Long. I $\frac{x}{2}$ lig. Larg. $\frac{2}{3}$ lig.

B. teftaceus, elytrorum fafcià duplici albidâ.

Ioc. Habitat hẹbaria, plantas ficcas devorat'

2. B. apterus.

La Bruche fans aîles.

Long. I lig. Larg. $\frac{3}{4}$ lig.

B. totus teftaceus, elytris coadunatiso

Ioc. Habitar plantas ficcas.

C ฯ. 


\section{S8 ENTOMOLOGIA}

* 3. B. cruciatus.

La Bruche à croix de S. André.

Long. 2 lig. Latg. I lig.

B. fufcus fubvillofus, fcutello albo, elytris cruce divaricatâ albidâ.

Ioc.

\section{XV.LAMPYRIS.LEVER-LUISANT.}

Antennx filiformes.

Caput clypeo thoracis marginato tectum.

Abdominis latera plicato-papillofa.

I. I. nocticula.

Le Ver-luifant ì femelle Jans aîles.

Le mâle. Long. $3 \frac{2}{3}$ lig. Larg. I $\frac{1}{3}$ lig.

La femelle. Long. 6 lig. Larg. $2 \frac{x}{2}$ lig.

L. fæminâ apterâ.

Zoc. Fæmina abdomine nudo campos habitat, mas in hortis volitat per noctem.

2. L. hemiptera.

Le Ver-luifant à demi-fourreaux.

Long. $2 \frac{2}{3}$ lig. Larg. $\frac{2}{3}$ lig.

L. hemiptera.

Loc, Idern. 


3. L. fanguinea.

Le Ver-luifant rouge.

Long. $4 \frac{x}{2}$ lig. Larg. $1 \frac{3}{4}$ lig.

L. elytris rubris, thorace rubro, nigrâ maculâ.

Loc. Idem.

\section{XVI.CICINDELA. LA CICINDELE.}

Antennæ fili formes.

Thorax planus, marginatus.

Caput detectum.

Elytra flexilia.

I. C. fufca.

La Cicindele noire à coreelet incs culé.

Long. 5 lig. Larg. I $\frac{2}{3}$ lig.

C. elytris nigricantibus thorace rubro, nigrâ maculâ.

Loc. Habitat flores.

2. C. livida。

La Cicindele à corcelet rouge.

Long. 5, 6 lig. Larg. I $\frac{\pi}{2}$ lig.

C. thorace rubro immaculato, genubus potticis nigris.

C ri 


$$
\begin{gathered}
V \text { urietas A. elytris'teftaceis, tho- } \\
\text { race rubro immacu- } \\
\text { lato, genubus pofticis } \\
\text { nigris: } \\
\text { B. elytris nigricantibus, } \\
\text { thorace rubro inma- } \\
\text { culato, genubus pof } \\
\text { ticis nigcis. }
\end{gathered}
$$

Ioc. Habitat flores.

3. C. nigra.

La petite Cicindele noire.

Long. $2 \frac{x}{2}$ lig. Larg. I lig.

C. elytris nigricantibus, thorace rubro immaculato, genubus omnibus rubris.

Ioc. Idem.

4. C. pallida.

La petite Cicindele pâle.

Long. 3 lig. Larg. $\frac{3}{4}$ lig.

C. elytris teftaceis, thorace rubro immaculato, genubus omnibus rubris.

Ioc. Idem.

s. C. maculata.

La Cicindele à étuis tachés de noir. Iong. 4 lig, Largo I lig. 

C. rubra, elytris teftaceis, apice nigris. Loc. Habitat flores.

6. C. lutercens,

La Cicindele noire à étuis jaunes: Long. $2,2 \frac{x}{2}$ lig. Larg. $\frac{2}{3}$ lig.

C. nigra, elytris pedibufque pallidis.

Varietas A. nigra, thorace om: nino nigro, elytris pedibufque pallidis. B. nigra, thoracis margine flavo, elytris pedibufque pallidis

Zoc. Idem:

7. C. xnẹa.

La Cicindele bedean.

Long. 3 lig. Larg. I $\frac{x}{2}$ lig.

C. viridi-ænea, elytris extrorum rubris:

Loc. Idem.

8. C. bipuftulata.

La Cicindele verte à points rouges: Long. 3 lig. Larg. I $\frac{x}{2}$ lig. .

C. æneo-viridis, elytris apice rubris,

Loc, Habisas flores. 


\section{ENTMOIOGIA}

9. C. elegans.

La Cicindele verte à points jaunes.

C. æneo-viridis, elytris apice favis.

$$
\begin{array}{r}
\text { Varietas A. tota æneo-viridis, } \\
\text { elytris apice- flavis. } \\
\text { B. cceruleo-viridis, tho- } \\
\text { racis margine iubro, } \\
\text { elytris apice flavis. }
\end{array}
$$

Zoc. Habitat flotes,

150. C. minima.

La Cicindele noire à points jaunes $\mathcal{E}$ corcelet rouge.

Long. I $\frac{x}{2}$ lig. Larg. $\frac{x}{2}$ lig.

C. furca, elytris apice flavis, thorace rubro nigrâ maculâ.

Loc. Idem.

11. C. bigutrata.

La Cicindele noire à points jaunes $\mathcal{E}$ corcelet noir.

C. furca, elytris apice flavis, thorace fuico.

Toc. Idem. 

$-$ 


\section{PAIISIENSIS。}

12. C. fafciata.

La Cicindele à bandes rouges.

C. elytris nigris, fafciis duabus rubris. Loc. Habitat flores.

13. C. thoracica.

La Cicindele verte à corcelet rouge. Long. I $\frac{x}{4}$ lig. Larg. $\frac{2}{3}$ lig.

C. viridis, thorace rubro immaculato. Los. Idem.

14. C. viridi-cœrulea.

La Cicindele verdâtre.

Long. 3 lig. Larg. I lig.

C. viridi-cœerulea.

$V$ arietas A. viridis.

B. corulea.

C. viridi-cœrulea,

2oc, Idem.

Is. C. plumbea.

La Cicindele plombée.

Long. 2 lig. Larg. $\frac{3}{2}$ ligy

C. plumbeo-nigra,

Loc. Idem. 
64 ENTOINOLIA

16. C. cinerea.

La Cicindele cendrée.

Long. 2 lig. Larg, $\frac{\mathrm{T}}{2} \mathrm{lig}$.

C. villoŕo-cinerea.

Loc. Habitat Alores.

I7. C. rotundata.

La Cicindele bronzée.

Long. i- lig.

C. plumbeo-cuprea, tibiis pallidis, ab: domine fubrotundo.

Loc. Idem.

XVII. OMALISUS. L'OMALISE.

Antennæ filiformes.

Thorax planus tetragonus, ąngulis porterioribus in fpinam productis.

I. O. fontis bellaquxi.

L'Omairife.

Iong. $2 \frac{x}{4}$ lig. Larg. I lig.

Loc. Habitat fontem bellaquatixa. 




\section{PARISIENSIS. 65}

\section{HYDROPHILUS, L'HYDRO-}

$$
\text { PHILE. }
$$

Antenne clavate perfoliatx antennu: lis breviores.

Pedes natatorii.

I. H. picæus.

Le grand Hydrophile.

Long. I 7 lig. Larg. 9 lig.

H. niger, elytris fulcatis, antennnis fufcis. Loc. Habitat rivulos \& ftagna.

2. H. ca raboides.

L'Hydroplizle noir picoté.

Long. 7 lig. Larg. 3 lig.

H. niger, elytrorum punctis per ftrias. digeftis, antennis nigris.

Loc. Habitat aquas.

3. H. punctatus.

L'Hydrophile liffe à points.

Long. 2 lig. Larg. $x$ lig.

H. niger, elytris lævibus denfe punc, tatis.

Loc. Idem. 


\section{ENTOMOLOGIA}

4. H. fufcipes.

L'Hydrophile noir ftrié.

Long. $3 \frac{1}{2}$ lig. Larg. I $\frac{2}{3}$ lig.

H. niger, elytris frriatis, pedibus fufcis. Ioc. Habitat aquas.

s. H. fulvus.

L'Hydrophile fauve.

Long. 2 lig. Larg. I lig.

$\mathrm{H}$. fulvus.

Loc. Iden.

XIX. DYTICUS. LE DItique.

Antennx filiformes, capite longiores. Pedes natatorii.

1. D. ftagnalis.

Le Ditique brun is bordure.

Long. 8 lig. Larg. 4 lig.

D. fulcus, margine coleoptrorum thoracifque flavo.

Loc. Habitat ftagnantes aquas.

2. D. marginalis.

Le Ditique noir à bordure. Iong. I pouce. Larg. 6 lig.

D. niger, margine coleoptrorum thoracifque flavo.

Loc. Habitát ftagna. 



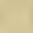


3. D. Semiftriatus.

Le Ditique demi-filloné. Long. I 4 lig. Larg. 7 lig.

D. elytris ftriis viginti dimidiatis.

$\boldsymbol{L} \propto c$, Habitat aquas.

4. D. cinereus.

Le Ditique à corcelet á bandes. Long. 7 lig. Larg. 4 lig.

D. cinereus, margine coleoptrorum fla: vo, thoracis medietate flavâ.

Loc. Habitat tagna.

5. D. fulcatus.

Le Ditique fillonné.

Long. 6 lig. Larg. 4 lig.

D. elytris fulcis decem longitudinalibus, thoracis medietate flavâ.

Loc. Idem.

6. D. luctuofus.

Le Ditique en deuil.

Long. 4 lig. Larg. 2 lig.

D. totus niger lævis.

Loc. Idem. 


\section{ENTOMOLOGIA}

7. D. reffelatus.

Le Ditique fauve à taches noires. Long. 3 lig. Larg. I $\frac{x}{2}$ lig.

D. fulvus, maculis fparfis nigris.

Loc. Habitat aquam.

8. D. variegatus.

Le Ditique à bordure panachée.

Long. 2 lig. Larg. I lig.

D. fufcus, elytris antice \& externe favis. Loc. Idem.

9. D. lividus.

Le Ditique noir à étuis bruns.

$$
\text { Long. } 2 \text { lig. Larg. I lig, }
$$

D. ater, elytris fufcis.

Loc. Idem.

Io. D. ovatus.

Le Ditique fphérique.

Long. 2 lig. Larg. I $\frac{T}{2}$ lig.

D. ovatus fufcus, capite thoraceque ru: bicundis.

Loc. Iden.

I1. D. melanophtalmos.

Le Ditique aux ycux noirs. Long. I $\frac{3}{4}$ lig. Larg. $\frac{3}{4}$ lig. 


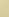


P A R IS I E NSIS.

D. flavo-furcus, oculis nigris; elytris lxvibus.

Lo. Habitat aquas fragnantes.

I 2. D. thoracicus.

Le Ditique frié à corcelet jaune. Long. I lig. Larg. $\frac{x}{2}$ lig.

D. cinereus, capitre nigro, thorace lutteo, elytris nigro-maculatis punctatom friatis.

Loc. Habicat ftagna,

3. D. quadratus.

Le Ditique panaché Sans fries. Long. 2 lig. Larg. I $\frac{1}{4}$ lig.

D. niger, thorace flavo, elytris Ixvis bus, maculis limboque luteis.

Loc. Idem,

4. D. monoftriatus.

Le Ditique à une feule frie.

Long. I lig. Larg, $\frac{1}{3}$ lig.

D. niger, elytris maculis o limboluteis Ariâ unicâ.

Eoc. İdem. 


\section{ENTOMOLOGIA}

I5. D. clavi-cornis.

Le Ditique à groffes antennes: Long. 2 lig. Larg. I lig.

D. furcus, capite thoraceque fulvo, antennis fubclavatis, fcutello nullo.

Loc. Habitat aquas ftagnantes.

* I6. D. hebraicus.

Le Ditique hébraique. Long. $3 \frac{x}{2}$ lig. Larg. 2 lig.

D. niger, capite thoraceque antice flavis, elytris lævibus, maculis aliquot luteis, nonnullis connexis.

Loc. Habitat ftagna.

* 17. D. punctatus.

Le Ditique picoté.

Long. 5 lig. Larg. $2 \frac{x}{2}$ lig.

D. thorace flavo maculâ nigrâ, elytris fufcis punctis nigris confertis.

Loc. Habitat aquas.

* I8. D. marmoratus.

Le Ditique marbré.

$$
\text { Iong. } 2 \text { lig. Larg, I lig. }
$$


. 
1

$=$

$+2$ 


\section{PA R I SIENSIS. 7T}

D. furco-pallidus, elytris externe maculis obliquis lineifque albidis.

Loc. Habitat rivulos \& fragna.

\section{GYRINUS. LE TUURNIQUET:}

Antennx rigid $x$, capite breviores. Pedes natatorii.

Oculi quatuor.

1. C. natator.

Le Tourniquet.

Long. $2 \frac{x}{2}$ lig. Larg. I $\frac{1}{3}$ lig.

Loc. Habitat aquarum fuperficiem quam per ortes concentricos vivaciffime perag rat.

ORDO SECUNDUS. Caract. Ordinis II.

Tarforum articuli quatuor.

XXI. MELOLONTHA. LA MELO- LONTE.

Antennæ ferratæ ante oculos polite.

I. M. quadri-punctata.

La Melolonte quadrille à corceles noir.

Long. + lig. Larg. 2 lig, 


\section{ENTOMOIOGIA}

M. coleoptris rubris, maculis quatuor nigris, thorace nigro.

Loc. Habitar pruni fylveitris folia.

2. M. rubra.

La Melolonte quadrille à corcelet rouge.

Long. 2 lig. Larg. I lig.

IN. coleoptris rubris, maculis quatuor nigris, thorace rubro nigrâ maculâ.

Lo6. Habitat prunum fylveftrem.

3. M. pallida.

La Melolonte lifette.

Long. 2 lig. Larg. I lig,

MI. nigro-viridis, elytris luteo-pallidis. Loc. Habitat fylvas.

4. M. cœrulea.

La Melolonte bleuette. Long. I $\frac{\pi}{2}$ lig. Lerg. $\frac{3}{4}$ lig.

M. cœrulea, thorace pedibufque ferru: gineis.

Loc. Idem.

5. M. murcoides.

La Melolonte mouche. Long, I $\frac{3}{4}$ lig, Larg. I lig. 
.

.

. 


\section{$=$}




\section{PAR ISIENSIS.}

M. viridi-coruleo, thorace rubro coeruleâ maculâ, tibiis ferrugineis.

Loc. Habitat fylvas.

6. M. cuprea.

La Melolonte cuivrenfe.

Long. 2 lig. Larg. $\frac{3}{4}$ lig.

M. oblenga nigro-cuprea, fubvillora elytris punctatis.

Loc. Idem.

\section{PRIONUS. LE PRIONE.}

Antenne ferrata in oculo pofitz.

I. P. coriarius.

Le Prione.

Long. Is lig. Larg. 9 lig.

Loc. Habitat fylvas, larva arborum truncos. XXIII. CERAMBYX. LE CAPRICORNE.

Antennæ à bafí ad apicem decrefcen. tes, in oculo pofitz.

Thorax aculeattus.

x. C. cerdo.

Le grand Capricorne noir. Long. I $\frac{x}{2}$ pouce. Larg. 6 lig.

C. fufco-niger, elytris rugofis, apice 


\section{ENTOHOLOGIA}

interiore fpinofis, antemnis corpore longioribus.

Loc. Larva truncos arborum habitat; cerambix fylvas.

2. C. piceus.

Le petit Capricorne noir.

Long. 9 lig. Larg. $3 \frac{I}{2}$ lig.

C. ater, elytris rugofis integris, antennis corpore longioribus.

Loc. Idem.

3. C. textor.

Le Capricorne noir chagriné. Long. I pouse. Larg. 5 lig.

C. ater, elytris punctis elevatis, antennis corpore brevioribus.

Loc. $1 \mathrm{dem}$.

4. C. alpinus.

La Rofalie.

Long. Is lig. Larg. 4 lig.

C. cinereo-corulefcens, elytrorum maculis fex fufcis.

Loc. Habitat exefos arborum truncos.

5. C. mofchatus.

Le Capricorne vert à odeur de rofe. Iong. I pouce. Larg. $3 \frac{T}{2}$ lig. 
$$
\text { . }
$$ 



\section{PAIISIENSIS.}

C. viridi-cœrulefcens.

Loc. Habitat truncos \& folia falicis.

6. C. ruber.

Le Capricorne rouge.

Long. 8 lig. Larg. $2 \frac{2}{3}$ lig.

C. niger, elytris thoracifque lateribus rubris.

Loc. Ha'itat truncos arborum.

7. C. monilis.

Le Capricorne noir marbré de gris. Long. $3 \frac{\pi}{2}$ lig. Larg. I lig.

C. niger, elytris veliere cinereo marmoratis, antennis pedibufque cinereo interfectis.

Loc. Habitat falices.

8. C. fafciatus.

Le Capricorne ovale cendré.

Long. 6 lig. Larg. $2 \frac{r}{2}$ lig.

C. ater ovatus, antennis corpore dimidio brevioribus, elytris veilere cinereo albidis.

$V$ arietas A. elytris fufcis vellere cinereo falciatis.

Loc. Habitat fepium arbufta, 
76 ENTOMOLOGIA

9. C. hifpidus.

Le Capricorne à étuis dentelés.

Long. 3 lig. Larg. I, I $\frac{5}{3}$ lig.

C. ovatus, fuccus, elytris antice cinereis, apice bidentatis.

Loc. Habitat pratorum gramina.

10. C. ovatus.

Le Capricorne brun de forme ovale. Iong. 2 lig. Larg. $\frac{2}{4}$ lig.

C. ovatus fufcus, eljtris integris.

Luc. Idem.

II. C. compreffus.

Le Capricorne applati.

Long. 2 lig. Larg. $\frac{2}{3}$ lig.

C. niger, compreffus, fcaber, thorace utrinque ferrato, pedibus fulvis.

Lac.

* I2. C. dentatus.

Le Capricorne à poinies.

Long. $2 \frac{\mathrm{r}}{3}$ lig. Larg. $\frac{2}{3}$ lig.

C. fufco-nebplofus, elytris antice cine: reis, apice unidentatis.

Lac。 




\section{PARISIENSIS.}

13. C. nebulofus.

Le Capricome nébuleux.

Long. I $\frac{2}{3}$ lig. Larg. $\frac{2}{3}$ lig.

C. fufco-nebulofus, elytris artice thoracifque medio fubcinereis, olytris integris.

Loc.

\section{LEPTURA. LA LEPTURE.}

Antenne à bafi ad apicem decrefcentes, in oculo pofitix.

Thorax inermis.

Famil. I. Thorace cylindraceo.

I. L. carcharias.

La Lepture chagrinée.

Long. I pouce. Larg. 4 lig.

L. cinerea, nigro-punttata, thorace $c y$ lindraceo.

Loc. Habitat truncos arborum.

2. L. fubcorulea.

La Lepture ardoifée.

Long. $4 \frac{x}{2}$ lig. Larg. I $\frac{I}{4}$ lig.

L. tota cœruleo-atra, capite thoraceque fubvillo?.

Loc. Habitat flores,

D iij 


\section{ENTOMOLOGIA}

3. L. betulina.

Ia Lepture ì corcelet cylindrique $\&$ taches jaunes.

Iong. 4, S, 6 lig. Larg. I, I $\frac{x}{2}$ lig.

L. nigra, thoracis lineis tribus, elytrorumque maculis villofo-flavis', thorace cylindraceo, antennis corpus æquan: tibus.

Loc. Habitat betulam.

4. L. pilofa.

La Lepture noire à étuis jaunes. Long. 2 lig. Larg. $\frac{x}{2}$ lig.

L. nigra ; elytris flavis, apice nigris;

Loc. Habitat hortos.

5. L. oculata.

La Lepture aux yeux de Paon. Long. 5 lig. Larg. $=\frac{x}{2}$ lig.

L. nigro-cinerea, thorace elytrifque maculis oculiferis atris, circulo cinereo, thorace fubcylindraceo.

Lcc. Habitat hortos, rara, in horto regio inventa.

* 6. L. nebulofa.

La Lepture nébuleufe. Long. $6 \mathrm{lig}$, Larg. $2 \frac{x}{2} \mathrm{lig}$. 




\section{PARISIENSIS.}

L. fufca, fubvillofa, maculis cinereis marmorata.

Loc.

7. L. ferruginea.

La Lepture rouillée.

Long. 7 lig. Larg. 5 lig.

L. tota nigro-ferruginea, thorace fubcylindraceo.

Loc. Habitat fylvas.

* \&. L. fulvipes.

La Lepture à pattes fauves.

Long. $\sigma$ lig. Larg. I $\frac{1}{4}$ lig.

L. atra, punctata, pedibus flavis, thorace cylindraceo.

Loc. Habitat agros fontis-Bellaquai.

FAMIL. II. Thorace globofo.

9. L. variegata.

La Lepture à corcelet rond $\mathcal{E}$ taches jaunes.

Long. $6 \frac{1}{2}$ lig. Larg. 2 lig.

L. nigra, maculis villofo-flavis, thorace globofo, antennis corporis dimidio brevioribus.

Loc. Habitat hortos.

$D$ iv 
80 ENTOMOLOGIA

ro. L. villofa.

La Lepture velontrs janne.

Long. 5 lig. Larg. 2 lig.

L. nigra, villo?o-flava, maculis duabus in elytro fingulo glabris nigris.

Loc. Habitat flores.

I. L. punctata.

La Lepture à corcelet rouge ponctué.

Iong. 4 , lig. Larg. I lig.

L. nigricans, capite thoraceque rubro; punctis nigris.

Loc. Habitat hortos.

12. L. arcuata.

Ia Lepture aux croiffans dorés.

Iong. 5, 6, 8 lig. Larg. I $\frac{\mathrm{x}}{2}, 2$ lig.

L. nigra, elytrorum lineis quatuor arcuatis, puntilique flavis, pedibus teftaceis.

Loc. Habitat arborum truncos.

I3. L. arietis.

La Lepture à trois bandes dorées.

Long. 3 lig. Larg. I lig.

L. nigra, elytrorum lineistribus tranfver 




\section{PA.RISIENSIS. SI}

fis punct:que flavis, pedibus teftaceis. Loc. Habitar flores.

14. L. ruftica.

La Lepture à raies blanches.

Long. $2 \frac{\pi}{2}, 4$ lig. Larg. I, I $\frac{\pi}{2}$ lig.

C. nigra, elytrorum lineis tranfverfis pun tiffque albis.

Loc. Habitat umbelliferarum flores.

15. L. fignata.

La Lepture noire à étuis gris tachés de jaune.

Long. $4 \frac{x}{2}$ lig. Larg. I $\frac{2}{2}$ lig.

L. nigra, elytris pallido-fufcis, fignaturis flavis.

Loc. Habitat flores.

16. L. gammoides.

La Lepture jaune à bandes noires. Long. 4 lig. Larg. I lig.

L. villofo-flava, elytris lineis tribus tranfverfis nigris.

Loc. Idem.

17. L. myftica.

La Lepture arlequine.

Long. 5 lig. Larg. I. $\frac{T}{2}$ lig. 


\section{ENTOMOLOGIA}

L. nigra, elytris maculis teftaceis, nigris, albidis, lineifque nigris \& albicantibus variegatis.

Ioc. Rar. hab. hortos, in regio horto inventa.

I8. L. cyanea.

La Lepture bleue.

Long. 3 lig. Larg. $\frac{3}{4}$ lig.

L. corulea, tribus rufis thorace fubgloboro.

Loc. Habitar arborum truncos.

FAMIL. III. Thorace incequali fcabro.

19. L. quadri-punctata.

La Lepture brune à corcelet rhom: boïdal.

Long. $5 \frac{x}{2}$ lig. Larg. 2 lig.

I. teftaceo-fufca, thorace rhomboidali villofo, elytroruin maculis quatuor albidis tranfverfim pofitis.

Loc. Habitat arbores.

* 20. L. vidua.

La Lepture veuve:

Long. 7 lig. Larg. 2 lig. 




\section{PARISIENSIS。 83}

L. tota atra, denfe punctata.

Loc. Habitat arbores.

21. L. teftacea.

La Lepture livide à corcelet liffe. Long. $4 \frac{3}{4}$ lig. Larg. $x \frac{\mathrm{T}}{2} \mathrm{lig}$.

L. teftacea, thorace glabro.

Loc. Habitat flores.

22. L. punctuola.

La Lepture maroquinée. Long. 6 lig. Larg. $1 \frac{3}{2}$ lig.

L. atra, denfe punctata, femoribus rufis. Loc.

23. L. femorata.

La Lepcure noire à corcelet rougeâtre.

L. atra, thorace teftaceo, femoribus craflis.

Loc. Habitat flores.

* 24 . L. turcica.

La Lepture aux croiffans d'argeni。 Long. $2 \frac{1}{3}$ lig. Larg. $\frac{3}{4}$ lig.

L. nigra, elytris antice rufis, poftice lineis quatuor albis arcuatis.

Loc. Habitat hortos.

$$
\text { D vi }
$$




\section{ENTOMOLOGIA}

25. L. craflipes.

La Lepture noire à grofjes cuilfes brunes.

L. atra, femoribus craflis rufis.

Loc. Habitat flores.

26. L. fufca.

La Lepture brune.

Long. $2 \frac{x}{2}$ lig. Larg. I $\frac{2}{3}$ lig.

L. tota fufca punktata.

Ios. Idem.

27. L. fanguinea.

La Lepture veloutée couleur de feul.

Iong. 5 lig. Larg. I $\frac{3}{4}$ lig.

L. nigra, thorace coleoptrifque fericeorubris.

Loc. Habitat truncos arborum \& frequentifimè loca domorum ubi lignum fervatur.

28. L. attenuata.

La Lepture à étuis étranglés.

$$
\text { Long. } 4 \text { lig. Larg. I lig. }
$$






\section{PARISIENSIS. 85}

L. nig:a, elytris pedibufque rubefcentibus lividis, coleoptris attenuatis.

Loc. Habitat flores.

\section{STENOCORUS. LE STEN- CORE.}

Antennx à bafí ad apicem decrefcentes, ante sculos pofita.

Elytra apice anguftiora.

Famil. I. Thorax armatus fpintit

vel tuberculo laterali.

I. S. parifinus.

Le Stencore liffe à bandes jaunes: Long. 8,9 lig. Larg. $2 \frac{x}{2}$ lig.

S. glaber, è fuŕco niger, elytro fingulo lineis tribus elevatis, maculis duabus luteis, thorace f́pinoro,

Loc. Habitat fylvas.

2. S. inquifitor.

Le Stencore noir velouté de jaune. Long. $6 \frac{\mathrm{T}}{2}$ lig. Larg. 2 lig.

S. niger, vellere Alavo variegatus, ely $j$ 
tris lineis duabus elevatis, thorace rpinolo.

Loc. Habirat flores.

3. S. geniculatus.

Le Stencore à genoux noirs.

Long. 7,8 , 10 lig. Larg. I $\frac{x}{2}, 2,2 \frac{3}{3}$ lig.

$S$. è fufco niger, femoribus rufis articulis nigris.

Loc. Idem.

4. S. rubro-violaceus.

Le Stencore rouge à étuis violets. Lung. 9 lig. Larg. $2 \frac{x}{2}$ lig.

S. ruber, oculis nigris, elytris violaceis. Ioc. Habrtat artores.

S. S. rubeus.

Le Stencore jaune à bandes noires. Long. 6 lig. Larg. I $\frac{x}{2}$ lig.

S. niger, elytris teftaceo-flavis, punctis duobus, cruce fafciifque nigris.

Loc. Habitat rgubum.

Famila II. Thorax inermis.

6. S. lamed.

Le Stencore bedeau. 




\section{P. A R I SIEN S I S. $\quad-87$}

S. niger, elytris rubefcentibus, apice futuræque medietate nigris.

Loc.

7. S. melanurus.

Le Stencore noir à étuis rougecittres:

S. niger, elytris rubefcentibus lividis, apice nigris. Mas.

S. niger, elytris rubefcentibus lividis, apice fimili. Fomina.

Loc. Habitat fepes \& arbores.

8. S. lutefcens.

- Le Stencore noir à étuis jaunes:

S. niger, elytris luteis, apice nigris. Loc. Habirat rubum.

9. S. piceus.

Le Stencore noir à ventre rougeátre.

Long. 3 lig. Larg. I lig.

S. niger nitidus, abdomine furco-rubente. Loc. Idem.

ro. S. clavipes.

Le Steniore noir à cuiffes rouges. Long. $2 \frac{x}{2}$ lig. Larg. $\frac{x}{2}$ lig. 
S. niger, femoribus clavatis rufis, apice nigris.

$V$ arietas A. S. totus niger.

Long. $3 \frac{3}{4}$ lig. Larg. $\frac{1}{3}$ lig.

Ios.

II. S. fylveftris.

Le Stencore noir ì corcelet rouge. Long. 4 lig. Larg. I $\frac{x}{4}$ lig.

S. niger, thorace rubio.

Loc. Habitat urbern Fontainebleau.

12. S. aquaticus.

Le Stencore doré.

Iong. $2 \frac{x}{2}, 3,4$ lig. Larg. $\frac{2}{3}$, I lig.

S. deauratus, femoribus pofticis dentatis.

$V$ arietas A. Stenocorus rubro-ancus, femoribus polticis dentatis.

B. Stenocorus viridi-æneus, femoribus pofficis dentatis.

C. Stenocorus fiavo-æneus, femoribus poficis dentatis.

D. Stenocorus violaceo-rneus, femoribus pofticis dentatis.

E. Stenocorus nigro-aneus, femoribus polticis dentatis, 




\section{PARISIENSIS.}

Loc. Habitat rivulorum ripas, \&r irides pratorum.

* I . S. ruber.

Le Stoncore rouge.

Jong. 6 lig. Larg. 2 lig.

$S$. totus ruber, oculis nig ris.

Ioc.

* I4. S. iggnitus.

Le Stencore noir à étuis rouges. Long. $4 \frac{x}{2}$ lig. Larg. $x \frac{r}{3}$ lig.

S. niger, elytris, ruberrimis denfe punci tatis.

Loc.

* Is. S. funereus.

Le Stencore en deuil.

Long. 9 lig. Larg. 3 lig.

$S$. totus niger punctatus.

Loc.

XXVI. LUPERUSS. LE LUPERE.

Antenna filiformes articulis longis.

Thorax planus, marginatus.

1. L. ulmarius.

Le Lüpere noir à corcelet E pattes. rouges. 


\section{ENTOMOLOGIA}

L. niger, thorace pediburque rufis.

Loc. Habitat ulmum.

2. L. betulinus.

Le Lupere noir à pattes rouges. Long. I $\frac{\pi}{2}$ lig. Larg. $\frac{3}{4}$ lig.

L. niger, pedibus rufis.

Los. Habitat berulam.

XX VII. CRYPTOCEPHALUS. LE GRIBOURI.

Antenne filiformes articulis longiso Thorax gibbus hemifpliaricus.

x. C. alni.

Le Gribouri bleu de l'aulne.

Long. 4 lig. Larg. 3 lig.

C. violaceus, punctis inordinatis.

Ioc. Habitat alnum,

2. C. vitis.

Le Gribouri de la vigne.

Long. 2 lig. Larg. I lig.

C. niger, elytris rubris.

Loc. Habitar vitis folia. 




\section{PARISIENSIS. 9I}

3. C. Sericeus.

Le Velours vert.

Long. 3, 4 lig. Larg. 2 lig.

C. viridi-auratus fericeus.

Loc. Hahitat falicem.

4. C. bolati.

- Le Gribouri à deux bandes jaunes. Long. $5 \frac{x}{2}, 2$ lig. Larg. $\frac{3}{4}$ lig.

C. niger, elytro fingulo duplici lines longitudinali Hava.

Luc. Habicai prara \& fepes.

S. C. 4-maculatus.

Le Gribouri à deux taches jaunes.

C. niger, capite thoraceque antice luteis, elytro fingulo externe maculâ duplici flavâ.

Loc, Idem.

6. C. bi-punctatus.

Le Gribouri rouge frié à points ncirs.

Long. $2 \frac{1}{4}$ lig. Larg. I $\frac{T}{2}$ lig. 
92 ENTOMOLOGIA

C. niger, elytris rubris ftriatis, mactlis quatuor limboque nigris.

Loc. Habitat cirfium.

7. C. cirfii.

Le Gribouri rouge fans fries, à points noirs.

C. niger, thorace lineis flavis, elytris rubris punctatis, maculis quatuor limboque nigris.

Loc. Idem.

8. violaceus.

Le Gribouri bleu frié. Long. 2 lig. Larg. I lig.

C. cœruleo-violaceus, puntis per frias digentis.

Ioc.

9. S. cœruleus.

Le Gribouri bleu ì points. Long. 2 lig. Larg. I $\frac{1}{4}$ lig.

C. cœruleus, puntis fparfis, tibiis anticis ferrugineis.

Loc, 



\section{PARISIENSIS.}

1 0 . C. niger.

Le Gribouri noir frié. Long. I $\frac{1}{4}$ lig. Larg. $\frac{3}{4}$ lig.

C. niger Atriatus, pedibus rufis.

Loc.

II. C. rufipes.

Le Gribouri noir à corcelet rouge. Long. I $\frac{T}{2}$ lig. Larg. $\frac{3}{4}$ lig.

C. niger friatus, thorace pedibufque rufis.

Loc.

12. C. fulvus.

\section{Le Gribouri funve.}

Long. I lig. Larg. $\frac{2}{3}$ lig.

C. capite thoraceque fulvo, elytris pallidis.

Loc.

* I3. C. ro-maculatus.

Le Gribouri rouge à Io taches noires.

Long. 3 lig. Larg. $\pm \frac{2}{3}$ lig.

C. niger, elytris rubris punetatis macuLos, lis decem nigris. 


\section{EN TOMOLOGIA}

* I4. C. limbofus.

Le Gribouri rouge à corcelet jauñe. Long. $2 \frac{\frac{1}{3}}{3}$ lig. Larg. I $\frac{\pi}{2}$ lig.

C. thorace flavo maculis nigris; elytris rubris punctatis, maculis fex limboque nigris.

\section{Loc}

* Is. C. chermefinus.

Le Gribouri couleur de feu. Long. 3 lig. Larg. I $\frac{x}{2}$ lig.

C. niger thorace elytrifque rubris punctatis.

Loc.

* 16. C. fufcipes.

Le Gribouri à pattes brunes. Long. 2 lig. Latg. I $\frac{x}{2}$ lig.

C, cœruleus, punctis inordinatis, pedibufque villoro.fufcis.

Ioc.

\section{CRIOCERIS. LE CRIO- $C E R E$.}

Antennx cylindracex articulis globofis. Thorax cylindraceus. 




\section{PARISIENSIS.}

95

I. C. merdigera.

Le Criocere rougge du lys. Long. 3 lig. Larg. I $\frac{x}{2}$ lig.

C. rubra.

Loc. Habitat lilia,

2. C. I2-punctata.

Le Criocere rouge ì points noirs. Long. $2 \frac{x}{2}$ lig. Larg. $I \frac{1}{3}$ lig.

C. rubra, punctis tredecim nigris.

Loc. Halitat afparagum.

3. C. afparagi.

Le Criocere porte-croix de l'afperge.

Long. $2 \frac{2}{3}$ lig. Larg. I lig.

C. thorace rubro punctis duobus nigris, coleoptris flavis, cruce caruleo-nigra.

Loc. Idem.

4. C. hordei.

Le Criocere bleu à corcelet rouge. Long. 2 lig. Laig. $\frac{2}{3}$ lig.

C. coruleo-viridis thorace femoribufque rufis,

Loc. Habitat hordeum \& avenam. 
26 ENTOMOLOGIA

5. C. cyanella.

Le Criocere tout bleu.

$$
\text { Long. } 2 \text { lig. Larg. } \frac{3}{4} \text { lig. }
$$

C. tota cœruleo-viridis.

Ioc.

G. C. pallida.

Le Criocere aux yeux noirs.

Long. $2 \frac{1}{4}$ lig. Larg. I lig.

C. pallida, oculis nigris.

Loc.

* 7. C. fuinofifima.

La Châtaigne noire.

Long. I $\frac{x}{2}$ lig. Larg. $\frac{2}{3}$ lig.

C. tota atra, fpinis horrida.

Loc. Habitat gramen loliaceum,

* 8. C. thoracica.

Le Criocere noir à corcelet rouge.

Long. 2 lig. Larg. $\frac{3}{4}$ lig.

C. atro-cœrulea, thorace femoribufque furcis, elyris punctis fparfis.

Loc.

9. C. atrata.

Le Criocere noir frié.

Long. I $\frac{2}{3}$ lig. Larg. $\frac{3}{4}$ lig. 

$\cdot$ 
C. tota atro-cœrulea friata.

Loc.

ro. C. paleata.

Le Criocere paillet.

Long. $2 \frac{2}{3}$ lig. Larg. I lig.

C. nigra, elytris pedibufque pallidis.

Loc.

\section{ALTICA. L'ALTISE:}

Antennx ubique $x$ quales.

Femora poftica craffa fubglobofa.

I. A. helxines.

L'Altife bleue.

$$
\text { Long. } 2 \text { lig. Larg. I lig. }
$$

A. viridi-cœrulea.

Loc. Habitat hortos.

2. C. malvx.

L'Altije de la mauve.

A. nigra, elytris coruleis, thorace pedibufque rubris.

1.oc. Habitat folia malva

3. A. bicolor.

L'Altije bedaude.

Long. I $\frac{x}{2}$ lig. Larg. I lig. 
$90^{\circ}$ ENTOMOLOGIA

A. nigra, elytris nigro-æneis ftriatis, thorace rubro, pedibus nigris.

Loc. Habitat malvam.

4. A. hortenfis.

L'Altife noire dorée.

Long. I lig. Larg. $\frac{1}{2}$ lig.

- A. nigra-ænea, elytris frriatis, pedibus ferrugineis.

Loc. Habitar hottos frequentifima.

5. A. ovata.

L'Altife noire ovale.

Long. I $\frac{1}{2}$ lig. Larg. I lig.

A. nigro xnea, ovata, pedibus nizris.

Loc. Habitat hortos.

6. A. brafficx.

L'Aliife noire allongée des cruciferes.

Long. I lig. Larg. $\frac{1}{3}$ lig.

A. nigro-ænea, oblonga, pedibus nigris. Ioc. Habitat cruçiferas.

7. A. laxvis.

L'Altife noire à pattes fauves.

Long. I $\frac{2}{4}$ lig. Larg. $\frac{5}{6}$ lig. 




\section{PARISIENSIS.}

A. nigra, ovata, pedibus rufis, elytris non ftriatis.

Loc. Habitat hortos.

8. A. minuta.

L'Altife noire à jambes jaunes.

Long. $\frac{2}{3}$ lig. Larg. $\frac{x}{2}$ lig.

A. nigra, fubrotunda, tibiis ferrugineis:

Loc. Idem.

9. A. nemorum.

L'Altife à bandes jaunes.

Long. $\frac{1}{2}$, I lig. Larg. $\frac{1}{4}, \frac{x}{2}$ lig,

A. atra, elytris longitudinaliter in medio flavefcentibus.

Loc. Habitat aromaticas plantas.

10. A. marginata.

L'Altife à bordure noire.

Long. I $\frac{1}{4}$ lig. Larg. $\frac{2}{3}$ lig.

A. nigra; thorace êlytrifque flavis, oris nigris.

Loc. Habitat hortos.

11. A. hyofciami.

L'Altife du choux.

Long. I lig. Larg. $\frac{x}{2}$ lig.

$E$ ij 
100 ENTOMOLOGIA

A. cœrulea, elytris friatis, tibiis ferrugineis.

Loc. Habitat brafficam \& hyofciamum.

I2. A. cœrulea.

L'Altije bleue fans fries.

Long. I $\frac{x}{2}$ lig. Larg. $\frac{4}{5}$ lig.

A. cœrulea, elytris punctis $\mathrm{fpar}$.13, tibiis ferrugineis.

Loc. Habitat brafficam.

3. A. nitidula.

L'Altife rubis.

Larg. I lig. Larg. $\frac{x}{2}$ lig.

A. nigro-aurata, thorace aureo, femoribus ferrugineis.

Loc. Habitat falicem.

14. A. aurea.

Le Plutus.

Long. I $\frac{2}{3}$-lig. Latg. $\frac{2}{3}$ lig.

A. aurea, pedibus flavis.

Loc. Habitat hortos.

I5. A. 4-punctata.

L'Altije à points rouges.

Long. I $\frac{x}{2}$ lig. Larg. $\frac{4}{5}$ lig. 




\section{PARISIENSIS. IOI}

A. nigra, coleoptris punctis quatuor rubris.

Loc. Idem.

15. A. ferruginea.

L'Altijè fauve à fries.

A. oblonga, ferruginea, e'ytris friatis. Loc. Idem.

17. A. fulva.

L'Altife fauve Sans ftries.

Long. lig. Larg. lig.

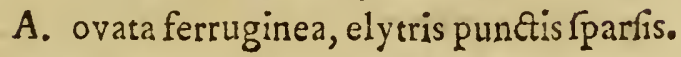

Loc. Idem.

18. A. exfoleta.

L'Alicife jaune.

Long. I $\frac{\pi}{2}$ lig. Larg. I lig.

A. flava.

Loc. Idem.

29. A. pallida.

La Paillette.

Long. I lig. Larg. $\frac{T}{2}$ lig.

A. elytris pallido-flavis, capite nigro. Loc. Idem. 


\section{ENTOMOLOGIA}

* 20. A. ænea.

L'Aliife bronz ée.

Long. I $\frac{x}{2}$ lig. Larg. I lig.

A. nigro-ænea, ovata, pedibus rufis, elytris punctis fparlis.

Ioc. Habitar hortos.

XXX. GALERUCA. LA GALERUQUE.

Antennæ ubique æquales, articulis fubglobofis.

Thorax inæqualis, fcaber, marginatus.

I. G. tanaceti.

Ia Galeruque brunette.

Long. 4 lig. Larg. 3 lig.

G. atro-fufca, elytris lineis tribus ele: vatis, punctis numerofis.

Varietas A. fufca, elytris lineis elevatis interruptis.

2oc. Habitat tanacetum, \& flores compofitos in pratis.

2. G. fanguinea.

La Galeruque fanguine.

Long. $2 \frac{x}{2}$ lig. Larg. I $\frac{x}{2}$ lig. 
$-$ 



\section{PARISIENSIS. 103}

G. fanguineo-rubra.

Loc. Habitat fiores.

3. G. ulmi.

La Galeruque à bandes de l'orme. Long. 2, 3 lig. Larg. I $\frac{x}{2}, 2$ lig.

G. pallida, thorace nigro variegato, elytris farciis duabus longitudinalibus nigris.

Loc. Habitat folia ulmi, abundans,

4. G. aquatica.

Ia Galeruque aquatique. Long. 2 lig. Larg. I $\frac{x}{2}$ lig.

G. pallida, thorace nigro variegato, ely. tris unicoloribus pallidis.

Loc. Habitat potamogeton in tivis \& ftagnis.

s. G. livida.

La Galeruque grifette.

Long. $2 \frac{1}{2}$ lig. Larg. $1 \frac{1}{2}$ lig.

G. nigra, thorace elytrifque luteo-lividis。

Ioc. Habitat betulam.

6. G. violacea.

La Galeruque violette.

Long. 3 lig. Larg. I $\frac{T}{2}$ lig.

$\mathrm{E}$ iv 
IO4 ENTOMOLOGIA

Loc.

G. nigro-violacea.

* 7. G. viridis.

La Galeruque verte.

Long. $2 \frac{x}{2}$ lig. Larg. I $\frac{x}{2}$ lig.

G. thorace pallide flavefcente, elytris viridibus nitentibus.

Loc.

8. G. 4-maculata:

La Galeruque quadrille.

Long. $2 \frac{x}{3}$ lig. Larg. I lig.

G. rubro-lutea, maculis quatuor nigris: Loc.

XXXI. CHRYSOMELA. LA CHRYSOMELE.

Antennx à bafi ad apicem crefcentes, articulis globofis.

Thorax æqualis marginatus.

1. C. populi.

La grande Chryfomele rouge à corcelet bleu.

Long. 5, 6 lig. Larg. 4 lig. 




\section{PARISIENSIS. 105}

C. nigro-cœrulea, ely tris rubris apice nigris. $V$ ariet. A. ead. elytris ommino rubris. La petite Cryfomele rouge à corcelet bleus.

Long. 3 lig. Larg. 2 lig.

Loc. Habitat populum.

2. C. polita.

La Chryfomele rouge à corcelet doré.

Long. $3 \frac{\pi}{2}$ lig. Latg. $2 \frac{8}{3}$ lig.

C. viridi-xnea, elytris rubicundis, punctis fparfis.

Loc.

3. C. Ariata.

La Chryfomele rouge à corcelet noir.

Long. $2 \frac{T}{2}$ lig. Larg. I $\frac{3}{4}$ lig.

C. nigra, elytris rubris ftriatis, ftriis punctatis.

Loc.

4. C. 1o-punctata.

La Chryfomele rouge à points noirs.

Long, 3 lig. Larg, 2 lig. 


\section{ENTONOLOGIA}

C. rubra, elytro fingulo maculis quinque nigris.

Loc. Habitat falicem.

s. C. hæmoptera.

La Chryfomele violette.

Long. $3 \frac{1}{2}$ lig. Larg. 3 lig.

C. tota violacea.

\section{Loc.}

6. C. violaceo-cœrulea.

La Chryfomele bleue à corcelet violet.

Long. 4 lig. Larg. $2 \frac{\mathrm{T}}{2}$ lig.

C. cœrulea, thorace violaceo.

$V$ ariet. ead, thorace nigro-violaceo.

Loc.

7. C. nigra.

La Chry fomele noire ì aîles rouges.

Long. 3 lig. Larg. 2 lig.

C. tota nigra. ${ }^{3}$

Loc.

8. C. fanguinolenta.

La Chryfomele noire à bordure rouge.

Lorg. S lig. Larg. 4 lig. 




\section{P A R ISIENSIS。}

C. nigro-cœrulea, elytris atris punctatis, margine exteriore rubro.

Loc. Habitat fylvas.

9. C. marginata.

La Chryfomele bleule à bordure rouge.

Long. $3 \frac{\mathrm{r}}{2}$ lig. Larg. 3 lig.

C. nigro-cœrulea, elytris lucidis, punce? tatis margine exteriore \& anteriore rubris.

Lec. Habitat prata; rara.

10. C. graminis.

Le grand Vertubleu.

Long. 4 lig. Larg. 3 lig.

C. viridi-cœrulea.

Loc. Habitar galeopfim, lamium, mentham \& gramina.

11. D. viridula.

La Chryfomele dorée.

Long. 2,3 lig. Larg. $1 \frac{x}{2}, 2$ lig.

C. viridis nitida, thorace antice $x$ quali, ely ris pone contiguis.

Loc, Habisat flores labiatos. 
108

\section{ENTOMOLOGIA}

12. C. xnea.

Le petit Vertubleu.

Long. $2 \frac{x}{2}$ lig. Larg. $x \frac{x}{2}$ lig.

C. viridis nitida, thorace antice excavato, fafciis elytrorum longitudinalibus cœruleis.

Zoc. Habitat flores labiaros,

13. C. nitidula.

La Chryfomele à gallons. Long. 4 lig. Larg. 3 lig.

C. viridis nitida, ftriis decem cupreis, punctorum duplici ferie divifis.

Zoc. Idem.

14. B. fafciata.

L'Arlequirs doré.

Long. $3,3 \frac{T}{2}$ lig. Larg. $2,2 \frac{T}{4}$ lig.

C. aurea, fafciis cœruleis, cupreifque alternis, punetis inordinatis.

Toc. Habitat colles aridos.

Is. C. rubro-cuprea.

La Chryfomele briquetée. Long. $4 \frac{\mathrm{r}}{2}$ lig. Larg. 3 lig. . 




\section{PARISIENSIS.}

109

C. fupra rubro-cupraa, infra nigra nitens.

Loc.

16. C. malvx.

La Chryfomele verte à corcelet rouge.

Long. I $\frac{1}{4}$, I $\frac{x}{2}$ lig. Larg. I lig.

C. nigra, elytris cœruleo-viridibus, thorace pedihus antennarumque bafis rufis.

Loc. Habitat malvam.

17. C. betulx.

La Chryfomele bleue du faule:

Long. I $\frac{x}{2}, 2$ lig. Larg. I, I $\frac{1}{3}$ lig.

C. nigro-purpurea, punctis excavatis, Ariata.

Loc. Habitat falicem \& betulam.

18. C. thoracica.

La Chryfomele à future noire: Long. I $\frac{3}{4}$ lig. Larg. $\frac{4}{5}$ lig.

C. rubra, thorace punctis duobus nigris, coleoptrorum Cuturâ nigrâ.

Los. 


\section{ENTOMOLOGIA}

19. C. caraboides.

La Chryfomele à un feul étui.

Long. $3,6,7$ lig.

C. atro-purpurea, elytris coadunatis, alis nullis.

Loc. Habitat hortos \& fylvas; Iarva Gallium.

20. C. phellandrii.

La Chryfomele a bandes jaunes. Long. $2 \frac{x}{2}$ lig. Larg. $\frac{4}{5}$ lig.

C. oblonga nigra, elytrorum lineis duabus longitudinalibus luteis.

Loc. Habitat phellandrium.

2I. C. ferruginea.

La Chry fomele brunie.

Long. 2 lig. Larg. I lig.

C. nigro-cuprea, punctis elytrorum per frias digeftis.

Ioc.

22. C. gemellata.

La Chryfomele à fries jumelies. Long. $2 \frac{1}{3}$ lig. Larg. I $\frac{1}{3}$ lig.

C. viridis, punctis elytrorum per ftrias gemellas digeftis.

Ioc. 


\section{.}

1 



\section{PARISIENSIS.}

* 23. C. fcabra.

La Chryfomele grefillée.

Long. $1 \div$ lig. Larg. $1 \frac{\mathrm{x}}{2}$ lig.

C. viridi-aurea, elytris fcabris nitentibus.

Loc.

24. C. antiqua.

La Chryfomele antique.

Long. $3 \frac{1}{2}$ lig. Larg. 2 lig.

C. tota fulvo-cuprea punitata.

Loc.

25. C. futurata.

La Chryfomele couturée.

Long. $1 \frac{2}{3}$ lig. Larg. I lig.

C. rubefcens, elytrorum ftriis punctatis, futura nigra.

Loc.

26. C. tulipa.

La Chryfomele tulipe.

Long. I $\frac{1}{2}$ lig. Larg. I lig.

C. thorace pedibufque fulvis; elytris an= tice luteis maculâ fufcâ; poftice fuf: cis, maculis luteis.

Loc. 
II 2 ENTMOLOGIA

XXXII. MYLABRIS. LE MYLABRE.

Antennx, renfim crefcentes, articulis hemi phæricis, roftro brevi plano infidentes.

Antennæe quatuor in extremo roftri.

I. M. crucigera.

Le Mylabre à croix blanche.

Long. 2 lig. Larg. I lig.

M. fufca, cinereo-nebulofa abdominis apice cruce albâ.

Loc. Larva legumina habitat, mylabris flores.

2. M. fuíca.

Le Mylabre brun.

Long. 3 lig. Larg. $x \frac{x}{2}$ lig.

M. tota fufca.

Los.

3. M. fericea.

Le Mylabre Satiné.

Long. I lig. Larg. $\frac{\mathrm{T}}{2}$ lig.

M. nigra, abdomine albo fericeo.

Ioc. Habitat flores. 




\section{PARISIENSIS. \\ 113. \\ XXXIII. RHINOMACER. $L E B E C$ - $M A R E$.}

Antennx clavatx integrx, roftro longo infidentes.

I. R. elongatus.

Le Becmare levrette.

Long. 3 lig. Larg. $\frac{2}{3}$ lig.

R. corpore angufto longo niger, thorace faciis quatuor albicantibus.

Loc. Habitat carduum.

2. R. viridis.

Le Becmare vert.

Long. 3 lig. Larg. 2 lig.

R. totus viridi-fericeus.

Loc.

3. R. auratus.

Le Becmare doré.

Long. 2 lig. Larg. I $\frac{x}{2}$ lig.

R. viridi-auratus, fubtus nigro-violaceuss.

Loc.

4. R. ruber:

Le Becmare doré à étuis rouges. Long. I $\frac{1}{4}, 2$ lig. Larg. $\frac{2}{3}$ I lig. 


\section{4 ENTOMOLOGIA}

R. niger, elytris rubris, capite thoraceque aureis, probofcide longitudine fere corporis.

Loc.

s. R. coruleus.

Le Becmare bleu à poir.

Iong. $x, 1 \frac{x}{2}, 2 \frac{x}{2}$ lig. Larg. $\frac{x}{2}, 3,3 \frac{x}{4}$ lig.

$R$. fubvillofus cœruleus.

Loc. Habiat flores.

6. R. niger.

Le Becmare non frie.

R. nigro-fufcus, glaber, punetato ftriatus. Loc. Idem.

7. R. oblongus.

Le Becmare allongé.

Long. I $\frac{1}{3}$ lig. Larg. $\frac{1}{3}$ lig.

R. nigro-viridefcens, oblongus friatus.

Loc. Habitat umbelliferarum flores.

8. R. fulvipes.

Le Becmare noir à pattes fauves. Long. I lig. Larg. $\frac{\pi}{2}$ lig. 




\section{PARISIENSIS. IIS}

R. fubglobofus, niger, Atriatus, femo= ribus rufis.

Loc. Habicat flotes.

9. R. minutus.

Le Becmare puce.

Long. $\frac{2}{3}$ lig. Larg. $\frac{1}{3}$ lig.

R. fubglobofus, villofus, niger, pedibus elytriqque rufis.

Loc. Idem.

10. R. coccineus.

Le Becmare laque:

Lon. I $\frac{x}{2}, 3$ lig. Larg. $\frac{2}{3}, I^{\frac{x}{4}}$ lig.

R, niger, thorace elytrifque rubris, probofcide longitudine capitis.

Ioc.

II. R. coryli.

La Tête écorchée.

Long. 3 lig. Larg. $I \frac{x}{2}$ lig.

R. niger, thorace elytrifque rubris, eapite pone elongato.

Los. Habitat corylum.

* 12. R. Priatus.

Le Becmare noir à trompe fauve. Long. I $\frac{1}{3} \mathrm{lig}$. Larg. $\frac{\mathrm{I}}{2} \mathrm{lig}$. 
ENTOMOLOGIA

R. oblongus, nigro cupreus; pedibus \& probofcide fulvis, punctis elytrorum Loe. per frias digeftis.

* I3. R. fulgidus.

Le Becmare rouge.

Long. I $\frac{x}{2}$ lig. Larg. I lig.

R. ovatus, frriatim punctatus, fupra ruber, infra cupreus; antennis, pro. Loc. bofcide pedibufque nigris.

XXXIV. CURCULIO. LE $\mathcal{C}_{H A-}$ RANSON.

Antenne clavatx fractx, roftro longo corneo infidentes.

FA MIL. I. Femoribus inermibus.

1. C. nebulofus.

Le Charanfon à trompe fillonnée. Long. 6 liç Larg.' 2 lig.

C. albo nigroque varius, probolcide planiưculâ carinatâ, thoracislongitudine.

Loc. Habitat arbores. 




\section{PARISIENSIS. IIT}

2. C. rugofus.

Le Charanfon ridé.

i.ong. 4 lig. Larg. 2 lig.

C. totus fufcus rugofus.

Loc. Habitat prata. -

3. C. fulcatus.

Le Charanfon à corcelet fillonné.

Long. $3 \frac{x}{2}$ lig. Larg. $=$ lig.

C. fufco-nebulofus, thorace fulcato; elytris Atriatis.

Loc. Idem.

4. C. paraplecticus.

Le Charanfon à Suture noire.

Long. 5 lig. Larg. I $\frac{x}{2}$ lig.

C. oblongus, elytris villoro-cinereis, futurâ nigrâ.

Loc.

5. C. pictus.

Le Charanfon à côtes tachetées. Long. $3 \frac{x}{2}$ lig. Larg. I $\frac{2}{3}$ lig.

C. fufcus, fulvo maculatus; elytris fria: tis, ftriis alternatim nigro maculatis

Loc. Habițą loca arida, 
II ENTOMOLOGIA

6. C. bipunctatus.

Le Charanfon à deux points blancs. Long. 4 lig. Larg. I $\frac{x}{2}$ lig.

C. oblongus, fufcus thoracis lateribus albidis, elytris ftriatis puncto albo.

Loc.

7. C. falciatus.

Le Charanfon ì deux bandes tranfverfes.

Long. 9 lig. Larg. 4 lig.

C. nigro-fulcus, thorace utrinque fafciâ long itudinali, "elytris duplici tranfverßâ cinereâ.

Loc. Habitat carduum.

8. C. cardui.

Le Charanfon tacheté des têtes de chardon.

Long. $2 \frac{x}{2}, 4$ lig. Larg. $1 \frac{x}{4}, 2$ lig.

C. niger, ftriatus, maculis villofo-furcis nebulofus.

Loc. Idem.

9. C. elegans.

Le Charanfon brodé. Long. $3 \frac{2}{3}$ lig. Larg. I $\frac{x}{4}$ lig. 


C. niger, thorace punctato, elytris alternatim ftriatis \& punctatis.

Loc.

10. C. incanus.

Le Charanfon gris, ftrié \& Sans aîles.

Long. $2 \frac{x}{2}, 4$ lig. Larg. $1 \frac{x}{2}, 2 \frac{x}{4}$ lig.

C. cinereus, fquamolus, alis carens, elytris ftriatis.

Loe. Habitat hortos, flores, arbores; abundans.

I t. C. incifus.

Le Charanfon noir à fillons.

Long. 2 lig. Larg. $\frac{2}{3}$ lig.

C. oblongus, toius niger, thorace punetato, elytris fulcatis.

Loc.

I 2. C. argentatus.

Le Charanfon à écailles vertes, $\mathcal{E}$ pattes fauves.

Long. 2,3 lig. Larg. $\frac{2}{3}, 1 \frac{1}{3}$ lig.

C. fquamoro-viridis, roftro thorace breviore, pedibus rufis.

Los. Habitat hortos, arbores, \&re. 


\section{20 ENTOMOLOGIA}

I3. C. falciolatus.

Le Charanfon à corcelet rayé. Long. $2 \frac{x}{2}$ lig. Larg. I $\frac{x}{2}$ lig.

C. roft:o thoracis longitudine, thorace tribus ftriis pallidioribus.

Loc. Habitat arbores fepium.

4. C. interfectus.

Le Charanfon écailleux à bandes. Long. 2 lig. Larg. $\frac{2}{3}$ lig.

C. roftro thorace breviore, fquamis nitentibus, thoracis elytrorumque fal. ciis longitudinalibus.

Loc. Habirat Hores.

Is. C. modeftus.

Le Charanfon grifette.

Long. I $\frac{x}{2}$ lig. Larg. $\frac{2}{5}$ lig.

C. rufus, fubvillofus, capite nigricante, roftro thorace breviore,

Loc. Idem.

6. C. viridis.

Le Charanfon fatin-vert. Long. I $\frac{x}{2}$ lig. Larg. $\frac{x}{2}$ lig. 




\section{PARISIENSIS. I I I}

C. cœruleo-viridis nitens, thorace punctato, elytris ftriatis.

Loc. Habitat cruciferas.

17. C. funereus.

La Pleureufe.

Long.

C. oblongus, niger; abdomine fquamoro; lateribus albis.

Loc.

I 8. C. granarius.

Le Charanfon brun du bled.

Long. I $\frac{x}{2}$ lig. Larg. $\frac{x}{2}$ lig.

C. rufo-teftaceus oblongus, thorace elys trorum fere longitudin'e.

Ioc. Habitat grana; horrzis infeltus.

19. C. faltator.

Le Charanfon fauteur brun.

C. rufus, femoribus pofticis craflioribus, elytris rufis.

Loc. Habitat ulmum,

F. 


\section{ENTOMOLOGIA}

20. C. alni.

Le Charanfon fauteur à taches noires.

$$
\text { Long. I } \frac{T}{2} \text { lig. Larg. } \frac{2}{3} \text { lig. }
$$

C. rufus, femoribus pofticis craffioribus, elytris naculis quatuor nigris.

Loc. Habitat ulmum \& alnum.

21. C. quadrilis.

Le Charanfon quadrille à courte trompe. Long. I $\frac{x}{2}$ lig. Larg, $\frac{2}{3}$ lig.

C. cinereus elytrorum puncto quadruplic i nigricante, probofcide thorace breviore.

Loc.

22. C. 5-maculatus.

Le Charanfon quadrille à longue trompe.

$$
\text { Long. } 2 \text { lig. Larg. I lig. }
$$

C. cinereus, elytrorum puncto quadruplici albo, probofcide thorace longiore. 


PAR ISIENSIS.

123

23. C. communis.

Le Charanfon fatin gris.

Long. I $\frac{x}{2}$ lig. Larg. I lig.

C. niger, ovatus, ftriatus, totus villoro: cinereus, thorace inermi.

Ioc

24. C. armatus.

Le Charanfon à corcelet épineux. Long.

C. ovatus, nigro.cinereus, thorace utring que denticulato.

Loc.

25. C. pultiaris.

Le Charanfon à bandes blanches. Long. Larg.

C. fubrotundus, niger, fquamofus, elytris ftriatis; thorace utrinque occuleaLoc. to, lateribus lineâque mediâ albis.

26. C. Horiger.

Le Charanfon noir frié.

Long. i lig. Larg. $\frac{\mathbf{x}}{2}$ lig.

$F$ ij 


\section{ENTOMOLOGIA}

C. fubglobofus, cinereo-ater, friatus, probofcide thoracis longitudine.

Ioc. Habitat Aores.

27. C. cinctus.

Le Charanfon roux à bande tranfverfale blanche.

Long. I lig. Larg. $\frac{2}{3}$ Iig.

C. globofus rufus, elytris friatis, fafciâ tranfverlâ albâ.

Loc.

28. C. vittatus.

Le Charanfon noir à bande tranfverfale blanche.

C. globofus niger, elytris Ariatis, fafcia tranfveriâ albâ.

Loc. Habitat falicem.

29. C. murinus.

Le Charanfon fouris.

Long. I lig. Larg. $\frac{x}{2}$ lig.

C. fubvillofo-murinus, fcutello albicante. Los. 

s 
30. C. Spinifer.

Lè Charanfon à côtes épineufes. Long. $1 \frac{x}{2}$ lig. Larg. $\frac{2}{3}$ lig.

C. totus fufcus [pinofus, elytris ftriis elevatis villoro-fpinofis, Loc.

31. C. denticulatus.

Le Charanfon noir à côtes. Long. I lig. Larg. $\frac{x}{2}$ lig.

C. niger, fcutello albicante, elytrorum friis utrinque denticulatis.

Loc.

32. C. acridulus.

Le Charanfon pyriforme. Long. I $\frac{x}{4}$ lig. Larg. $\frac{x}{2}$ lig.

C. pyriformis, nigro-corulefcens, abdomine ovato.

Lcc. Habitat flores.

3j. C. marmoratus.

Le Charanfon marbré à bandes. Long. $\frac{2}{3}$ lig. Larg. $\frac{\frac{1}{3}}{3}$ lig.

C. livitus, coleoptris fafciis plurimis obfcuris.

Loc. Habitar flores falicarix.

F iij 
126 ENTOMOLOGIA

Famil. II. Femoribus denticulatis. 34. C. coronatus.

Le Charanfon à corcelet couronné. Long. 6 lig. Larg. $2 \frac{x}{2}$ lig.

C. niger apterus, thorace utrinque puncto duplici fulvo, bafi pilis fulvis co= ronatâ.

Ioc.

* 35. C. Scabrofus.

Le Charanfon noir chagriné.

Long. 5 lig. Larg. 2 lig.

C. totus niger, nitidus, elytris ftriatis fubrugofis.

Ioc.

36. C. tigrinus:

Le Charanfon tigré.

Long. 6 lig. Larg. 3 lig.

C. niger, maculis villoro-havis, elytris fubrugofis.

Loc. Habitat Normanniam.

* 37. C. contractus.

Le Charanfon levrier.

Long. 2 lig. Larg. $\frac{2}{3}$ lig. 


\section{-}

-

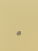

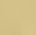

年 



\section{PARISIENSIS.}

C. oblongus, totus niger, thorace punctato, elytris ftriato-punctatis.

Loc.

38. C. monopterus.

Le Charanfon gris à étuis réunis E chagrinés. Long. 6 lig. Larg. $2 \frac{\pi}{2}$ lig.

C. cinereus, fquamolus, alis carens, elytris rugolis.

Los.

* 39. C. furcipes.

Le Charanfon noir à pattes brunes. Long. I lig. Larg. $\frac{x}{2}$ lig.

C. niger ftriatus, pedibus fufcis. Loc.

40. C. rugofiflimus.

Le Charanfon cartifanne. Long. $3,4 \frac{x}{2}$ lig. Larg. I $\frac{x}{2}, 2 \frac{x}{z}$ lig.

C. fulcus, apterus, elytris rugo[o-ftriatiso Loc.

4I. C. auratus.

Le Charanfon à écailles vertes. Iong. 4 lig. Larg. I $\frac{x}{2}$ lig.

$F$ iv 


\section{I28 ENTOMOLOGIA}

C. fqamofus, viridi-auratus.

Loc. Habitat hortos, arbores.

42. C. querneus.

Le Charanfon à étuis fauves.

Long. $2 \frac{x}{2}$ lig. Larg. I lig.

C. oblongus, niger, elytris pedibufque teftaceis.

Ioc. Habitat arbores.

43. C. geographicus.

Le Charanfon géographie. Long. 2 lig. Larg. I $\frac{1}{3}$ lig.

C. fubglobofus, nigro-fufcus, fquamo? fus, lineolis albis variegatus.

Loc. Habitat viperinam.

44. C. Atellifer.

Le Charanfon brun à bandestranfverfes de taches blanches. Long. 4 lig. Larg. I $\frac{T}{2}$ lig.

C. furcus, elytris ftriatis macularm albarum fáciâ triplici tranfrerlâ.

Loc. 

$-1$

. 


\section{PARISIENSIS.}

45. C. nucum.

Le Charanfon trompette.

Long. $2,3,3 \frac{x}{2}$ lig. Larg. $1,1 \frac{x}{2}, 2 \frac{2}{3}$ lig.

C. rufo-marmoratus, fcutello cordato àlbo, probofcide fubulatâ long iffinâ. Loc. Habitat nuces.

46. C. teffelatus.

Le Charanfon damier.

Long. 2 lig. Larg. I lig.

C. flavefcens, elytris luteo \& rufo teffelatis.

Loc.

47. C. fcrophularis.

Le Charanfon à lozange de-la fcrophulaire.

Long. 3 lig. Larg. I $\frac{T}{2}$ lig.

C. Yubglobofus niger, punctis duobus a r.s futurx longitudinalis coleoptroru'n, thorace exalbido.

Loc. Habitat Scrophulatiam.

48. C. hortulanus.

Le Charanfon gris de la fcrophulaire.

Long. I $\frac{x}{2}$ lig. Iarg. $\frac{3}{4}$ lig. 


\section{I3O ENTOMOLO GIA}

C. fubglobofus, cinereus, punctis duobus nigris futurx longitudinalis coleop. trorum.

Zoc. Habitat fcropuulariam.

49. C. pericarpius.

Le Charanfon porte-caur de la Scrophulaire.

Long. I lig. Larg. $\frac{\pi}{2}$ lig.

C. fubglobofus ; fufco-nebulofus, ma* culâ cordatâ albâ in medio dorfo.

Ioc. Idem.

50. C. tripunctatus.

Le Charanfon brun à points blancs.

C. fubglobofus, fquamolus, cinereofufcus elytrorum maculis tribus \& apice albis.

Loc. Habitat prata.

SI. C. armiger.

Le Charanfon noir à corcelet armé.

Long. 2 lig. Larg. I lig.

C. niger, thorace utrinqe dentato. Loc. 




\section{PARISIENSIS.}

S2. C. plebeius.

Le Charanfon noir à corcelet fans points.

Long. I lig. Latg. $\frac{x}{2}$ lig.

C. fufco-niger thorace inermi.

Loc.

53. C. fcutellatus.

Le Charanfon brun à écufon blanc. Long. I $\frac{\pi}{2}$ lig. Larg. $\frac{2}{3}$ lig.

C. fufcus, fcutello puncto albo, elytris maculâ rubefcente.

Loc.

54. C. rubigineus.

Le Charanfon couleur de rouille. Long. I $\frac{x}{4}$ lig. Larg. $\frac{2}{3}$ lig.

C. ferrugineus, elytris ftriatis, oculis nigris.

Loe.

55. C. villofus.

Le Charanfon velouté.

Long. 2 lig. Larg. I lig.

$F$ vi 


\section{ENTO INOLOGIA}

C. obfcure rufus, villis cinereis arperfus, rofiro, thorace breviore.

Loc.

56. C. virgo.

Le Charanfon vierge.

$$
\text { Long. I lig. Larg. } \frac{x}{2} \text { lig. }
$$

C. oblongus, villis cinereis afperfus, roftro thoraci xquali.

Ioc. Habitat flores.

* 57. C. punctulatus.

Le Charanfon noir'picoté.

Long. 4 lig. Larg. I lig.

C. totus niger, oblongus, thorace punetato, elytris punctato-firiatis, femoribus denticulatis.

Ioc.

* 58. C. cordifer.

Le Charanfon à cocur.

Long. I $\frac{1}{2}$ lig. Larg. $\frac{2}{3}$ lig.

C. cinereus, fcutello albo, fafciâque elytroìum interruptâ albâ, probolcide longiffimâ.

Loc. 




\section{PAR ISIENSIS.}

59. C. fafciatus.

Le Charanfon fafcié.

Long. 2 lig. Larg. $\frac{3}{4}$ lig.

C. fufco-cinereus villofus elytrorum futurâ maculifque albis.

$\mathbf{Z}_{o c}$.

XXXV. BOSTRICHUS. LE BOS$T R I C H E$ 。

Antennæx clavatxe, clavâ ex articulis tribus compofitâ, capiti infidentes. Roftrum nullum. Thorax cubicus caput intra fe recondens. Tarfi nudi fpinofi.

1. B. ruber.

Le Boftriche.

Long. 5 lig. Larg. 2 lig.

B. niger, elytris rubris.

Loc. Habitat fylvas.

* 2. B. fufcus.

Le Boftriche brun.

Long. I $\frac{\pi}{2}$ lig. Large $\frac{3}{4}$ lig. 


\section{ENTOMOLOGIA}

B. fufcus, thorace coftis, elytris frriis punetatis elevatis.

Loc.

\section{CLERUS. LE CLATRON.}

An tennæx clavatx, clavâ ex articulis tribus compofitâ, capiti infidentes. Rofrum nullum.

Thorax fubcylindraceus, non marginatus.

Tarfi fpongiofi.

I. C. apiarius.

Le Clairon à bandes rouges. Long. $\sigma$ lig. Larg. 2 lig.

C. nigro-violaceus, hirfutus, elytris fafciâ triplici coccineâ.

Zoc. Larva nidos apium habitat, clerus fores.

2. C. violaceus.

Le Clairon bleu.

Long, $x \frac{x}{2}, 2,2 \frac{x}{2}$ lig. Larg. $\frac{2}{3}$, I, I $\frac{x}{4}$ lig.

C. nigro-cœruleus.

Loc. Larva \& clerus purrida loca habitat frequens in domis. 


PARISIENSIS.

3. C. cruciger。

Le Clairon porte-croix.

Long. 4 lig. Larg. I lig.

C. fufcus, villofus, elytris flavis cruce fưcâ.

Loc. Habitat fores.

4. C. villofus.

Le Clairon fatiné.

Long. I lig. Larg. $\frac{2}{3}$ lig.

C. niger, fubovatus, villis cinereis.

20c. Habitat fores refedx.

* s. C. fafciatus.

Le Clairon porte-livrée:

Long. 5 lig. Larg. I $\frac{2}{3}$ lig.

C. niger villofus, elytrorum fafciâ anj ticâ rufâ, pofticâ albâ.

$V$ arietas A. Id. thorace rufo: Long. $3 \frac{2}{3}$ lig. Larg. I lig.

B. Id. niger fubvillom fus, elytrorum fafciâ anticâ rufâ, mediâ flavâ, pofticâ albâ.

Long. $1 \frac{x}{2}$ lig. Larg. $\frac{3}{4}$ lig.

Ioc. Habitat arbores vetuftas。 


\section{I36 ENTOMOLOGIA.}

* 6. C. maculatus.

Le Clairon à taches jaunes.

Long. 4 lig. Larg. 1 lig.

C. fufco-niger fubvillofus, elytro fingulo maculis duabus flavis.

Loc.

\section{ANTRIBUS. L'ANTRIBE.}

Antennx clavatxe, clavâ ex articulis tribus compofitâ capiti infidentes. Roftrum nullum.

Thorax latus, marginatus.

Tarfi fpongiofi.

1. A. marmoratus.

L'Antribe marbré.

Long. I $\frac{x}{2}$ lig. I 1 irg. $1 \frac{7}{5}$ lig.

A. ovatus, niger, elytris ftriatis, rubro nigroque marmoratis.

Loc. Habitat jaceam pratenfem.

2. A. variegatus.

L'Antribe minime.

Long. $1 \div$ lig. Larg. $\frac{2}{3}$ lig.

A. ovatus fubvillofus, è fufco cinereoque variegatus.

Loc. Habitat flores. 



\section{PARISIENSIS.}

3. A. ater.

\section{L'Antribe noir frié.}

Long. 6,7 lig. Larg. $2 \frac{1}{3}$ lig.

'A. ater, elytris apice cinerafcentibus:

Loc. Habitat flores.

4. A. pulicarius.

L'Antribe des fleurs.

Long. I lig. Larg.

A. niger, elytris abdomine brevioribus. Loc. Habitat umbeliiferas plantas.

j. A. bimaculatus.

L'Antribe à deux points rouges au bout des étuis.

Long. I lig. Larg. $\frac{x}{2}$ lig.

A. niger ovatus, elytris apice puncts duobus rubris.

Loc. Habitat flores.

6. A. lœvis。

L'Antribe noir liffe.

Long. $\frac{2}{3}$ lig. Larg. $\frac{1}{3}$ lig.

A. niger, ovatus, elytris abdomen tea gentibus.

Loc. Iden. 
138 ENTOMOLOGIA

* 7. A. fulvus.

L'Antribe fauve.

Long. I lig. Larg. $\frac{r}{4}$ lig.

A. oblongus, totus rufuse

Loc, Habitat vetufta ligna.

- 8. A. connexus.

L'Antribe panaché.

Long. \& lig. Latg. $\frac{r}{3}$ lig.

A. oblongus niger fubvillofus, elytris maculis connexis luteis.

Loc. Habitat flores.

* 9. A. nitidus.

L'Antribe perlé.

Long. I lig. Larg. $\frac{2}{3}$ lig.

A. ovatus totus fufcus.

Loc. Idem.

* I0. A. vittatus.

L'Antribe à bandes.

Long. $\frac{2}{3}$ lig. Larg. $\frac{x}{2}$ lig.

A. ovatus fufcus, futurâ longitudinali nigrâ.

Loc. Idem. 




\section{PARISIEN SIS.}

Ir. A. pallidus.

L'Antribe paillet.

Long. I lig. Larg. $\frac{1}{3}$ lig.

A, ovatus, fubtùs pallidus, fupra fulcus. fubvillofus.

Loc. Habitat flores.

12. A. interfectus.

L'Antribe bigaré.

Long. 2 lig. Larg. I lig,

A. oblongus ater, elytris fignaturis albis pedibufque annulis albis interfectis.

Loc. Idem.

\section{SCOLYTUS. LE SCO-} LYTE.

Antennæ clavatæ, clavâ folidâ. Roftrum nullum.

1. S. niger:

Le Scolyte. Long. $I \frac{x}{2}$ lig. Lerg. $\frac{2}{3}$ lig.

Loc, Habitat cortices. 


\section{ENTOMOLOGIA \\ XXXIX. CASSIDA. LA CASSIDE.}

Antennæ extrorfum craffiores, nodorx.

Thorax \& elytra marginata.

Caput thorace tectum,

I. C. viridis.

La Caljide verte.

Long. I, I $\frac{x}{2}$ lig. Larg. $\frac{2}{3}$, I lig.

C. viridis, corpore nigro.

Loc. Habitat plantas verticillatas \& carduos,

2. C. nebulofa.

La Cafjide brune.

Long. 2,3 lig. Larg. I $\frac{x}{2}$ lig. .

C. nebulofa, pallida, corpore nigro.

Loc. Idem.

3. C. nobilis.

La Caffide à bandes d'or.

Long. I $\frac{3}{4}$ lig. Larg. $3 \frac{x}{4}$ lig.

C, pallida, lineâ duplici longitudinali, virici-deaurata.

Loc. Idem. 



\section{PARISIENSIS. I4I}

4. C. thoracica.

La Cafjude verte à corcelet brun. Long. $2 \frac{x}{2}$ lig. Larg. $x \frac{2}{3}$ lig.

C. viridis, thorace ferrugineo.

Lo. Habitat afteris varias fpecies.

5. C. variegata.

La Caffide panachée. Long. $3 \frac{x}{2}$ lig. Larg. 2 lig.

C. viridis maculis nigris variegata:

$V$ ariezas A. Caffida rubra maculis nigris variegata.

Loc. Habitat enulam campanam。

\section{ANASPIS。 L'ANASPE.}

Antennæ filiformes fenfim créfentes.

Scutellum vix apparens.

Thorax planus, lrvis non marginatus.

I. A. nigra.

L'Anafpe noire.

Long. I, I $\frac{\pi}{2}$ lig, Larg $\frac{x}{2}$ lig.

A. tota nigra.

Loc. Habitat flotes. 


\section{ENTOMOLOGIA}

2. A. bicolor.

L'Anajpe à taches jaunes.

A. nigra, elytro fingulo antice maculå flavâ.

Loc. Habitat flores.

3. A. thoracica.

L'Anajpe à corcelet jaune.

Long. I lig. Larg. $\frac{2}{5}$ lig.

A. nigra, thorace luteo.

Loc, Habitat rarior.

4. A. maculata.

L'Anajpe fauve.

Long. $\frac{3}{4}$ lig. Larg, $\frac{x}{3}$ lig.

A. villofo-flavefcens, coleoptrorum ma= culis tribus obfcuris.

Loc. Idem. 




\section{PARISIENSIS. 143}

O R D O TER T IUS.

Caract. Ordinis III.

Tarforum articuli tres.

\section{COCCINELLA. LA Cocci- NELLE.}

Antenne extrorfum craffiores, no: dofx, antennulis breviores.

Corpus hæmi(phæricum.

I. C. bi-punctata.

La Coccinelle rouge à 2 points noirs. Long. $2 \frac{x}{2}$ lig. Larg. 2 lig.

C. coleoptris rubris, punctis duobus nigris. Loc. Habitat alnum; aphivora.

2. C. s-punctata.

La Coscinelle rouge à 5 points noirs. .

C. coleoptris rubis punctis quinque nigris. Loc. Habitat hortos.

3. C. 7-punctata.

La Coccinelle rouge à 7 points noirs.

Long. 3, 4 lig. Larg, $2 \frac{x}{2}, 3$ lige 


\section{ENTOMOLOG I A}

C. coleoptris rubris, punctis feptem nigris.

Loc, Habitat tiliam.

4. C. 9-punctata.

La Coccinelle rouge à 9 points noirs \& corcelet noir.

Long. $2 \frac{x}{2}$ lig. Larg. 2 lig.

C. coleoptris rubris, punctis novem nigris, thorace nigro, lateribus albis.

Ioc. Habitat atbufta.

s. C. carpini.

La Coccinelle rouge $\hat{a} g$ points. noirs \& corcelet varié.

C. coleoptris rubris, punctis novem nigris, thorace nigro, antice albo.

Loc, Habitat carpinum.

6. C. I3-punctata.

La. Coccinelle rouge d̀ $I_{3}$ points noirs $\mathcal{E}$ corcelet jaune varié. Long, 2 lig, Larg. I $\frac{x}{2}$ lig. 


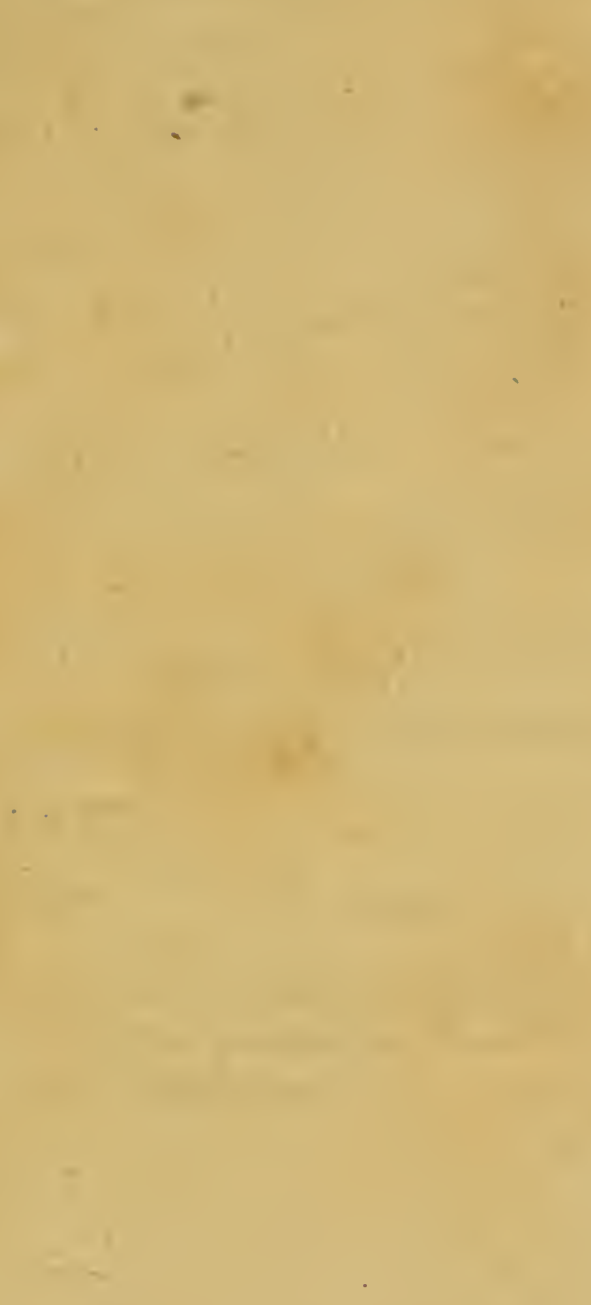





\section{PA R I S I ENSIS.}

C. coleoptris rubris, punctis tredecim nigris.

Loc. Habitat arbufta.

7. C. trinacris.

La Coccinelle rouge à $I_{3}$ points noirs $\dot{\&}$ corcelet rouge à bande. Long. $2 \frac{1}{2}$ lig. Larg. 2 lig.

C. coleoptris rubris, puncis tredecim nigris, thorace rubro, medio nigro,

Loc. Habitat flores.

8. C. 11-punctata.

La Coccinelle rouge d̀ II points E corcelet jaune.

Long. $I \frac{x}{2}, 2$ lig. Larg。 $x, x \frac{x}{2}$ lig.

C. coleoptris rubris, punctis undecim nigris; thorace luteo nigro punctato.

Loc. Habitat ulnum.

9. C. argus.

La Coccinelle argus.

Long. 3 lig. Larg. I $\frac{7}{3}$ lig.

C. rubra, punctis undecim nigris, thorace rubro immaculato.

Loc. Stabitat fepes. 
146 ENTOMOLOGIA

10. C. 19-punctata.

La Coccinelle rouge à Ig, points noirs.

Long. 2 lig. Larg. I $\frac{x}{2}$ lig.

C. coleoptris rubris, punetis novem decim nigris.

Loc. Habitat fepes.

I1. C. 24-punctata.

La Coccinelle rayée.

Long. I $\frac{z}{2}$ lig. Larg. I lig.

C. coleoptris rubris, pun Etis viginti-quatuor nigris, quiburdam connexis.

Loc. Habitat flores.

12. C. conglobata.

La Coccinelle à bordure.

Long. 2 lig. Latg. I $\frac{T}{2}$ lig.

C. coleoptris rubris, punctis plurimis nigris, quibußdam connexis futurâ longitudinali nigrâ.

Loc. Habitat hortos.

12. C. 14-guttata.

La Coccinelle à I 4 points blancs. Long. $z, 2 \frac{x}{2}$ lig. Larg. $1 \frac{x}{2}, 2$ lig. 



$$
\text { PAR I S I E N S I s. }
$$

C. coleoptris rubris, punctis quatuordecim albis.

Loc. Habitat hortos.

14. C. marginaia.

La Coccinelle à points \& bordure blanche.

Long. $2 \frac{x}{2}$ lig. Larg. 2 lig.

C. coleoptris rubris, punctis quatuorde: cim limboque albis.

Loc. Idem.

Is. C. I4-punctata.

La Coccinelle à l'échiquier. Long. $2 \frac{1}{3}$ lig. Larg. I $\frac{3}{4}$ lig.

C. coleoptris flavis, punctis quadratis nigris, quiburdam connatis.

Loc. Idem.

16. C. 16-punctata.

La Coccinelle jaune à future. Long. I lig. Larg. $\frac{3}{4}$ lig.

C. coleoptris flavis, purctis fexdecim nigris, plurimis conrexis, futurâ nigrâ. Loc. Idem. 
1 8 ENTOMOLOG I A

+ 17. C. 22-punctata.

La Coccinelle jaune fans future. Long. I $\frac{x}{2}$ lig. Larg. I lig.

C. coleoptris flavis, punAtis viginti nigris.

Loc. Habitat fepes.

18. C. I 4-puntulata.

La Coccinelle noire à 14 points jaunes.

Long. I $\frac{x}{2}$ lig. Larg. I $\frac{x}{5}$ lig.

C. coleoptris nigris, punctis quatuordecim flavefcentibus.

Loc. Habitat arbores.

I9. C. 10-puftulata.

La Coccinelle noire à zo points jaunes.

C. coleoptris nigris, punctis decem flavercentibus aut rubris.

Loc. Habitat hortos.

20. C. 6-puftulata.

La. Coccinellc noire à points rouges. Long. I $\frac{x}{2}, 2$ lig. Larg. I lig. 


$$
\begin{aligned}
& \text { trit } \\
& \text { 2. } \\
& \text {. }
\end{aligned}
$$$$
1
$$

$-$

1

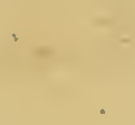





\section{PARISIENSIS. I49}

C. ovata, coleoptris nigris, punctis fex rubris.

$V$ arietas A. punctis quatuor rubris. B. punctis duobus rubris. C. punctis duobus luteis.

Loc. Habirat hortos.

21. C. fafciata.

La Coccinelle velue à bandes. Long. I lig. Larg. $\frac{x}{2}$ lig.

C. fubvillofa nigra, fafciis duabus tranfverfis rubris.

Loc. Habitat flores.

2. C. villofa.

La Coccinelle velue à points. Long. $1 \frac{2}{4}$ lig. Larg. $\frac{2}{3}$ lig.

C. fubvillóa nigra, punctis quatuor luteo-rubris.

Loc. Idem.

23. C. interrupta.

La Coccinelle velue à bande interrompue.

Long. I lig. Larg. $\frac{x}{2}$ lig.

G iij 


\section{IjO ENTOMOLOGIA}

C. fubvillofa nigra, coleoptrorum bafi fałciâ tranfverfa rubrâ interruptâ.

Zoc. Habitar cortices \& folia pruni; larva pilis albis \& longis confperfa dicitur, le Barbet blanc des écorces.

24. C. pygmæa.

La Coccinelle velue à taches rouges all corcelet.

Long. $\frac{3}{4}$ lig. Larg. $\frac{x}{2}$ lig.

C. fubvillofa nigra, thorace utrinque maculâ rubrâ.

Loc. Habitat flores.

25. C. 4-puftulata.

La Coccinelle tưrtue à 4 points rouges.

Long. I $\frac{x}{2}$ lig. Larg. I $\frac{x}{3}$ lig.

C. rotuhida nigra, coleoptrorum margine reflexo, punctis quatuor rubris.

Loc. Habitat urticam.

- 26. C. 2-pufulata.

La Coccinelle tortue à bande rouge. Long. I lig. Larg. $\frac{4}{5}$ lig. 



$$
\text { . }
$$




\section{PARISIENSIS. ISI}

C. rotunda nigra, coleoptrorum margine

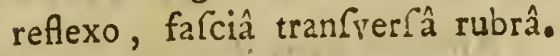

Loc. Habitat utricam.

27. C. teftudinaris.

La Coccinelle noire à points rouges au corcelet.

C. rotunda nigra, coleoptrorum margine reflexo, thorace uirinque maculâ rubrâ.

Loc. Idem.

* 28. C. I6-guttata:

La Coccinelle à If points blancs. Long. I $\frac{1}{2}$ lig. Larg. 2 lig.

C. coleoptris rubris, punftis fexdecim albis.

Loc.

* 29. C. I2-guttata:

La Coccinelle à 12 points blancs. Long. I $\frac{x}{3}$ lig. I arg. I lig.

C. coleoptris rubris, punctis duodecim albis.

Ior.

$\mathrm{G}$ iv 


\section{Y 2 ENTOMOLOGIA}

XLII. TRITOMA. LA TRITOME. Antennx extrorfum fenfin crafiores, antennulis longiores.

Corpus oìlongum.

1. T. bimaculata.

La Tritôme.

Long. $2 \frac{\pi}{2}$ lig. Larg. $I \frac{1}{4}$ lig.

Loc. Habitat corticis falices; rariffinia.

OR D O Q URTUS.

Caract. Ordin. IV.

Tarforum primi \& fecundi pedum paris articuli quinque : pedum vero pofteriorum articuli quatuor.

X LIII. DIAPERIS. $L_{A} D_{I A-}$ PERE.

Antennx taxiformes, articulis lentiformibus per centrum perfoliatis. Thorax convexus, marginatus. 


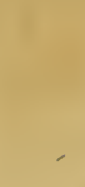

42

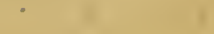

a

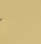





\section{PAKISIENSI3. 153}

1. D. fafciata.

La Diapere.

Long. 3 lig. Larg. $8,8 \frac{3}{4}$ lig.

Loc. Habitat ilicem, Fontis.Bellaquai incola.

XLIV. PYROCHROA. LA $C_{A R-}$ $D I N A L E$.

Antennæ uno verfu pectinatx.

Thorax inæqualis, fcaber, non mar: ginatus.

ๆ. P. ruberrima.

La Cardinale.

Iong. s lig. Larg. 2 lig.

Loc. Habitat fepes, autumnalis.

\section{CANTHARIS. LA $C_{A N-}$ $T H A R I D E$.}

Antennæ filiformes.

Thorax inæqualis, fcaber; non mar: ginatus.

G r 
IS4 ENTOMOLOGIA

Fanil. I. Tarforum articulis nudis.

I. C. veficatoria.

La Cantharide des boutiques.

Long. $4,5,8,9$ lig. Larg. I $\frac{x}{2}, 2,3$ lig.

C. viridi-aurata antennis nigris.

Loc. Habitat fraxinos.

2. C. attenuata.

La Cantharide à bande jaune: Long. 5 lig. Larg. $1 \frac{2}{3}$ lig.

. C. nigra, elytris attenuatis, antice luteis. Ioc.

Famil. II. Tarforum articulis jpongiofis.

3. C. craflipes.

La Cantharide verte à großjes cuifes.

Long. $3 \frac{x}{2}$ lig. Larg.

C. viridi-coerulea, elytris attenuatis, femoribus pofticis globofis.

Varietas A. viridi-cœrulea, elytris attenuatis.

Lac. Habizat prata. 
- $r$

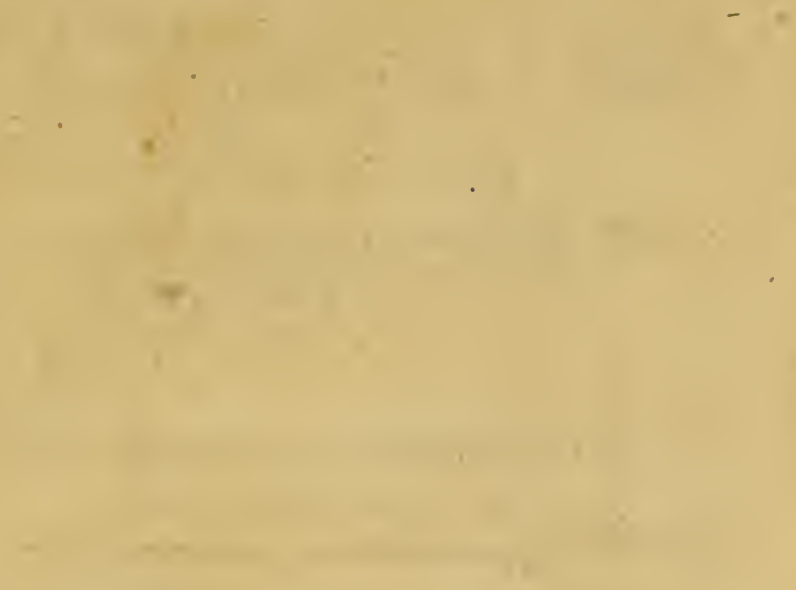





\section{PARISIENSIS.}

4. C. fulva.

La Cantharide fauve ì grolfes cuiffes.

I.ong. 4 lig. Larg. I lig.

C. nigra, elytris attenuatis fulvis, femo, ribus pofticis globolis.

Loc. Habitat flores.

s. C. villofa.

La Cantharide jaune veloutée.

Long. 4 lig. Larg. I lig.

'C. flavefcens, fubvillofa, elytris atte: nuatis.

Loc. Idem.

6. C. flava.

La Cantharide noire à étuis jaunes. Long. $3 \frac{x}{2}$ lig. Larg. I lig.

C. fubvillofa, nigra, elytris flavis, extremo antennarum articulo reliquis triplo majore.

Loc. Habitat fylvas.

7. C. teftacea.

La Cantharide fauve avecta pointe des étuis noire.

Iong. 5 lig. Larg. I $\frac{2}{3}$ lig.

$\mathrm{G}$ vj 
Ig6 ENTOMOLOG IA

C. teftacea, elytris apice nigris.

Loc.

8. C. formicoides.

La Cantharide fourmi.

Long. I $\frac{1}{4}$ lig. Larg. $\frac{1}{3}$ lig.

C. furca, elytris antice, thoraceque elongato rubris.

Ioc.

2. C. variegata.

La Cantharide fourmi panachée: Long. I $\frac{\mathrm{I}}{4}$ lig. Larg. $\frac{\mathrm{x}}{2}$ lig.

C. nigra, elytris fulvis maculis quinque nigris connexis, thoace elongato.

Loc.

XLVI. TENEBRIO. $L_{E}$ TÉNÉ-

Antennæ filiformes. $B R I O N$.

Thorax planus marginatus.

famr. I. Antennce articulis globofis, extrorfum craflores.

x. T. mortifaga.

Le Ténébrion liffe à prolongement. Long. so lig. Larg. 4 lig. 




\section{PARISIENSIS.}

T. atra, aptera, coleoptris lavibus, pone acuminatis.

Loc. Habitat plantas coacervatas \& exefas ix hortis.

2. T. rugofa.

Le Ténébrion ridé.

Long. 5 lig. Larg. 3 lig.

I. atra, aptera, coleoptris rugofis, pone acuminatis.

Loc. Habitat arenam.

3. T. gemellata.

Le Ténébrion à fries jumelles. Long. 4 lig. Larg. $2 \frac{x}{2}$ lig.

T. nigra, aptera, elytrorum ftriis octo punctatis per paria difpofitis.

Loc, Habitat hortos.

4. T. Atriata

Le-Ténebrion à 8 ftries liffes.

Long. $s \frac{2}{2}$ lig. Larg. $1 \frac{x}{2}$ lig.

T. nigro- fufca ovata, elytro fingulo ftrins otto lievibus.

Loc. Habițat arva. 
Is 8 ENOMOLOGIA

5. T. cuprea.

Le Ténébrion bronzé.

Long. $5 \frac{x}{2}$ lig. Larg. 2 lig.

T. nigro-cuprea, elytro fingulo ftriis octo, coleoptris pone acuminatis.

Loc. Idem.

6. T. molitoria.

Le Ténébrion à 9 fries lifjes.

Long. 7 lig. Larg. $2 \frac{2}{3}$ lig.

T. atra, oblonga, elytris friis novem lavibus.

Loc. Larva farinam habitat; tenebrio domos.

7. T. fabulofa.

Le Ténébrion à fries dentelées. Long. 3 lig. Larg. 2 lig.

T. atra, elytris ftriis quinque utrinque dentatis.

Loc. Habitat putrida loca.

8. T. nigra.

Le Ténébrion noir life. Long. 3 lig. Larg. $x \frac{x}{2}$ lig. 


T. nigra, tota lxvis, coleoptris pone rotundatis.

Loc. Habirat arenam.

9. T. villofa.

Le Ténébrion fauve velu. Long. I $\frac{3}{4}$ lig. Larg. $\frac{2}{3}$ lig.

T. tota ferruginea fubvillofa.

Loc.

Iо. T. ferruginea.

Le Ténébrion fauve liffe.

Long. I $\frac{x}{2}$ lig. Larg. $\frac{2}{3}$ lig.

T. tota ferruginea lrvis.

Loc.

II. T. fulcata.

Le Ténébrion cannelé.

Long. 7 lig. Larg. $4 \frac{x}{2}$ lig.

T. atra, aptera rotundata, elytris fulcio tribus elevatis.

- Loc. Habitat provincias Gallize metidionales.

Familia II. Antennce articulis

longis, ubique aquales.

I2. T. Iutea.

Le Ténébrion jaune.

Long. $3 \frac{r}{2}$ lig. Larg. $3 \frac{1}{4}$ lig. 
160 ENTOMOLOGIA

T. lutea.

Loc. Habicat flores.

* 12. T. arenaria.

Le Ténébrion à étuis fauves. Long. $6 \frac{\pi}{2}, 6,5 \frac{\pi}{2}$ lig. Larg. 2 lig.

T. nigra, elytris ftriatis ferrugineis,

Loc.

* I3. T. rotundata.

Le Ténébrion arrondi.

Long. $3 \frac{x}{2}$ lig. Larg. 2 lig.

T. nigra-cuprea, elytris fingulis friis octo punctatis, coleoptris pone rotundatis.

Ioc.

* I4. T. globulofa.

Le Ténébrion à corcelet arronä. Long. 6 lig. Larg. 2 lig.

T. atra fabra, thorace globoro.

Loc.

* is. T. corulea.

Le Ténébrion blew.

Lung. $4 \frac{x}{2}$ lig. Larg. $1 \frac{x}{2}$ ling. 




\section{PARISIENSIS. 161}

T. ccerulea punctata, elytris Ariatis, tarfis fulvis.

Loc.

XL V I I. MORDELLA. LA MOR-

DELLE.

Antennæ fubferratx, articulis triangularibus.

Thorax antice attenuatus, convexus.

I. M. aculeata.

La Mordelle noire à pointe.

Long. 2 lig. Larg. $\frac{2}{3}$ lig.

M. atra, caudata, unicolor.

Loc. Habitat flores.

2. M. iriformis.

La Mordelle veloutée ì pointe.

Long. 3 lig. Larg. I $\frac{1}{4}$ lig.

M. atra, caudata, fafciis villofo-aureis.

Loc. Idem,

3. M. Atriata.

La Mordelle ì étuis jaunes friés. Long. 4 lig. Larg. $1 \frac{2}{3}$ lig. 


\section{ENTOMOLOGIA}

M. nigra, elytris fulvis Atratis.

Loc. Habitat arbores in fylvis.

4. T. fulva.

La Mordelle à étuis jaunes Jans fries.

Long. I lig. Larg. I $\frac{x}{2}$ lig.

M. nigra, elytris fulvis lavibus.

Loc. Idem.

S. M. Alavipes.

La Mordellebrune à paltes fauves. Long. $3 \frac{x}{2}$ lig. Larg. I ' $\frac{3}{4}$ lig. M. fufca, pedibus ferrugineis. Loc. Idem.

XLVIII. NOTOXUS. LA CUCULIE.

Antennx filiformes.

Thorax cucullatus, dente acuto.

I. C. cucullatus.

La Cuculle.

Long. $=$ lig. Larg. $\frac{2}{3}$ lig.

Loe. Habitat umbelliferas, rarifimus. 
$\checkmark$

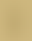

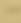

$-$

s.

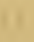

, 



\section{PARISIEN 3 I 3 .}

XLIX. CEROCOMA. LA CEROCOME.

$\therefore$ Antennæ ultimo articulo clavaro: ( mafculis complicatie, in medio pectinatæ).

I. C. viridis.

La Cerocome.

Long. 4 lig. Larg. I lig.

Ioc.

ARTICULUS SECUNDUS,

Caract. articuli II.

Coleoptra dimidiata dura.

O R D O PR I M U S.

Curact. ordinis $I$.

Tarforum articuli quinque.

L. STAPHYLINUS. LE STAPHY-

IIN.

Antenne filiformes.

Alx tęctx.

Abdomen inerme. 


\section{I64 ENTOMOLOGIA}

I. S. maxillofus.

Le grand Staphylin noir liffe.

Long. I I lig. Larg. $2 \frac{3}{4}$ lig.

S. ater, extremo antennarum articulo lunulato.

Loc. Habitat fylvas, hortos, \&kc,

2. S. cœrulefcens.

Le Staphylin bleu:

Long. 7 lig. Larg. I $\frac{I}{2}$ lig.

S. atro-corrlefcens, extremo antennarum articulo lunulato.

Loc. Habitat hortos.

3. S. globulifer.

Le petit Staphylin noir.

Long. $\sigma$ lig. Larg. $x \frac{1}{3}$ lig.

S. ater, extremo antennarum articulo fubgloboro, elytris thorace brevio: ribus.

Loc. Idem.

4. S. macroclytron.

Le Staphylin noir à longs etuis. Long. 2 lig. Larg. I lig. 




\section{PAR IS I E NSIS.}

S. ater, elytris thorace duplo longioribus.

Loc. Habitat hortos.

5. S. nebulofus.

Le Staphylin nébuleux.

Long. 8 lig. Larg. 2 lig.

S. niger, elytris abdomineque cinereonebulofis. -.

Loc. Hahitat bovinas faces.

6. S. teffellatus.

Le Staphylin velouté.

Long. $5 \frac{x}{2}$ lig. Larg. I $\frac{5}{4}$ lig.

S. villofus, è fucco cinereoque viridi teffellatus.

Loc. Habitat hortos.

7. S. hirtus.

Le Staphylin bourdon.

Long. Io lig. Larg. 3 lig.

S. niger villofus, capite thorace anoque pilis fulvo-aureis.

Loc. Habicat fylvas, rarus.

8. S. chryfocephalus.

Le Staphylin à tête jaune.

Long. $5 \frac{x}{4}$ lig. Larg. I $\frac{4}{5}$ lig. 
S. pubercens, capite flavo, thorace elytrifque furco nigroque nebulolis, punctis impreflis.

Iuc. Habitat arva.

9. S. erytropterus.

Le Staphylin à étuis couleur de rouille.

Long. $6 \frac{\mathrm{x}}{2}$ lig. Larg. $\mathrm{I} \frac{\mathrm{T}}{2}$ lig.

S. ater, non nitens, elytris pedibulque rufis.

Ioc.

10. S. flavopterus.

Le Staphylin noir à étuis fauves E liffes.

Long. $1,3,3 \frac{T}{2}$ lig. Larg. $\frac{x}{2}, \frac{3}{4}$ lig.

S. niger nitens, pedibus, elytrifque lævibus teftaceis.

Varieras A. Staphylinus niger nitens, pedibus elytrifque lxvibus teftaceis, thoracis punctis per ftrias digeftis.

Le Staphylin à étuis fauves E corcelet frié.

Loc. 




\section{P A RISIENSIS. 167}

II. S. fulvopterus.

Le Staphylin à étuis marons pointillés.

Long. 3 lig. Larg. $\frac{2}{3}$ lig.

S. niger, nitens, pedibus coleoptrifque teiftaceis, elytris punctatis.

Loc.

12. S. brachypterus.

Le Staphylin à étuis très-courts. Long: 3 lig. Larg. I lig.

S. niger, nitens, pedibus elytrifque furcis punitatis, thorace plano marginato.

Loc.

13. S. compreffus.

Le Staphylin applati à étuis bruns.

Long. I lig. Larg. $\frac{1}{3}$ lig.

S. niger, nitens, antennis, pedibus; elytris, anoque teftaceis, thorace mar: ginato.

Vurietas A. Idem; antennis clavatis;

Loc. Habitat flores. 
268 ENTOMOLOGIA

14. S. punctatus.

Le Staphylin noir à pattes fauves $\mathcal{E}$ étuis pointillés.

Long. $3 \frac{2}{3}$ lig. Larg. $\frac{2}{5}$ lig.

S. niger, punctatus; antennis pediburf que ferrugineis.

Loc. Habitat flores.

I5. S. rufipes.

Le Staphylinnoir à corcelet liffe E bordé.

Long. I $\frac{x}{2}$ lig. Larg. $\frac{x}{2}$ lig.

S. niger, thorace marginato lxvi, pedibus rufis.

Loc. Hahitat atenam.

I6. S. fulcatus.

Le Staphylin noir à corcelet fillonné Es bordé.

Long. I $\frac{x}{2}$ lig. Larg. $\frac{x}{2}$ lig.

S. niger, thorace marginato futurato, pee dibus rufis.

Loc. Idem.

17. S. xneus.

Le Staphylin à étuis bronzés. Long. 4 lig. Latg. I lig. 




\section{PARISIENSIS.}

S. niger, elytris nigro-xneis.

Loc.

18. S. chryfomelinus.

Le Staphylin couleur de paille. Long. I lig. Larg. $\frac{2}{3}$ lig.

S. niger, thorace, elytris, pedibufque fubteftaceis.

Los. Habitat arenam.

I9. S. marginatus.

Le Staphylin à étuis bordés de jaune.

Long. 2 lig. Larg. I lig.

S. niger, elytris fufcis murgine flavo.

Loc. Habitat arva.

20. S. maculatus.

Le Staphylin noir à taches jaunes.

Long. 2 lig. Latg. I lig.

S. ńiger; thorace utrinque, finguloque elytro, maculâ flavâ,

Loc, Idem, 


\section{7O ENTOMOLOGIA}

2 I. S. riparius.

Le Staphylin rouge à tête noire E étuis bleus.

Long. 3 lig. Larg. $\frac{x}{2}$ lig.

S. rufus, elytris cœruleis, capite abdo= minifque apice nigris.

I.oc. Habitat arenam humidam.

22. S. rufus.

Le Staphylin jaune à tête, étuis $\mathcal{E}$ anus noirs.

Long. 3 lig. Larg. I lig.

S. flavus, capite, elytris abdomineque pone nigris.

Loc.

23. S. thoracicus.

Le Staphylin noir à corcelet rouge.

Long. $3 \frac{\pi}{2}$ lig. Larg. $\frac{1}{3}$ lig.

S. atro-cœrulefcens, thorace rubro. Loc.

24. S. biguttatus.

Le Staphylin junon.

Long. $2 \frac{x}{2}$ lig. Larg. $\frac{1}{3}$ lig. 




\section{PARISIENSIS. I7I}

S. ater, oculis prominentibus craffis. $V$ arietas A. Id. elytro fingulo puncto Alavo.

Loc. Halitat atenam.

25. S. clavicornis.

Le Staphylin à antennes en demi. maffues.

Long. $\frac{2}{3}$ lig. Larg. $\frac{8}{3}$ lig.

S. antennis fubclavatis.

Loc.

* 26. S. melanophtalmos.

Le Staphylin fauve aux yeux noirs.

Long. I $\frac{x}{2}$ lig. Larg. $\frac{1}{3}$ lig.

S. pallidus, oculis anoque nigris, antennis fubclavatis.

Loc.

* 27. S. elongatus.

Le Staphylin noir à bandes de points.

Long. 3 lig. Larg. $\frac{x}{2}$ lig.

S. niger nitens, elytris punctatis, thorase elongato levi, ftriis quatuor punctatis.

Los. 


\section{I72 ENTOMOLOGIA}

* 28. S. anguftatus.

Le Staphylin à corcelet étranglé. Long. $=\frac{x}{2}$ lig. Larg. $\frac{x}{2}$ lig.

S. niger, thorace angultato fulvo, pedibus fufcis.

Loc.

* 29. S. variegatus.

Le Staphylin applati à étuis bigarrés.

Long. 3 lig. Larg. $\frac{2}{3}$ lig.

S. niger compreflus, elytris poftice pedibufque fufcis.

zoc.

* 30. S. arenarius:

Le Staphylin à étuis jaunes au milieu.

Long. I $\frac{x}{2}$ lig. Larg. $\frac{2}{3}$ lig.

S. ater, elytris in medio flavefcentibus. Loc.

* 3 r. S. melonocephalus.

Le Staphylin à tếte noire.

Long. I lig. Larg. $\frac{1}{3}$ lig. 




\section{PARISIENSIS.}

S. fulvus, capite anoque nigris.

Loc.

* 32. S. nigro-fulvus.

Le Staphylin arlequin à longues ináchoires.

Long. 4 lig. Larg. $\frac{1}{3}$ lig.

S. niger, thorace pedibus elytrorum abdoninifque bafi fulvis, apice nigris, maxillis longitudine capitis.

Loc.

* 33. S. cupreus.

Le Staphylin cuivreux.

Long. $5 \frac{x}{2}$ lig. Larg. I $\frac{x}{2}$ lig.

S. xneus punctatus, elytris veluti teffelatis.

Loc.

ORDO SECUNDUS.

Caract. ordinis $I I$.

Tarforum articuli quatuor.

LI. NECYDALIS. $L_{A} N E C Y D A L E$.

Antenna filiformes.

Alx nudx. 


\section{ENTOMOLOGIA}

I. N. punctata.

La Necydale à points jaunes.

Long. 2 lig. Larg. $\frac{\mathrm{r}}{2}$ lig.

N. elytris apice puncto flavo.

$V$ arietas A. Necydalis elytris apice punito flavo, thorace luteo.

B. Necydalis elytris apice puncio flavo, thorace nigro.

Loc. Habitat folia ilicis.

* 2. N. major.

La grande Necydale.

Iong. 9 lig. Larg. I $\frac{2}{3}$ lig.

N. elytris ferrugineis immaculatis, antennis corpore brevioribus.

Loc. 


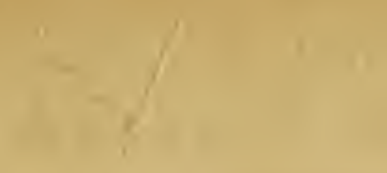

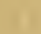

is

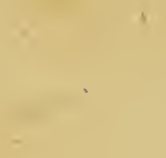





\section{PARISIENSIS. 175}

OR D O TERTIUS.

Caract. ordinis III.

Tarforum articuli tres.

\section{FORFICULA. LE PERCE- \\ OREILIE.}

Antenna fliformes.

Alre tectr.

Abdomen forficibus armatum.

I. F. auricularia.

Le grand Perce-oreille.

Long. 7 lig. Larg. 2 lig.

F. antennarum articulis quatuordecim.

Loc. Hiabitat hortos, gramina, flores.

2. F. minor.

Le petit Perce-oreille.

Long. 3 lig. Larg. $\frac{2}{3}$ lig.

F. antennarum articulis undecim.

Loc. Habitat arenam humidam.

$\mathrm{H}$ iv 
I76 ENTOMOLOGIA

\section{ORDO QUARTUS.}

Carıct. ordinis $I V$.

Tarforum primi \& fecundi pedum paris articuli quinque, pedum vero pofteriorum articuli quatuor.

LIII. MELOE. LE PROSCARABÉ.

Antennx à medio ad bafim \& apicem decrefcentes,

Alæ nullæ.

1 M. profcarabeus.

Le Profcarabé.

Iong. so, I lig. Larg. 5 lig.

Ioc. Habitat hortos, 




\section{PARISIENSIS.}

ARTICULUS TERTIUS.

Caract. articuli III.

Coleoptra mollia membranacea.

OR D O PRI M U S.

Caract. ordinis $I$.

Tarforum primi \& fecundi pedum paris articuli quinque, pedum vero pofteriorumi articuli quatuor.

LIV. BLATTA. LA BLATTE.

Antenne filiformes.

Ad ani latera apendices veficulofi tranfverfim fulcati.

I B. orientalis.

La Blatte des cuifines.

Long. 9 lig. Larg. $4 \frac{x}{2}$ lig.

B. ferrugineo-fufca, elytris fulco ovato impreflis, abdomine brevioribus.

Loc. Habitat loca calida domorum; fatinam.

2. B. Aurelianenfis.

La grande Blatte.

Long. Is lig. Larg. s lig.

$\mathrm{H} \mathbf{v}$ 
178 ENTOMOLOGIA

B. fufco-flavefcens, elytris fulco ovato impreffis, abdomine longioribus.

Loc. Habitat agrum Aurelianenfem.

3. B. laponica.

La Blatte jaune.

Long. $3 \frac{x}{2}, 4 \frac{\pi}{2}$ lig. Latg. 2 lig.

B. flavefcens, elytris ad angulum acutum friatis.

Ioc. Habitat farinam.

\section{O R D O SECUNDUS.}

Caract. Ordin. II.

Tarforum articuli duo.

LV. TRIPS. LE TRIPS.

Antennæ filiformes.

Os rimulâ longitudinali.

Tarfi veficulofi.

1. T. juniperina.

Le Trips à pointe.

Long. I lig. Larg. $\frac{1}{6}$ lig.

T. elytris albidis, corpore nigro, abdon minali fetâ.

Loc. Habitat corcices atbor. vetuftas. 




\section{PARISIE NSIS.}

2. T. phyfapus.

Le Trips noir des fleurs.

Long. $\frac{x}{4}$ lig. Larg. $\frac{1}{10}$ lig.

T. elytris glaucis, corpore atro.

Loc. Habitat flores compofitos.

3. T. fafciata.

Le Trips à bandes.

T. elytris albis nigrifque falciis, corpore atro.

Loc. Idem.

OR D O TERTIUS.

Caract. Ordin. III.

Tarforum articuli tres.

\section{GRYLLUS. LE GRILLON.}

Antennæ filiformes.

Cauda bifeta.

Ocelli tres.

I. G. grillo-talpa.

La Courtillière ou le Gaupe-Grillon.

Long. 18 lig. Larg. 4 lig.

$\mathrm{H}$ vi 


\section{ISO ENTOMOLOGIA}

G. pedibus anticis palmatis.

Ioc. Habitat humum recentem, horticolis infeftus.

2. G. domefticus.

Le Grillon.

Long. I pouce. Larg. $4 \mathrm{lig}$.

G. pedibus anticis fimplicibus.

Ioc. Habitar loca calida domorum \& atvai

\section{ACRYDIUM. LE $C_{R I}$.} QUET.

Antennx filiformes corpore dimidio breviores.

Ocelli tres.

I. A. cyaneum.

Le Criquet à aîles bleues.

Iong. I pouce. Larg. $2 \frac{x}{2}$ lig.

A. elytris fufcis, alis fubcœruleis.

Lo6. Habitat arva ficca.

2. A. cœrulefcens.

Le Criquet à aîles bleues E noires. Long. I pouce. Larg. 3 lig. 




\section{PARISIENSIS. I I}

A. elytris nebulofis, alis cœruleis extimo nigro.

Loc. Habitat prata.

3. A. Aridulum.

Le Criquet à aîles rouges.

Long. lig. Larg. lig.

A. elytris nebulofis, alis rubris extimo nigris.

Loc. Habitat vineas.

4. A. groffum.

Le Criquet enfanglanté.

Long. $S$, I 0 , in lig. Larg. I $\frac{x}{2}, 3$ lig.

A. femoribus fanguineis, alis fubfurcis reticulatis.

Ioc. Habitat arva.

5. A. bi-punctatum.

Le Criquet à capuchon:

Long. 4 lig. Larg. I $\frac{x}{2}$ lig.

A. elytris nullis, thorace producto abdo mini æquali.

Loc. Idem. 
1 \&2 ENTOMOLOGIA

6. A. fubulatum.

Le Criquet à corcelet allongé.

Long. 5 lig. Larg. I $\frac{x}{2}$ lig.

A. elytris nullis, thorace producto abdomine longiore.

Loc. Habitat arva.

ORDO QUARTUS.

Caract. Ordin. IV.

Tarforum articuli quatuor.

IVIII. LOCUSTA. LA SAUTERELLE.

Antennæ filiformes corpore longiores. Ocelli tres.

I. L. viridifina.

La Sauterelle à fabre. Long. I I lig. Larg. $2 \frac{x}{2}$ lig.

L. caudâ enfiferâ curvâ.

Loc. Habitat arva \& prata. 


2. L. vermivora. La Sauterelle à coutelas. Long. 22 lig. Larg. 3 lig.

L. caudâ enfiferâ rettâ.

Loc. Habitat arva \& prata.

\section{OR D O Q U I N T U S.} Caract. Ordin. $V$.

Tarforum articuli quinque.

\section{MANTES. LA MANTE.}

Antennx filiformes.

I. M. gongylodes.

La Mante.

Long. 2 pouces. Larg. S, 6 lig,

Loc. Habitat agrum Aurelianenfem. 
184 ENTOMOLOGIA

SECUNNDA SECTIO INSECTORUM.

INSECTA. HEMIPTERA.

Caracteres fectionis.

Alre fuperiores elytris accedentes.

Os fub thorace inflexum.

IX. CICADA. LA CIGAIE:

Articuli tarforum tres.

Antennz capite breviores.

Ocelli duo.

Roftrum inflexum.

Alæ quatuor, inferiores cruciatx.

Cin. C. nervofa.

La Cigale à aîles tranfparentes. Long. 3 lig. Larg. $1 \frac{x}{4}$ lig.

C. fufca, alis aqueis fufco maculatis; nervis punetatis.

Ioc. Habitat plantas \& gramina.

0 2. C. Spumaria.

La Cigale bedeaude.

Long. 4 lig. Larg. $x \frac{\pi}{2}$ lig. 


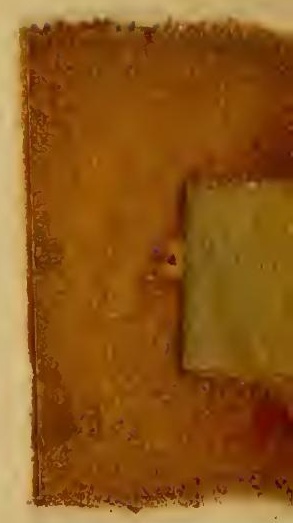

,

r 


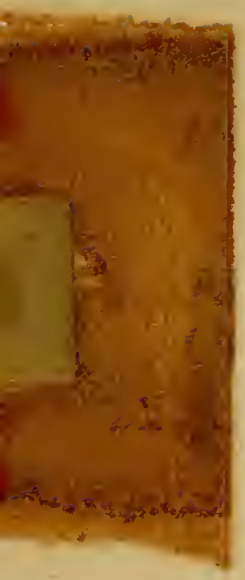




\section{PARISTENSIS. ISS}

C. fufca, elytris falciâ duplici interruptâ tranßverfà albidâ.

Loc. Habitat prata \& medicaginem.

Q3. C. lateralis.

La Cygale à bordure. Long 3 lig. Larg. $1 \frac{x}{5}$ lig.

C. nigra, elytrorum lateribus albịis.

Loc. Idem.

4. C. nembranacea.

La Cigale ì aîles membranęufes. Long. $2 \frac{r}{2}$ lig. Larg. I lig.

C. fufco-pallida, elytris membranaceis venofis, ficutello maculâ duplici triangulari.

Loc. Iden.

DS. C. viridis.

La Cigale verte à tête panachée: Long. $2 \frac{2}{3}$ lig. Larg. I lig.

C. elytris viridibus, capite Alavo punctis nigris.

Loc. Idem.

$\checkmark$ 6. C. fanguinea.

La Cigale à taches rouges. Iong, 4 lig. Larg. 2 lig. 


\section{86 ENTOMOLOGIA}

C. nigra, elytris maculis rex rubris.

Loc. Habitat prata \& medicaginem; ratior.

7. C. gibbola.

La Cigale boffue.

- Long. $3 \frac{\mathrm{T}}{2}$ lig. Larg. I $\frac{3}{4}$ lig.

C. fufco-viridis reticulata, alarum bafi dilatatâ.

Lot. Id. rata.

0. C. pallida.

La Cigale pâle.

Long. 3 lig. Larg. I $\frac{r}{3}$ lig.

C. Alavo-pallida, thorace puncis fex impreffis.

Varietas A. Cicada Alavo-pallida, oculis nigricantibus.

B. Cicada flavo-pallida, dorf lineâ longitudinali nigrâ.

C. Cicada flavo-pallida, thoracis polficâ, fcutelli anticâ parte, fứcis.

Loc. Idem.

La Cigale jaune à raies noires obliques. Long. 2 lig. Larg. I lig. 


$$
\text { Evacap linge }
$$





\section{PARISIENSIS. $\quad 187$}

C. elytris Alavis, lineâ abruptâ duplici longitudinali nigra.

$0^{\text {Loc. Idem. }}$

10. C. regalis.

La Cigale à diadême.

Long. $2 \frac{x}{2}$ lig. Larg. I $\frac{x}{4}$ lig.

C. fufca, capitis thoraciqque fafciâ tranfverfâ flavâ.

Loc. Idem.

O Ix. C. torquata.

La Cigale à collier jaune. Long. $2 \frac{\mathrm{T}}{2}$ lig. Larg. I $\frac{\mathrm{T}}{3}$ lig.

C. fufco-nebulora, fcutelli cavitate rotundâ, thorace puncis luteis impreffis tranfverfim pofitis.

Loc. Idem.

O 2. C. variegata.

La Cigale à pattes bigarées. Long. $3 \frac{1}{2}$ lig. Larg. I $\frac{x}{2}$ lig.

C. fufco-neoulofa, icutello tranfverfim fulcato, tibiis pofticis, elytrorumque limbo è flavo fufcoque variegatis. Loc. Idem. 


\section{ENTOMOLOGIA}

I3. C. marginata.

La Cigale à tête E bordure jaune. Long. $2 \frac{\mathrm{x}}{2}$ lig. Larg. I lig.

C. fufco-nebulofa; capite, thoracis anticâ parte, elytrorunique limbo flavis. Loc. Habitat prata \& medicaginem.

0 I4. C. venofa.

La Cigale à veines blanches. Lon. I $\frac{x}{2}, 2$ lig, Larg $\frac{2}{3}$ lig.

C. fufco-nebulofa punctata, nervis elytrorum albidis.

Loc. Idem.

s. C. nigra.

La Cigale noire:

Long. 2 lig. Larg. $I \frac{r}{3}$ lig.

C. tota nigra.

Ioc. Habitat caftaneas.

16. C. fafciolata.

La Cigale noire à bandes jaunes fur le corcelet.

Long. 2 lig. Larg. I lig.

C. nigia, thorace ely trifque falciâ croceâ, Los. Habitar prata. 

<smiles>CCCCC</smiles> 


\section{PARISIENSIS. 189}

17. C. alirita.

Le grand Diable.

Long. 7 lig. Larg. 2 lig.

C. thorace obtule bicorni.

I.oc. Habitat prata; rariffima.

I 8. C. cornuta.

Le petit Diable.

Long, 4 lig. Larg. I $\frac{T}{2}$ lig.

C. thorace acute bicorni, pone producto.

Loc. Habitat in fylvis filicem, cirfiun, faltator.

I9. C. infernalis.

Le demi-Diable.

Long. 2 lig. Larg. $\frac{2}{3}$ lig.

C. thorace inermi pone producto.

Loc. Rar. in agro lutetiano ; in Campanià frequens.

20. C. Atriata.

La Cigale rayée.

Long. I $\frac{\pi}{2}$ lig. Larg. $\frac{2}{3}$ lig.

C. elytris albido nigroque ftriatis ad ant gulum acutum futurx dorfalis.

Ioc. 


\section{IgO ENTOMOLOGIA}

O 2 I. C. trifafciata.

La Cigale à 3 bandes brunes. Long. I $\frac{x}{2}$ lig. Larg. $\frac{2}{3}$ lig.

C. fufca, elytris albidis, fafciis tribus tranfverfis fufcis.

V ariet. A. Eadem elytris unicoloribus, thorace antice punctorum ni:

Loc. grorum falciâ tranfverlâ.

22. C. tranfverfalis.

La Cigale à deux bandes brunes. Long. I $\frac{2}{3}$ lig. Larg. $\frac{2}{3}$ lig.

C. Alava, elytrorum facciis duabus tranfverfis fufcis.

Loc. Habitat arbores.

23. C. cosa.

La Cigale jaune aux yeux noirs. Long. I $\frac{3}{3}$ lig. Larg. $\frac{2}{3}$ lig.

C. flava comprefla, oculis nigris.

Loc.

24. C. flammigera.

La Cigale flamboyante.

Long. I $\frac{x}{2}$ lig. Larg. $\frac{x}{2}$ lig. 




\section{PARISIENSIS. I I}

C. flava, fáciâ duplici longitudinali rubrâ undulatâ.

Loc. Habitat domos.

25. C. carpini.

La Cigale verte à points noirs. ]

C. viridi-flava, elytris punctis tribus nigris, apice fufcis.

Loc. Habicac folia arborum.

26. C. geographica.

La Cigale géographie.

C. viridis, elytris maculis plurimis furcis ovatis.

Loc. Idem.

$\mathrm{O}_{27} \mathrm{C}$. ulmi.

La Cigale moucheron verte.

C. alis viridi - luteis apicibus nigrantibus deauratis.

Loc. Ha'icat folia ulmi.

23. C. rofx.

La Cigale des charmilles. Long. I $\frac{x}{2}$ lig. Larg. $\frac{x}{4}$ lig. 


\section{ENTOIOLOGIA}

C. flava, alis albis apicibus nembra= naceis.

- Loc. Habitat arbores \& rofam.

* 29 C. nervoptera.

La Cigale à nervures.

$$
\text { Long. } 2 \text { lig. Larg. I lig. }
$$

C. furca, thoracis margine flavo; alis aqueis nervis fulcis.

Loc.

* 30. C. acephala.

La Cigale verte à tête renfoncée. Iong. 2,3 lig. Larg. $\frac{2}{3}$, I lig.

C. tota viridis, capite brevi lato.

Ioc.

* 3 1. C. triftis.

La Cigale à bandes blanches.

$$
\text { Long. I } \frac{x}{2} \text { lig. Larg. } \frac{2}{3} \text { lig. }
$$

C. nigro-fufca, fafciis quatuor tranfrerfis albis, mediâ interruptâ.

Ioc,

32. C. porrecta.

La Cigale à tête allongée.

$$
\text { Long: } 2 \frac{2}{3} \text { lig. Larg. } \frac{3}{4} \text { lig. }
$$






\section{PARISIENSIs. 193}

C. pallida, oculis nigris, cap.te antice producto acuto, thorace duplo longiori.

luc.

33. C. dilatata.

La Cigale renflée.

Long. 3 lig. Larg, I $\frac{x}{4}$ lig.

C. fufca, maculis irregularibus albis elytrorum lateribus dilatatis.

Loc.

CICADA. (1) TETIGONIA nofras:

LACIGALE. LA PROCIGALE.

Antennæcapite breviores, fetacex, articulis quinque.

Ocelli tres.

Roftrum inflexum. Alx quaituor laterales. Articuli tarforum tres.
Antennæ capite breviores, articulis duobus globofo \& fetaceo. Ocelli duo.

Roftrum inflexum. Alæ quatuor, infetiores cruciatæ. Articuli tarforum tres.

(i) Adduntur hic caracteres Cicada vere Gallo. provincialis, noftræ Cicadæ Tetigonia vocatæ oppofitio 
3.9. ENTOMOLOGI A

Annumerantur dux prxcipux Cicadce verxe fpecies Gallo-provinciam habitantes, quae in muf $x$ is noftris frequentilfine affervantur.

1. La Cigale à bordure jaune.

C. fufca, thoracis \& fcutellis margine navo, alis nervofis.

Loc. Hatitat Gallo-provinciam.

2. La Cigale panachée.

C. fufca, thorace fcutelloque flavis, varie: gatis, alis nervofo-punctatis.

Loc. Habitat Gallo-provinciam.

LXI. CIMEX. LA PUNAISE.

Articuli tarforum tres.

Antenn $x$ capite longiores articulis quathor vel quinque. Roftrum inflexum. Alæ quatuor, fuperiores femi-elytra. 



\section{PARISIENSIS.}

F A M IL. I. Antennarum articuli quatuor.

I. C. lectularius. La Punaije des lits.

C. apterus.

Loc. Habitat lecta.

2. C. fcutellatus.

La Punaife cuiraffe.

Long. I $\frac{x}{2}$ lig. Larg. $2 \frac{x}{2}$ lig.

C. hemifphericus nigro-æneus, fcutello totum abdomen tegente, amplifimo.

Loc. Habitat viciam multifloram fontis Bellaquxi.

3. C. teftudinarius.

Ia Punaife tortue brune.

Long. 3 lig. Larg. $2 \frac{T}{2}$ lig.

C. fufcus, fcutello totum abdomen tegente, ampliffimo.

Loc. Habitat fylvas.

4. C. perfonatus.

La Punaije mouche.

Long. 7,8 lig. Larg. 2 lig. 


\section{I96 ENTOMOLOGIA}

C. oblongus niger, roftro arcuato, antennis apice capillaceis, elytris membranaceis.

Eoc. Habitat domos.

5. C. annulatus.

La Punaife mouche à paties rouges. Long. $5 \frac{x}{2}$ lig. Larg. I $\frac{x}{2}$ lig.

C. oblongus niger, roftro arcuato, elytris niembranaceis, pedibus abdomineque rubro nigroque variegatis.

Loc. Habitat fylvas.

6. C. bidentatus.

La Punaije porte-épine. Long. 6 lig. Larg. I lig.

C. longus, fufcus, roftro arcuato, thorace fubtùs antice bijentato.

Loc. Habitat plantas, tarus.

7. C. pellucidus.

La Punaife brune à étuis trantsparens.

Long. I lig. Larg. $\frac{x}{2}$ lig. 




\section{PA RISIENSIS。}

C. oblongus, fulco-niger, pedibus pallidis, elytris pellucidis apice fufco.

Loc.

8. C. boopis.

La Punaife marbrée aux gros yetix: Long. I $\frac{x}{2}$ lig. Larg. $\frac{x}{2}$ lig.

C. oblongus, luteo nigroque marmora; tus, oculis crafiffimis.

Loi.

9. C. leviatan.

La Punaife leviatan.

Long. 2 lig. Larg. I lig.

C. planus, fufcus, thorace elytrifque alatis, capite antice cornuto, antennis brevibus craflis.

Loe.

ro. C. eryngii.

La Punaife rouge à taches triangulaires.

Long. $3 \frac{x}{2}$ lig. Larg. $1 \frac{x}{4}$ lig.

C. oblongus niger, thorace elytrifque rubris, elytrorum exiremo maculâ triangulari nigrâ.

Loc. Habitat folia Eryngii, 
I98 ENTOMOLOGIA

I. C. apterus.

La Punaife rouge des jardins.

Long. $3 \frac{2}{3}$ lig. Larg. $I \frac{1}{2}$ lig.

C. oblongus, rubro nigroque variegatus, elytris maculâ rotundâ, punauloque nigris.

Loc. Habitat arborum infimam partem, multiplex.

2. C. hyofciami.

La Punaife rouge à croix de chevalier.

Long. 4 lig. Larg. I $\frac{7}{3}$ lig.

C. oblongus, rubro nigroque variegatus, fcutelli nigri apice rubro.

Loc. Habitat folia hyofciami.

13. C. Atellifer.

La Punaife rouge à baje des aîles blanches.

Long. 4 lig. Larg. I $\frac{2}{3}$ lig.

C. oblongus, rubro nigroque variegatus, centro crucis albo.

Loc. Habitat hortos. 


14. C. equeftris.

La Punaife rouge à bandes noires E taches blanches.

Long. 5 lig. Larg. I $\frac{3}{4}$ lig.

C. oblongus, rubro nigroque variegatus, elytris fafciâ nigrâ, alis fúcis maculis albis.

Ioc.

15. C. nobilis.

La Punaife rouge à point noir E taches blanches.

Long. 3 lig. Larg. I $\frac{x}{4} \mathrm{lig}$.

C. oblongus, rubro nigroque variegatrs, elytris punctulo nigro, alis furcis, sinaculis albis.

Loc.

16. C. teffellatus.

La Punaife rouge à damier.

Long. 4 lig. Larg. I $\frac{I}{2}$ lig.

C. oblongus, thorace nigro lineis tribus rubris, elytris rubro nigroque teffelatis, limbis nigris.

Loc, In Campaniâ multiplex. 


\section{0 \\ ENTOMOLOGIA}

I7. C. crocelis.

La Punaife fafranée.

Long, 3 lig. Larg, I $\frac{3}{3}$ lig.

C. croceus, elytrorum arice rubmo, alis nigris, antennarum articulo fecundo clavato.

$V$ ariet. A. Cimex niger, pedibus rufis, antennarum articulo fecundo clavato.

B. Cimex niger, capite, thorace pedibuique rufis, anternarum articulo fecundo clavato.

Los.

8. C. gothicus.

La Punaife rougeâtre à antennes incarnat.

Long. $3 \frac{7}{2}$ lig. Larg. I $\frac{2}{4}$ lig.

C. oblongus, fufca-ruber, eiytris apice fanguineis, antennarum articulo fecundo longifimo incarsato.

Loc.

19. C. variegatus.

La Punaife à brocard jaune.

Iong. $4 \frac{5}{4}$ lig. I arg. 2 lig. 




\section{PARISIENSIS, 201}

C. oblongus niger, thoracis lateribus fcutelloque flavis, elytris antennis pedi. bufque flavo-variegatis.

Loc.

20. C. marginatus.

La Punaife à aîlerons.

Long. 6 lig. Larg. $2 \frac{x}{2}$ lig.

C. oblongus, furcus, immaculatus, thorace utrinque obtufe angulato, capite prope antennas externe denticulato.

Loc.

21. C. roftratus.

La Punaife à bec.

Long. $5 \frac{x}{2}$ lig. Larg." $2 \frac{x}{2}$ lig.

C. oblongus, fufcus, "immaculatus, thorace utrinque obtufe angulato, cam pite inter antennas hidentato.

Loc.

22. C. acutus.

La Punaife brune à corcelet poinum E liffe.

Long. 9 lig. Larg. 2 lig. 
202 ENTOMOLOGIA

C. oblongus rufus, immaculatus, thorace utrinque acute angulato, margine lxvi.

Loc.

23. C. fimbriatus.

La Punaife brune à corcelet pointu É épineux.

Long. $3 \frac{x}{2}$ lig. Larg. $x \frac{x}{2}$ lig.

C. oblongus, rufus, immaculatus, thorace utrinque acute angulato, margine rpinolo.

Loc.

24. C. chelifer.

La Punaife à pattes de crabes. Long. 3 lig. Larg. $i \frac{x}{2}$ lig.

C. oblongus furcus, pedibus primi paris cheliformibus.

Loc. Habitat fylvas.

25. C. Cabulofus.

La Punaife à nervures pointillées.

L Long. 3 lig. Larg. I lig. 

$=$

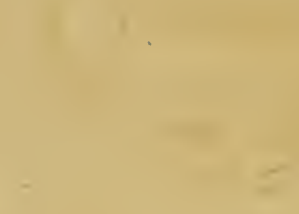

$\checkmark$

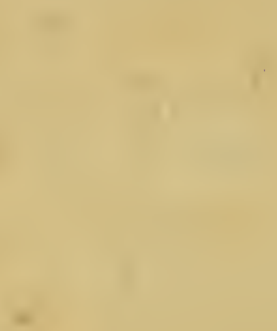

-

$-$

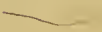

. 


\section{PARISIENSIS. 203}

C. oblongus, viridi-fufcus, elytrorum nervis punctatis, antennis rufis.

Ioc.

26. C. monilis.

La Punaife brune à antennes $\mathcal{E}$. pattes panachées.

Long. 5 lig. Larg. $I \frac{x}{3}$ lig.

C. oblongus, fufcus, antennis, pedibus abdominifque marginibus nigro luteoque variegatis.

Loc.

27. C. catharix.

La Punaije grife panachée de noir. Long. 3 lig. Larg. 1 lig.

C. oblongus, cinereo nigroque variega. tus, alis glaucis.

Loc. Habitar labiatas, præcipue cathariam.

28. C. crucifer.

La Punaife grife porte-croix.

C. oblongus niger, thorace poffice cinereo, elytris cinere's, maculâ nigrâ, alifque nigris.

Loc. Habitat arida loca. 


\section{ENTOMOIOGIA}

29. C. apicaris.

La Punaife brune à pointe des étuis blanche. i.ong. 2 lig. Larg. $\frac{2}{3}$ lig.

C. oblongus niger, thorace poftice cinereo, elytris fufcis apice albo.

Loc.

30. C. femoralis.

La Punaije verdâtre à cuifjes pointillées.

Long. i $\frac{x}{2}$ lig. Larg. $\frac{\mathrm{r}}{2}$ lig.

C. oblongus, pallide-viridefcens, femoribus nigro-punctatis.

Loc.

31. C. conftellaris.

La Punaife noire à taches fauves $\mathcal{E}$ aîles panachees.

Long. I $\frac{T}{2}$ lig. Laig. I $\frac{2}{3}$ lig.

C. oblongus, niger, elytris antice rufis, alis albo maculatis.

Loc. Habitat cortices arborum. 




\section{PARISIENSIS. 20 S}

32. C. fuligineus.

La Punaife brune ponctuée. Lorg. I lig. Larg. $\frac{x}{2}$ lig.

C. oblongus, atro-fufcus punitatus, alis venofis.

Loc.

33. C. pratenfis.

La Punaije gris-fauve porte-cour. Long. 3 lig. Larg. I lig.

C. grifeus, fcutello maculâ cordatâ fla vâ, elytris apice puncto fufco.

Loc.

34. C. campeltris.

La Punaife verte porte-cour. Long. I $\frac{x}{2}$ lig. Larg. $\frac{2}{3}$ lig.

C. oblongus, viridis, fcutello maculẫ cordatâ viridi, elytris maculâ ferzugineâ.

$V$ arietas A. Cimex oblongus, furcos luteus, fcutello maculâ cordatâ viridi, elytris fafciâ duplici fưcâ.

Loc. Habitat flores 


\section{ENTOMOLOGIA}

35. C. cordatus.

La Punaife porte-caur à taches jaunes uu bout des étuis.

Long. $2 \frac{T}{2}$ lig. Larg. $\frac{x}{2}$ lig.

C. oblongus, fufco-ruber, fcutello maculâ cordatâ luteâ, elytris apice luteis. Ioc.

36. C. porrectus.

La Punaije jaune à antennes droites. Long. $3 \frac{\mathrm{T}}{2}$ lig. Larg. I lig.

C. oblongus, flavefcens, thorace fafciis duabus nigris, fcutello maculis flavis, antennis antice porrectis.

Ioc.

37. C. ternatus.

La Punaife à trois taches. Long. 3 lig. Iarg. I $\frac{1}{3}$ lig.

C. oblongus niger, thorace fafciis tribus flavis, fcutello elytrorumque apice maculis luteis.

Loc. 



\section{PARISIENSIS. 207}

38. C. ftriatus.

La Punaife rayée de jaune Es de noir.

Long. 3 lig. Larg. I lig.

C. oblongus niger, thorace fafciis tribus flavis, fcutello nigro, elytris flavis apice fulvo.

Loc.

39. C. nigro-punctatus.

La Punaife jaune à corcelet tacheté E étuis verts.

Larg. 3 lig. Larg. I lig,

C. oblongus viridi-fiavus, capite tho: raceque nigro maculatis, elytris viridious.

Loc. .

40. C. viridefcens.

La Punaîfe verdâtre à tache brune.

Long. $2 \frac{7}{2}$ lig. Larg. $1 \frac{2}{3}$ lig.

C. oblongus viridis, elytrorum maculâ fußcâ.

Ioc. 
208 ENTOMOLOG A

41. C. albinus.

La Punaife verdâtre ì taches blanches.

Long. 3 lig. Larg. I lig.

C. oblongus viridis, elytrorum apice albido, fcutello lineolâ fưcâ.

Loc.

42. C. elongatus.

La Punaife verdâtre à bande brune. Long. $3 \frac{x}{2}$ lig. Larg. I lig.

C. oblongus viridis, thorace fcutelloque lineis quatuor nigris, elytris interne fulcis.

Ioc.

43. C. xrugineus.

La Punaife verte aux yeux bruns. Long. 3 lig. Larg. I $\frac{3}{4}$ lig.

C. oblongus, totus viridis, oculis furcis. Loc.

44. C. cruentatus.

La Punaife verte enfanglantée. Long, $3 \frac{x}{4}$ lig. Iarg, $1 \frac{x}{2}$ lig. 


C. oblongus viridis, elytrerum lineis fanguineiş.

Loc.

45. C. ruficornis.

La Punaife verte à antennes fauves. Long. $2 \frac{1}{2}$ lig. Larg. $\frac{x}{2}$ lig.

C, oblongus, pallido-viridis, antennis retaceis rufis.

Iuc.

46. C. Jateralis.

La Punaife blanchâtre aux yeux noirs.

Long. $3 \frac{x}{2}$ lig. Larg. $\frac{2}{3}$ lig.

C. longus albidus, oculis nigris.

Loc.

47. C. recticornis.

La Punaife verte $\hat{a}$ antennes

droites.

Long. 4 lig. Latg. $\frac{2}{3}$ lig.

C. longus totus viridis antennis antice porrectis.

Loe. 


\section{ENTOMOLOGIA}

48. C. Sponfalis.

La Punaife pâle à tache noire Sur l'éculjon.

$$
\text { Long. } 3 \frac{x}{2} \text { lig. Larg. } \frac{2}{3} \text { lig. }
$$

C. longus, albidus, oculis fufcis feutello maculâ nigrâ.

Eoc.

49. C. conicus.

La Punaife grife conique.

Long. 3 lig. Larg. $\frac{1}{3}$ lig.

C. cblongus conicus, furco - cinereus, oculis prominentibus, elytris nervofis.

Ioc. Habitat hortos.

5o. C. Alamneus.

La Punaife noire à pointe des étuis ronges.

- Long. $3 \mathrm{lig} / \mathrm{Larg}$. I $\frac{8}{3} \mathrm{lig}$.

C. oblongus niger, capite, elytrorum apice, genubufque ferrugineo-rubris.

$\boldsymbol{L}_{\theta \varepsilon .}$ 


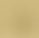

a

\section{.}

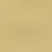


(n)

$-$

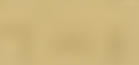

$x=5$

$\checkmark$

a

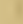

1.

$\cdot$ 


\section{PARISIENSIS. 2II}

g t. C. rolandri.

La Punaife couleur de fuic à alles jaunes.

Long. 3 lig. Larg. I lig.

C. oblongus atro.fufcus, alarum maculâ Gavâ.

Loc.

52. C. plæfrxus.

La Punaije noire à pattes panachées. Long. I $\frac{2}{3}$ lig. Larg. $\frac{2}{3}$ lig.

C. oblongus niger, pedibus viridi nigroz que variegatis.

Ioc.

33. C. atramentarius.

La Punaife toute noire.

Long. 3 lig. Larg. I $\frac{x}{2}$ lig.

C. oblongus totus ater, alis atris.

Loc.

54. C. ater.

La Punaife à groffes antennes terminées par un fil. Long. $2 \frac{5}{3}$ lig. Larg. $\frac{2}{3}$ lig. 
212 ENTOHOLOGIA

C. oblongus ater, antennis fex terminatis.

Loc. Habizat fylvas.

55. C. carthufianus.

La Punaife chartreufe.

Long. 2 lig. Larg. $\frac{3}{4}$ lig.

C. oblongus, infra niger, fupra albo= latieus, antennis craflis antice porrectis, capite pedibus antennifgue nigris.

Loc. Habitat Eryngium.

5. C. clavicornis.

La Punaife tigre.

Iong. I $\frac{2}{3}$ lig. Larg. $\frac{2}{3}$ lig.

C. ex albo fufcoque cinereus, elytrorurn thoracifque margine punctato antennis fubclavatis.

Icc. Larva flores chamxdrys diftendit,

5\%. C. appendiceus.

La Punaife à fraife antique. Long $x \frac{1}{3}$ lig. Larg. I lig.

C. antennis clavatis, thorace elytrifque corpore multo latioribus diaphanis, reticulatis, fafciâ duplici tranfyerfâ.

Ios. 




\section{PARISIENSIS.}

58. C. vagabundus.

La Punaife culiciforme.

Long. 2 lig. Larg. $\frac{2}{3}$ lig.

C. linearis pedibus anticis brevifimis, cœeteris antennifque filiformibus longiflimis, albo fulcoque variis,

Loc. Habitat arbores.

59. C. lacuftris,

La Punaife nayade.

Long. 4 lig. Larg. $\frac{4}{5}$ lig.

C. linearis fuprà niger, pedibus anticis breviflimis.

Loc. Habitat aquarum ftagnantium fuperficiems.

60. C. Pagnorum.

La Punaije aiguille.

Long. 5 lig. Larg. $\frac{1}{3}$ lig.

C. linearis nigricans compreffus, capite cylindraceo, pedibus anticis breviffimis.

Loc. Habitat ftagna. 
214 ENTOMOLOGIA

F A MI L. II. Antennarum articuli quinque.

6I. C. juniperinus. La Punaife verte. Long. $5 \frac{x}{2}$ lig. Larg. $3 \frac{x}{2}$ lig.

C. fubrotundus viridis.

Loc. Fetidiffimus, habitat groffulariam.

* 62. C. tridentatus.

La Punaife à trois cornes. Long. 3 lig. Larg. I $\frac{\mathrm{T}}{3}$ lig.

C. planus, depreffus, atro-furcus, capite antice tridentato, thoracis margine Serrato, elytris parvis.

Loc.

63. C. carminaris.

La Punaife verte lavée de rouge. Long. 6 lig. Larg. $3 \frac{x}{2}$ lig.

C. ovatus, thorace obtufe angulato, ¿̀ viridi rubroque nebulofus.

Loc.

* 64. C. biclavatus.

La Punaife à double mafje. Long. $2 \frac{x}{2}$ lig. Larg. $\frac{x}{2}$ lig. 




\section{PARISIENSI'S. 2 IS}

C. oblongus lividus, antennarum articulo primo \& extremo clavatis.

Ioc.

65. C. pungens.

La Punaije verte à pointes du corcelet rouges.

Long. 6 lig. Larg. 3 fig.

C. fubovatus viridis, angulis thoracis acutis rubris apice nigris, abdomine fubtus acuto.

Lo6.

66. C. baccarum.

La Punaife brune à antennes $\mathcal{E}$. bords panachés.

Long. 6 lig. Larg. 3 lig.

C. fufcus, antennis abdominifque margine nigro croceoque variegatis.

L ${ }_{\theta}$. Habitat groffulariam, fetidus.

67. C. annularis.

La Punaife brune à pattes panachées.

Long. 3 lig. Larg. I $\frac{2}{3}$ lig. 
216 ENTOIOEOGIA

C. fufcus, pedibus abdominifque limbo luteo fufco variegatis.

Los.

68. C. fecalinus.

La Punaife porte-chappe brune. Long. $5 \frac{\mathrm{T}}{2}$ lig. Larg. $3 \frac{\mathrm{T}}{2}$ lig.

C. nigro-ferrugineus, fcutello ad anum ufque producto.

Loc. Habitat fecale \& gramina.

69. C. cappatus.

La Punaije porte-chappe noire. Long. $5 \frac{5}{2}$ lig. Larg. 3 lig.

C. ater punctatus, fcutello ad anum lifque producto.

Loc. Habicat domos.

70. C. italicus.

La Punaife fiamoife.

Long. 4 lig. Larg. 3 lig.

C. rotundatus ruber, fupra fafciis longitudinalibus, infra puntis rigris, fcutello amplo totum fere abdomen tegente.

Loc. 




\section{PAIISIEN SIS.}

7 I. C. ornatus.

La Punaise rouge àu chou:

Long. $4 \frac{x}{2}$ lig. Larg. 3 lig.

C. rotundato-ovatus, nigro rubroque $\mathrm{V} 2=$ riegatus, capite alifque nigris.

Loc. Habitat brafficana.

72. C. carbonarius.

La Punaife noire.

Long. 4 lig. Larg. I $\frac{2}{3}$.lig.

C. ovatus, totus niger, alis pallidis:

Loc.

73. C. fumofus.

La Punaife brune luifante.

Long. I $\frac{x}{2}$ lig. Larg. I lig.

C. ovatus, fufco-niger, alis pallidis, Loc.

74. C. limbofus.

La Punaife noire à bordure blanche. Long. 2 lig. Larg. I lig.

C. ovatus niger, elytrorum limbo exte. riore albo.

Loc. 
$21 \%$ ENTOMOLOGIA

75. C. bicolor.

La Punaife noire à quatre taches blanches.

Long. 3 lig. Larg. $=$ lig.

C. ovatus niger, thoracis lateribus, elytrorumque maculis quatuor albis.

Ioc.

76. C. oleraceus.

La Punaife verte à raies $E$ taches rouges ou blanches. Long. 3 lig. Larg. 2 lig.

C. ovatus cœrulefcenti-æneus, thorace lineolâ, fcutelli apice, elytrifque puncto albo rubrove.

Loc.

77. C. cœruleus.

La Punaije verte bleuâtre. Long. 3 lig. Larg. $1 \frac{2}{3}$ lig.

C. ovatus, viridi-cœruleus æneus.

Ioc.

78. C. faltator.

La Punaife fauteufe.

Long. I $\frac{x}{2}$ lig. Larg. I lig. 




\section{PARISIENSIS. 219}

C. rotundato-ovatus niger, capite genubufque ferrugineis, pedibus faltatoriis.

I.oc.

79. C. acuminatus.

La Punaife à tête allongée.

Long. $3 \frac{x}{2}$ lig. Larg. I $\frac{2}{3}$ lig.

C. ovatus, antice attenuatus, fafciis lon. gitudinalibus cinereo - exalbidis, antennis extremo rufis.

Loc.

\section{NAUCORIS. LA NAUCORE。}

Articuli tarforum duo.

Antennæ breviffimæ infra oculos pod

fitx.

Roftrum inflexum.

Alæ quatuor cruciatx.

Pedes fex, primi cheliformes.

Scutellum præens.

I. N. cimicoides.

La Naucore.

Long. 4 , 5 lig. Larg. 3 lig.

Loc. Habitat aquam, 


\section{ENTOMOLOGIA LXIII. NOTONECTA. LAPU. NAISE A AVIRONS.}

Articuli tarforum duo.

Antenne breviffimæ infra oculos pofitx.

Roftrum inflexun.

Alx quatuor cruciatx.

Pedes fex natatorii.

Scutellum præfens.

x. N. glauca.

La grande Punaife à avirons.

Long. 6 lig. Larg. 2 lig.

N. capite luteo, elytris furco croceoque variegatis, fcutello atro.

Loc. Habitat aquam.

2. N. minutiflima.

La petite Punaife à avirons.

Long. I lig. Larg. $\frac{x}{2}$ lig.

N. cinerea anelytra.

Lóc. Idem. 




\section{PARISIENSIS: 22 I}

\section{IXIV. CORIXA. LA CORISE.}

Arriculus tarforum unicus.

Antennæ breviflimæ infra oculos pofitx.

Rofrum inflexum.

Alæ quatuor cruciata.

Pedes fex, prinni cheliformes, portici natatorii.

Scutellum nullum.

I. C. ftriata.

La Corife.

Long. $5 \frac{x}{2}$ lig. Larg. 2 lig.

Loc. Habitat rivulos \& Itagna, fetidifima:

IXV. HEPA. LE SCORPION AQUA. TIQUE.

Articulus tarforum unicus.

Antennæ cheliformes.

Rofrum inflexum.

Alx quatuor cruciatx.

Pedes quatuor.

K iij 
222 ENTOMOLOGIA

I. H. linearis.

Le Scorpion aquatique à corgs allongé.

Long. I 3 lig. Larg. I lig.

H. corpore lineari.

Loc. Habitat aquam ftagnantem.

2. H. cinerea.

Le Scorpion aquatique à corps ovale. Long. 8,9 lig. Larg. 3 lig.

H. corpore ovato.

Loc. Idem.

LXVI. PSYLLA. LA PSYLLE.

Articuli tarforum duo.

Roftrum pectorale inter primum \&

fecundum par femorum.

Alx quatuor laterales.

Pedts faltatorii.

Abdomen acuminatum.

Ocelli tres.

1. P. ficûs.

La Pfylle du figuier. Long. 2 lig. Larg. $\frac{x}{2}$ lig. 



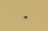

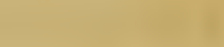

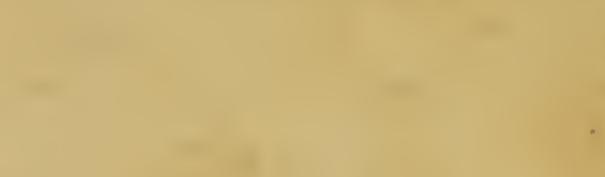

$+$ 


\section{PARISIENSIS. 223}

P. furca, antennis craflis pilofis, alarum nervis fufcis.

2. P. chermes buxi.

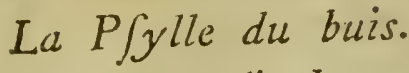

Long. 2 lig. Larg. $\frac{x}{2}$ lig.

P. viridis, antennis fetaceis, alis fufco: flavefcentibus.

3. P. ulni.

La Pfylle de l'aune.

P. viridis, antennis fetaceis, alis aqueis

4. P. fraxini.

La Pfylle du frêne.

Long. I $\frac{2}{3}$ lig. Larg. $\frac{x}{2}$ lig.

P. nigro luteoque variegata; alarum oris in apice fufcis.

5. P. abieris.

La Pfylle du fapin.

Long. I $\frac{2}{3}$ lig. Larg. $\frac{r}{2}$ lig.

P. pallidè favefcens, oculis fufcis, alis aqueis. 
2.2. ENTOMOLOGIA

6. P. pini.

La PSylle du pin.

Long.

Latg.

P. lanata pini.

7. P. lapidum, feu lichenis:

La Pfylle des pierres.

Long. I $\frac{1}{4}$ lig. Larg. $\frac{x}{4}$ lig.

P. furca, nigro punctata, antennis corpore longioribus, alis nervofis fufco maculis.

8. P. furca.

La PSylle brune à antennes fétacées $\mathcal{E}$ aîles nerveufes.

Long. I $\frac{x}{2}$ lig. Larg. $\frac{2}{3}$ lig.

P. fufca, antennis fetaceis lxvibus, alis nervofis.

9. P. rubra.

La Pfylle rouge.

Long. I $\frac{x}{2}$ lig. Larg. $\frac{2}{3}$ lig.

P. rubra, alis nervolis, Ioc. 
a 

PARISIENSIS.

LXVII. APHIS. LE PUCERON.

Articulus tarforum unicus.

Roftrum inflexum.

Alx quatuor erectre vel nullix.

Pedes ambulatorii.

Abdomen bicorne.

I. A. ulmi。

Le Puceron de l'orme.

A. ulmi. .

2. A. fraxini.

Le Puceron du frếne.

A. fraxini, nigro viridique variegata

3. A. fambuci.

Le Puceron du Jureau.

A. fambuci tota coruleo-atra.

4. A. roboris.

Le Puceron du chêne.

A. quercûs atro-fufca.

s. A. aceris.

- Le Puceron de l'érable. A. aceris, viridis, maculis nigris。 
6. A. tilix.

Le Puceron du tilleul.

A. tilix, alis, anternis, pedibufque nigro punctatis.

7. A. betulx.

Le Puceron du bouleau.

A. betulx, marginibus incifurarum abdominis punttis nigris.

8. A. tanaceti.

Le Fuceron de la tanaifie.

A. tanaceti furca, abdomine nigro-cœru. leo antice viridi.

9. A. acetofx.

Le Puceron de l'ofeille.

A. acetớx, atra fafciâ tranโver ‘̂a viridi.

10. A. padi.

Le Puceron du prunier.

A. pruni. 



$$
\text { PAR I S I E N SIS. }
$$

II. A. burfaria.

Le Puceron du peuplier noir.

A. populi nigra lanata.

12. A. fagi.

Le Puceron du hêtre.

A. fagi lanata.

13. A. lactucx.

Le Puceron du lait eron.

A. Conchi caudata.

14. A. quercûs.

Le Puceron des écorces à longues trompes.

A. fufca probofcide corpore triplo longiore.

IXVIII. CHERMES LE KERM ÈS.

Roftrum pectorale inter primum $\&$

fecundum par femorum. Alx dux mafculis, erectx. Abdomen appendicibus fetaceis. Fæmina folliculi formam induens. 
I. C. polonicus.

Le Kermés des racines.

C. radicum purpureus.

Loc, Habitat polygoni Knawel radices.

2. C. hefperidum.

Le Kermés des orangers:

C. hefperidum.

3. C. clematitis.

Le Kermés de la clematite:

C. clematitis oblongus.

4. C. perficx.

Le Kermès oblong du pếcher.

C. perficx oblongus.

s. C. amygdali.

Le Kermès rond du pêcher.

C. perficx roturdus.

6. C. vitis.

Le Kermés de la vigne.

C. vitis oblongus. 




\section{PARISIENSIS. 22,}

6. C. abietis.

Le Kermès du fapin.

C. abietis rotundus.

\&. C. ulmi.

Le Kermés de l'orme.

C. ulmi rotundus.

9. C. tilix.

Le Kermès du tilleul.

C. tilix hemifphricus.

10. C. coryli.

Le Kermés du coudrier.

C. coryli hemiphericus.

I r. C. quercûs.

Le Kermès rond E brun du chêne.

C. quercûs rotundus fufcus.

I2. C. roboris.

Le Kermès du chêne rond Ê de couleur panachée.

C. quercûs rotundus, ex albo flavefcente nigroque variegatus. 
230 ENTOMOLOGIA

I3. C. reniformis.

Le Kermès reniforme du chêne.

C. quercîs reniformis.

14. C. fericeus.

Le Kermès ovale E cotonneux du chêne.

C. quercûs oblongus ferico albo.

Ig. C. carpini.

Le Kermés cotonneux du charme.

C. carpini ferico albo.

I 6. C. mefpili.

Le Kermés cotonneux du neflier.

C. mefpili ferico albo.

17. C. linearis.

Le Kermés en écaille de moule.

C. arborum linearis.

18. C. aceris.

Le Kermés ovale de l'érable.

C. aceris ovatus. 



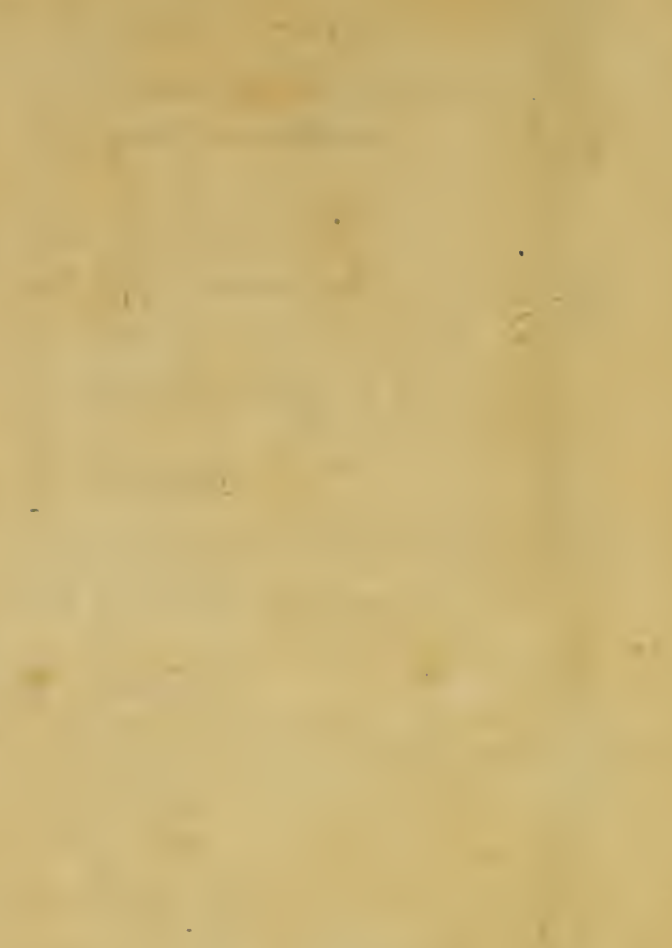




\section{PAIR ISIENSI9. 23 I \\ LXIX. COCCUS. LA COCHENILLE.}

Roftrum pectorale inter primum \& fecundum par femorun. Al $x$ dux mafculis, erectx. Abdomen appendicibus fetaceis. Fæmina infecti formam fervans.

I. C. adonidum.

La Cochenille des ferres.

C. adonidum, corpore rofeo, farinaceo, alis fetifque niveis.

2. C. phalaridis.

La Cochenille du chien-dent.

C. graminis corpore rofeo.

3. C. ulmi.

La Cochenille de l'orme.

C. ulmi, corpore fufco, ferico albo.

Finis prime Partis. 



(1)

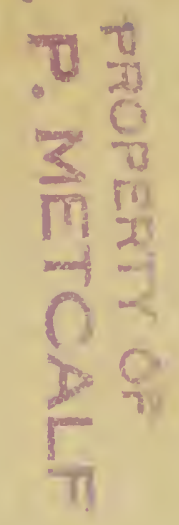

F 
